\title{
JAQUELINE GODOY
}

\section{Estudo de um novo compósito madeira-resina poliuretana para o desenvolvimento de um isolador híbrido}

Dissertação apresentada à Escola de Engenharia de São Carlos, da Universidade de São Paulo, para obtenção do título de Mestre em Engenharia Elétrica

Área de Concentração: Sistemas Elétricos de Potência

Orientador: Prof. Tit. Ruy Alberto Corrêa Altafim 

À minha família, meus pais Rene e Erondina, Simone, Juliano, Marcos e Alessandro pela compreensão, carinho e estímulo. 

Ao Professor Titular Ruy Alberto Corrêa Altafim, pela orientação fornecida durante a elaboração deste trabalho.

Ao Laboratório de Madeiras e de Estruturas de Madeiras (LAMEM) do Departamento de Engenharia de Estruturas (SET) da Escola de Engenharia de São Carlos (EESC) da Universidade de São Paulo (USP), pela colaboração durante todo o período de pesquisa. Em especial, ao professor Francisco Antônio Rocco Lahr, pela atenção e apoio dedicado, e aos técnicos Samuel, Silvio, Arnaldo e Cido, pelo suporte e paciência.

À Coordenação de Aperfeiçoamento de Pessoal do Ensino Superior (CAPES), pelo apoio financeiro.

Ao Grupo de Alta Tensão e Medidas (GATM), aos professores e aos funcionários do Departamento de Engenharia Elétrica da EESC/USP, em particular aos técnicos Rui Bertho e César pelos auxílios prestados. 

"Só existem dois dias no ano em que nada pode ser feito. Um se chama ontem e o outro se chama amanhã, por tanto hoje é o dia certo..."

(Dalai Lama) 



\section{SUMÁRIO}

RESUMO

xiii

ABSTRACT $\mathbf{x v}$

LISTA DE FIGURAS

xvii

LISTA DE TABELAS

xxi

LISTA DE ABREVIATURAS E SIGLAS

xxiii

LISTA DE SÍMBOLOS

XXV

1 INTRODUÇÃO

2 ANÁLISE BIBLIOGRÁFICA

2.1 ISOLADORES ELÉTRICOS E SEUS PRINCIPAIS PROBLEMAS . . . . 11

2.1.1 Problemas relacionados a isoladores em serviço . . . . . . . . . . 19

2.2 MADEIRA E SUAS PRINCIPAIS PROPRIEDADES . . . . . . . . . 23

2.2.1 Fisiologia da madeira . . . . . . . . . . . . . . 24

2.2.2 Propriedades mecânicas da madeira . . . . . . . . . . . . 26

2.2.3 Propriedades elétricas da madeira . . . . . . . . . . . . . 27

2.2.4 Vantagens e desvantagens do uso da madeira . . . . . . . . . . 32 
2.2.5 Fatores que influenciam as características da madeira . . . . . . 34

2.3 RESINAS POLIURETANAS DERIVADAS DO ÓLEO DE MAMONA . . 36

2.3.1 Resina poliuretana monocomponente . . . . . . . . . . . 39

2.3.2 Resina poliuretana bicomponente . . . . . . . . . . . . . 40

2.3.3 Reação de polimerização . . . . . . . . . . . . . . . 41

2.3.4 Conclusão da Bibliografia . . . . . . . . . . . . . 43

3 CARACTERIZAÇÃO DA MADEIRA IMPREGNADA COM AS RESINAS POLIURETANAS

3.1 PREPARAÇÃO DAS AMOSTRAS PARA IMPREGNAÇÃO . . . . . . . . 46

3.2 PROCESSO INOVADOR PARA IMPREGNAÇÃO DA MADEIRA . . . . 49

3.3 RESUltAdOS E ANÁLISE DAS IMPREGNAÇÕES . . . . . . . . . . . 53

3.3.1 Impregnação dos CPs com a resina poliuretana monocomponente . 54

3.3.2 Impregnação dos CPs com a resina poliuretana bicomponente . . . 56

3.3.3 Análise estatística dos resultados . . . . . . . . . 58

3.4 CONCLUSÕES DA IMPREGNAÇÃO $\ldots \ldots \ldots$. . . . . . . . . . 60

4 CARACTERIZAÇÃO MECÂNICA E ELÉTRICA DO COMPÓSITO

MADEIRA-RESINA POLIURETANA $\quad 61$

4.1 ENSAIOS MECÂNICOS NAS AMOSTRAS IMPREGNADAS . . . . . 61

4.1.1 Procedimentos dos ensaios mecânicos nas madeiras impregnadas. . . 62

4.1.2 Resultados dos ensaios mecânicos . . . . . . . . . . . . . 66

4.2 ENSAIOS ELÉTRICOS NAS AMOSTRAS IMPREGNADAS . . . . . 74

4.2.1 Procedimentos dos ensaios elétricos nas madeiras impregnadas . . . 74

4.2.2 Resultados dos ensaios elétricos . . . . . . . . . . . 78 


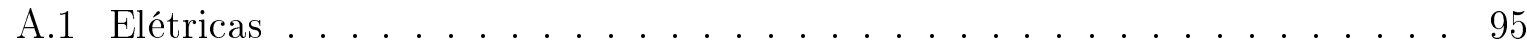




\section{RESUMO}

GODOY, J. Estudo de um novo compósito madeira-resina poliuretana para o desenvolvimento de um isolador híbrido. 2007. 96 f. Dissertação (Mestrado) Escola de Engenharia de São Carlos, Universidade de São Paulo, São Carlos, 2007.

Este trabalho visa ao estudo da aplicação da madeira de reflorestamento, da espécie $P i$ nus Taeda, impregnada com resina poliuretana derivada do óleo de mamona, como um novo material para a fabricação de isoladores elétricos híbridos. Esta pesquisa possui um grande apelo ecológico, pois o compósito madeira-resina poliuretana é derivado de madeira de reflorestamento e óleo de mamona. Estudos com cruzetas de madeira mostraram que este material apresenta excelente desempenho em ensaios de Nível Básico de Isolamento (NBI). A madeira apresenta boas características elétricas quando seca e também algumas boas propriedades mecânicas, como a tenacidade que minimiza os estragos causados pelo vandalismo, um dos grandes problemas do setor. A resina poliuretana atribui hidroscopicidade à madeira e proteção contra os ataques de agentes biológicos, além de melhorar suas propriedades mecânicas e elétricas. O processo para a impregnação de resina na madeira foi inovador, devido à utilização de vácuo tanto para o processamento da resina quanto para a impregnação; a pressão atmosférica expulsa o ar da resina, tornando-a mais homogênea, e força-a a preencher as cavidades da madeira.

Palavras-chave: Isoladores. Propriedades da madeira. Resina poliuretana derivada do óleo de mamona. 


\section{ABSTRACT}

GODOY, J. Study of a new wood-polyurethane resin composite for the development of a hybrid insulator. 2007. 96 f. Dissertação (Mestrado) - Escola de Engenharia de São Carlos, Universidade de São Paulo, São Carlos, 2007.

This work aims at the study of the application of reforestation wood, of Pinus Taeda species, impregnated with polyurethane resin derived from the castor-oil plant as a new product for the manufacture of hybrid electric insulators. This research possesses a great ecological appeal, as the wood-polyurethane resin composite derived from reforestation wood and castor-oil plant. Studies with wood squares have shown this material presents excellent performance in assays of Basic Level of Isolation (NBI). The wood shows good electric characteristics when dried and also some good mechanical properties, as tenacity, which minimizes the vandalism damage, one of the great problems in this sector. The polyurethane resin attributes hydrocospicity to the wood and protection against the attack of biological agents, improving its mechanical and electrical properties. An innovative process was used for the impregnation of the wood with resin, utilizing vacuum for both processing impregnation of the resin. The atmospheric pressure expels the air out of the resin, which becomes more homogeneous, and obliges it to fill the cavities of the wood.

Keywords: Insulators. Properties of the wood. Polyurethane resin derived of the castoroil plant. 


\section{LISTA DE FIGURAS}

1.1 Isolador Hewlett. . . . . . . . . . . . . . . . . . . 4

2.1 Isoladores de porcelana, vidro e polimérico, respectivamente. . . . . . . . 13

2.2 Isoladores tipo pino: (a) monocorpo e (b) multicorpo. . . . . . . . . . . . 14

2.3 Isoladores de suspensão e de ancoragem de vidro . . . . . . . . . . . . 15

2.4 Isolador do tipo bastão. . . . . . . . . . . . . . . 16

2.5 Isolador do tipo pino. . . . . . . . . . . . . . 16

2.6 Isolador do tipo pilar. . . . . . . . . . . . . . . . . . 17

2.7 Isoladores do tipo castanha e roldana. . . . . . . . . . . . . . 17

2.8 Isoladores do tipo pedestal. . . . . . . . . . . . . . . . 18

2.9 Danos típicos da corrosão em isoladores. . . . . . . . . . . . . 21

2.10 Causa de ruptura de isolador. . . . . . . . . . . . . . 22

2.11 Corte transversal de um tronco de madeira de carvalho mostrando as distintas formações $($ SILVA, 2006). . . . . . . . . . . . . 24

2.12 Três principais eixos da madeira $(\mathrm{SMITH}, 1990) \ldots \ldots \ldots \ldots$. . . . 25

2.13 Variação da resistência elétrica da madeira com o teor de umidade de algumas espécies norte-americanas. (FPL, 1999). . . . . . . . . . . 29 
2.14 Relação da constante dielétrica com a umidade de madeiras do tipo coníferas, nas freqüências entre 20 e $1000 \mathrm{~Hz}$ (densidade $=0,4-0,5 \mathrm{~g} / \mathrm{cm}^{3}$, t $\left.=20-25^{\circ} C\right)($ TORGOVNIKOV, 1993) . . . . . . . . . 31

2.15 Estrutura do óleo de mamona. . . . . . . . . . . . . . . . . . 37

2.16 Estrutura do uretano. . . . . . . . . . . . . . . . . . . 41

2.17 Polimerização da poliuretana. . . . . . . . . . . . . . . . 41

2.18 Estrutura do difenilmetano diisocianato (MDI) . . . . . . . . . . . 43

3.1 CP para determinação da umidade da madeira, valores em centímetros $(\mathrm{cm}) .47$

3.2 Agitador a vácuo. . . . . . . . . . . . . . . . 50

3.3 Pesagem do pré-polímero na balança de precisão Toledo. . . . . . . . . . 50

3.4 Processamento do pré-polímero/poliol no agitador a vácuo. . . . . . . . . 50

3.5 Amostra de madeira impregnada suspensa. . . . . . . . . . . . . . . . 53

3.6 Amostra de madeira impregnada com resina poliuretana. . . . . . . . . . 53

3.7 Escala equivalente a $1 \mathrm{~mm}$ para medir impregnação, ampliada $32 \mathrm{x} . \quad \ldots$. . 53

3.8 Amostra I - profundidade da impregnação longitudinal às fibras da madeira impregnada com resina monocomponente. . . . . . . . . . . . 55

3.9 Amostra II - profundidade da impregnação longitudinal às fibras da madeira impregnada com resina monocomponente. . . . . . . . . . . 55

3.10 Amostra III - profundidade da impregnação longitudinal às fibras da madeira impregnada com resina monocomponente. . . . . . . . . . . . 55

3.11 Amostra IV - profundidade da impregnação longitudinal às fibras da madeira impregnada com resina monocomponente. . . . . . . . . . . . . 55

3.12 Amostra V - profundidade da impregnação longitudinal às fibras da madeira impregnada com resina monocomponente. . . . . . . . . . . 55 
3.13 Amostra VI - profundidade da impregnação longitudinal às fibras da madeira impregnada com resina monocomponente. . . . . . . . . . . . 55

3.14 Amostra VII - profundidade da impregnação longitudinal às fibras da madeira impregnada com resina monocomponente. . . . . . . . . . . 56

3.15 Amostra I - profundidade da impregnação longitudinal às fibras da madeira impregnada com resina bicomponente. . . . . . . . . . . . 57

3.16 Amostra II - profundidade da impregnação longitudinal às fibras da madeira impregnada com resina bicomponente. . . . . . . . . . . . 57

3.17 Amostra III - profundidade da impregnação longitudinal às fibras da madeira impregnada com resina bicomponente. . . . . . . . . . . . 57

3.18 Amostra IV - profundidade da impregnação longitudinal às fibras da madeira impregnada com resina bicomponente. . . . . . . . . . . 57

3.19 Amostra V - profundidade da impregnação longitudinal às fibras da madeira impregnada com resina bicomponente. . . . . . . . . . . . 57

3.20 Amostra VI - profundidade da impregnação longitudinal às fibras da madeira impregnada com resina bicomponente. . . . . . . . . . . . . 57

3.21 Amostra VII - profundidade da impregnação longitudinal às fibras da madeira impregnada com resina bicomponente. . . . . . . . . . . . 58

4.1 CP para ensaio de dureza, valores em $\mathrm{cm} . \quad \ldots \ldots \ldots$. . . . . . . 62

4.2 Arranjo de ensaio para dureza Janka. . . . . . . . . . . . . 63

4.3 CP para ensaio de compressão paralela, valores em cm. . . . . . . . . . . 64

4.4 CP para o ensaio de compressão normal às fibras. . . . . . . . . . . . 65

4.5 Ensaio de dureza na direção paralela às fibras. . . . . . . . . . . . . 67

4.6 Ensaio de dureza na direção normal às fibras. . . . . . . . . . . . . 67 
4.7 Ensaio de compressão normal. . . . . . . . . . . . . . . . . 71

4.8 Ensaio de Flexão. . . . . . . . . . . . . . . . . . . . . . 74

4.9 CP após ensaio de flexão. . . . . . . . . . . . . . . . . . . 74

4.10 Esquema da montagem para a medição da resistividade volumétrica e superficial: 1 - medidor de resistividade volumétrica e superficial (ponte de resistência alta); 2- eletrodo superior; 3 - eletrodo central; 4 - eletrodo de guarda; 5 - CP. . . . . . . . . . . . . . 75

4.11 Agilent 16008B Resistivity Cell e Agilent 4339B High Resistance Meter Equipamentos utilizados para medir a resistividade volumétrica e superficial. 76

4.12 CPs de Pinus Taeda sem e com impregnação com as resinas monocomponente e bicomponente estudados nos ensaios de resistividade volumétrica. . 76

4.13 Arranjo dos eletrodos para ensaio ensaio de rigidez dielétrica. . . . . . . . 77

4.14 Kit para ensaios de alta tensão da marca HAEFELY-TRENCH. . . . . . . 77

5.1 Direção das fibras no isolador proposto. . . . . . . . . . . . . . . 81

5.2 Impregnação com resina monocomponente na superfície tangencial às fibras da madeira, ampliada 40x. . . . . . . . . . . . . 82

5.3 Impregnação com resina bicomponente na superfície tangencial às fibras da madeira, ampliada 40x. . . . . . . . . . . . . . 82

5.4 Corpo-de-prova impregnado com a resina bicomponente submetido ao ensaio de rigidez dielétrica. . . . . . . . . . . . . . . . 85

5.5 Isolador multicorpo proposto, valores em mm. . . . . . . . . . 86 


\section{LISTA DE TABELAS}

2.1 Opinião do mercado sobre os diferentes tipos de materiais usados para a fabricação de isoladores elétricos. . . . . . . . . . . . . . . . . 14

2.2 Resistividade tangencial: valores médios. . . . . . . . . . . . . . 28

2.3 Composição média do óleo de mamona. . . . . . . . . . . . . . . . 38

2.4 Características de diferentes tipos de óleo de mamona (ARAUJO, 1992). 38

3.1 Resultado da medição da umidade das amostras. . . . . . . . . . . . . . . 49

3.2 Resultados da Impregnação longitudinal às fibras da espécie Pinus Taeda com resina bicomponente sem e com carga. . . . . . . . . . . . . 52

3.3 Resultados da Impregnação longitudinal às fibras da espécie Pinus Taeda com resina monocomponente com carga. . . . . . . . . . . . . . 54

3.4 Resultados da Impregnação longitudinal às fibras da espécie Pinus Taeda com resina bicomponente sem carga. . . . . . . . . . . . . 56

3.5 Análise do intervalo de confiança entre os conjuntos de dados da profundidade da impregnação dos CPs com a resina poliuretana monocomponente e bicomponente. . . . . . . . . . . . . . . . 59

4.1 Resultados do ensaio de dureza na direção paralela às fibras $-f_{H 0} \ldots \ldots 7$ 
4.2 Intervalo de confiança entre os conjuntos de dados A - B, A - C e B - C dos resultados do ensaio de dureza na direção paralela às fibras. . . . . . . 68

4.3 Resultados do ensaio de dureza na direção normal às fibras $-f_{H 90} \ldots \ldots$. . 68

4.4 Intervalo de confiança entre os os conjuntos de dados A - B, A - C e B - C dos resultados do ensaio de dureza na direção normal às fibras. . . . . . . . 69

4.5 Resultados do ensaio de compressão na direção paralela às fibras da madeira

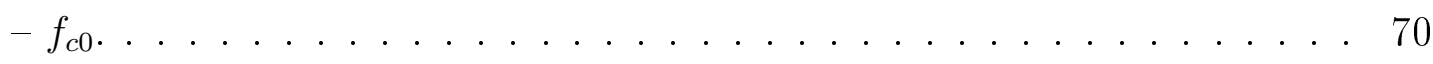

4.6 Intervalo de confiança entre os resultados dos conjuntos de dados A - B, A - C e B - C do ensaio de compressão na direção paralela às fibras dos CPs. 70

4.7 Resultados do ensaio de compressão na direção normal às fibras da madeira

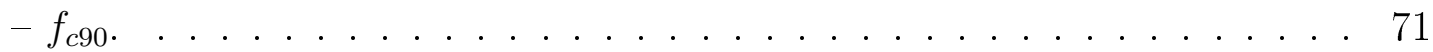

4.8 Intervalo de confiança entre os conjuntos de dados A - B, A - C e B - C dos resultados do ensaio de compressão normal às fibras dos CPs. . . . . . 72

4.9 Resultados do ensaio de flexão $-f_{M}$. . . . . . . . . . . . . 73

4.10 Intervalo de confiança entre os conjuntos de dados A - B, A - C e B - C dos resultados do ensaio de flexão dos CPs. . . . . . . . . . . . . 73

4.11 Resultados do ensaio de resistividade volumétrica. . . . . . . . . . 78

4.12 Resultados do ensaio de resistividade superficial. . . . . . . . . . . . . 79

4.13 Intervalo de confiança entre os conjuntos de dados dos CPs impregnados com a resina monocomponente (B) e os impregnados com a resina bicomponente $(\mathrm{C})$ dos resultados do ensaio de resistividade volumétrica. . . . . . 79

4.14 Resultados do ensaio de rigidez dielétrica. . . . . . . . . . . . 80

5.1 Intervalo de confiança entre os conjuntos de dados A - B, A - C e B - C. $\quad$. 83 


\section{LISTA DE ABREVIATURAS E SIGLAS}

ABNT Associação Brasileira de Normas Técnicas

ANEEL Agência Nacional de Energia Elétrica

CP Corpo-de-prova

CPM Compósitos Polímero-Madeira

DEC Duração Equivalente de Interrupção por Unidade Consumidora

DIC Duração de Interrupção Individual por Unidade Consumidora ou por Ponto de Conexão

DMIC Duração Máxima de Interrupção Contínua por Unidade Consumidora ou por Ponto de Conexão

EESC Escola de Engenharia de São Carlos

EPDM Etileno Polipropileno Dieno Monômero

EUA Estados Unidos da América

FEC Freqüência Equivalente de Interrupção por Unidade Consumidora

FIC Freqüência de Interrupção Individual por Unidade Consumidora ou por Ponto de Conexão

HDI Hexametileno Diisocianto

IPDI Isofurona Diisocianto

IQSC Instituto de Química de São Carlos

LAMEM Laboratório de madeiras e de Estruturas de Madeira

LAT Laboratóro de Alta Tensão 
MDI Poliuretana Difenilmetano Diisocianto

NBI Nível Básico de Isolamento

NBR Normas Brasileiras

NCO Isocianato

OH Grupo Hidroxilo

PTFE Politetrafluoretileno,

SI Sistema Internacional de Unidades

TDI Tolueno Diisocianto

USP Universidade de São Paulo

UV Ultravioleta 


\title{
LISTA DE SÍMBOLOS
}

\author{
$\mathrm{g} / \mathrm{cm}^{3} \quad$ gramas por centímetros cúbicos \\ $\gamma \quad$ gama \\ $\Omega \quad$ ohm \\ ת.cm ohm vezes centímetro \\ $k V \quad$ quilo volts \\ ${ }^{\circ} \mathrm{C} \quad$ graus celsius \\ $M P a \quad$ mega pascal \\ $\epsilon \quad$ constante dielétrica \\ $H z \quad$ hertz \\ $c P \quad$ viscosidade absoluta \\ F $\quad$ faraday \\ $t_{p} \quad$ tempo de processamento da resina \\ cm centímetros \\ g gramas \\ $K g \quad$ quilogramas \\ $m l \quad$ mililitros \\ mm milímetros \\ $m m H g$ milímetros de mercúrio
}


$t_{i m p}$ tempo de impregnação da resina

$\mathrm{cm}^{2} \quad$ centímetros quadrados

$N \quad$ newton

N.m newton metro

$m^{3} \quad$ metros cúbicos

V volts

$V / s \quad$ volts por segundo

$m A \quad$ miliamperes

$\mathrm{g} / \mathrm{m}^{2}$ gramas por metro quadrado

$\mu \quad$ intervalo de confiança 


\section{Capítulo 1}

\section{INTRODUÇÃO}

Energia de boa qualidade é aquela capaz de manter os processos operando normalmente, utilizada de maneira adequada e segura, sem afetar o meio ambiente nem o bem estar das pessoas. A qualidade da energia está relacionada a um conjunto de alterações que podem ocorrer no sistema elétrico, ou seja, qualquer problema de energia manifestado na tensão, corrente ou nas variações de freqüência que resulte em falha ou má operação de equipamentos de consumidores. Este requisito é, atualmente, um fator de fundamental importância para a competitividade de praticamente todos os setores industriais e dos serviços. Em alguns ramos de atividade, como nas indústrias têxtil, siderúrgica e petroquímica, os impactos econômicos da qualidade da energia são enormes. Nestes setores, uma interrupção elétrica de até 1 minuto pode ocasionar prejuízos de milhares de dólares.

Um dos aspectos de maior importância para a melhoria do atendimento às necessidades e expectativas dos clientes das concessionárias de energia elétrica é a redução das interrupções não programadas no fornecimento de energia elétrica ocasionadas pelos isoladores elétricos (MURAMOTO et al., 1997).

Em isoladores do tipo pino de porcelana e de vidro, por exemplo, as principais causas de interrupções não programadas são devidas à falha do material e a falhas não determinadas, as quais podem ser relacionadas à fuga de corrente e a perfurações 
normalmente não visíveis.

O desempenho das concessionárias de energia elétrica quanto à continuidade do serviço prestado é medido pela Agência Nacional de Energia Elétrica (ANEEL) com base em indicadores específicos. Esse indicadores são denominados (RES/ANEEL024, 2000):

- Duração Equivalente de Interrupção por Unidade Consumidora (DEC) - intervalo médio de tempo em que, no período de observação, ocorreu descontinuidade na distribuição de energia elétrica em cada unidade consumidora do conjunto considerado;

- Duração de Interrupção Individual por Unidade Consumidora ou por Ponto de Conexão (DIC) - intervalo de tempo em que, no período de observação, ocorreu descontinuidade na distribuição de energia elétrica em uma unidade consumidora ou ponto de conexão;

- Duração Máxima de Interrupção Contínua por Unidade Consumidora ou por Ponto de Conexão (DMIC) - tempo máximo de interrupção contínua da energia elétrica em uma unidade consumidora ou ponto de conexão;

- Freqüência Equivalente de Interrupção por Unidade Consumidora (FEC) número médio de interrupções ocorridas no período de observação em cada unidade consumidora do conjunto considerado; e

- Freqüência de Interrupção Individual por Unidade Consumidora ou por Ponto de Conexão (FIC) - número de interrupções ocorridas, no período de observação, em cada unidade consumidora ou ponto de conexão.

Os indicadores de continuidade representam a quantificação do desempenho de um sistema elétrico, e são utilizados para a mensuração da continuidade apurada e análise comparativa com os padrões estabelecidos (RES/ANEEL024, 2000).

Quando ocorre a violação dos padrões de continuidade fixados pela ANEEL, as 
concessionárias sofrem penalidades. Para a violação do Padrão do Indicador de Continuidade Individual, a penalidade aplicada é a compensação ao consumidor de valor a ser creditado na fatura de energia elétrica no mês subseqüente à apuração, e para a violação do Padrão do Indicador de Continuidade de Conjunto aplica-se multa (RES/ANEEL024, 2000).

Os isoladores elétricos estão diretamente ligados à continuidade do fornecimento de energia elétrica, pois são de fundamental importância tanto para a confiabilidade quanto para a qualidade do serviço e segurança do sistema elétrico - a falha de uma unidade de isoladores pode acarretar substanciais conseqüências técnicas, econômicas e sociais, apesar de representarem uma pequena porcentagem do custo das linhas e subestações (MURAKAMI, 2002).

Um exemplo de caso extremo das conseqüências de falha em isoladores é a possibilidade de que uma falha na cadeia de isoladores de uma linha de transmissão provoque eventos em cascata, ou seja, a retirada de operação da linha na qual ocorreu a falha exige que outras linhas assumam o fluxo da que saiu do sistema, o que pode sobrecarregar uma delas e tirá-la também de operação, devido à atuação dos mecanismos de proteção. Esses eventos em cascata podem levar ao blecaute uma região ou todo o sistema.

Os isoladores elétricos surgiram com as linhas do telégrafo, eram de porcelana e serviram de modelo aos primeiros isoladores dedicados a linhas de transmissão na década de 1880. A elevação nos níveis de tensão da transmissão exigiu caminhos maiores para a corrente de fuga na superfície do dielétrico, resultando em isoladores de maiores dimensões e associados em série. O primeiro a ser fabricado para suprir essas exigências foi o Hewlett, em 1907, no EUA, mostrado na figura 1.1. Melhorias no Hewlett propiciaram o surgimento 
dos isoladores do tipo disco e pino multicorpo utilizados atualmente (LIPTROT, 1996).

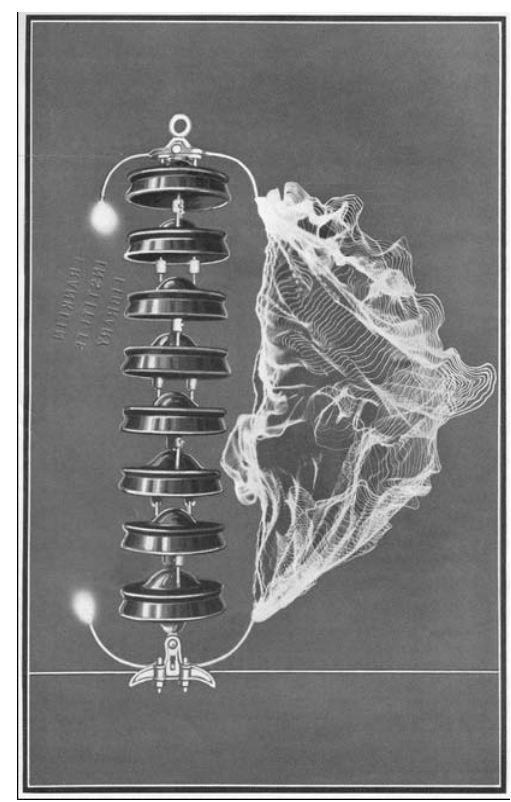

Figura 1.1: Isolador Hewlett.

Fonte: http://www.r-infinity.com/Hewlett/index.htm

Entre as décadas de 1950 e 60, a indústria de isoladores volta-se para as resinas sintéticas, principalmente epóxi e poliéster (CLARK et al., 2000), quando surgem os primeiros isoladores poliméricos internos de alta tensão. Estes materiais eram leves, resistentes a impactos, e poderiam ser usados em formas de partes complexas (BRUINS, 1968) apud (HALL, 1993). Os isoladores poliméricos para aplicação externa em linhas de transmissão somente foram desenvolvidos no fim da década de 60 e início da de 70 , e sua aplicação em campo somente ocorreu na década de 80 (HALL, 1993).

Apesar do longo histórico da utilização de isoladores de cerâmica, estes possuem limitações, como o peso, a possibilidade de existência de defeitos ocultos e a susceptibilidade ao vandalismo.

Outros materiais dielétricos também são empregados na fabricação de isoladores - entre os mais utilizados, além da porcelana, estão o vidro e os polímeros.

Os isoladores de vidro têm a vantagem de fácil visualização de defeitos inter- 
nos, porém, assim como os isoladores de porcelana, são susceptíveis ao vandalismo. Os isoladores poliméricos são mais robustos com relação ao manuseio e vandalismo, possuem bom comportamento sob poluição e são mais leves, porém sofrem mudanças químicas da superfície, provocadas por intempéries e arcos de banda seca, estão sujeitos à erosão e trilhamento que podem conduzir a falhas, e defeitos internos são de difícil visualização (GORUR \& ORBECK, 1991; KIM et al., 1994).

Devido às altas energias superficiais, isoladores de vidro e porcelana, quando expostos às condições úmidas como névoa, orvalho e chuva, podem ser altamente contaminados e umedecidos. Estas condições facilitam o surgimento de uma corrente de fuga, que pode provocar a ocorrência de flashover culminam com o desligamento do sistema (BONOMO, 2003).

Isoladores externos dependem da isolação da superfície, que é atingida não somente pela umidade e intempéries, mas também pela contaminação (SWIFT et al., 2006). Para superar esses problemas, metodologias de prevenção têm sido utilizadas, tais como técnicas de lavagem dos isoladores e aplicação de revestimento de uma fina camada de material polimérico. O revestimento com esse tipo de material tem apresentado bons resultados, pois promove a retenção de água na superfície dos isoladores, aumentando a hidrofobicidade e prevenindo correntes de fuga elevadas nos isoladores (CHERNEY et al., 1991; KIM et al., 1992).

Estudos têm mostrado que, em locais com fortes índices de contaminação, esses isoladores revestidos proporcionaram desempenho similar aos isoladores de borracha de silicone (KIM et al., 1991).

Para contornar os problemas citados, propõe-se a utilização da madeira como matéria-prima de isoladores, pois possui boas propriedades elétricas de isolação, fácil 
trabalhabilidade, baixa densidade aparente (aproximadamente entre 0,5 e 1,2 $\mathrm{g} / \mathrm{cm}^{3}$ ), diversas propriedades mecânicas elevadas em relação a sua massa específica - tais como, resistência à tração e ao impacto -, além de ser um recurso natural importante por ser renovável.

Observa-se uma maior resistência da madeira, quando submetida a esforços de tração ao longo das fibras em comparação com a sua resistência perpendicular às fibras, devido à expressiva diferença de propriedades ao longo e transversalmente a elas (FEIO et al., 2004).

Entretanto, existem alguns aspectos negativos quanto à utilização da madeira em eletricidade como, por exemplo, susceptibilidade a ataques de fungos e insetos, variação das propriedades elétricas com a umidade e temperatura, além da instabilidade dimensional, decorrente do processo de secagem, ou da variação da umidade relativa do ar (STOLF, 2005; TAREEV, 1965).

Estas características avessas da madeira podem ser contornadas ao impregná-la com resinas poliuretanas derivada do óleo de mamona, possibilitando, dessa forma, seu emprego na fabricação de isoladores elétricos externos.

Os primeiros materiais dessa classe, denominados Compósitos Polímero-Madeira (CPM), surgiram no período entre 1930 e 1960, com a descoberta dos polímeros sintéticos, a perspectiva de utilização da radiação na polimerização de vários monômeros e novos métodos de estabilização da madeira (MEYER, 1982) apud (STOLF, 2005).

Os CPMs resultavam da impregnação de madeiras por monômeros ou oligômeros líquidos, polimerizados no interior da madeira através de radiação $\gamma$ ou por simples aquecimento, utilizando iniciadores químicos de decomposição térmica (SCHNEIDER \& WITT, 2004). Este tratamento propicia um aumento significativo das propriedades mecâ- 
nicas, estabilidade dimensional, maior resistência química e à degradação biológica, além de reduzir a absorção de água pelos compósitos em relação à madeira não tratada (MANRICH, 1984). Sua resistência ao impacto também é melhorada; sendo assim, isoladores fabricados com este tipo de material podem ser considerados mais robustos a atos de vandalismo, e impactos leves - dependendo do local atingido - podem ser recuperados com a aplicação de resina no local.

Os compósitos propostos serão obtidos a partir de uma madeira de reflorestamento, da espécie Pinus Taeda introduzida no Brasil, segundo FUCHS (1977), como essência para reflorestamento-, e de duas resinas poliuretanas derivadas do óleo de mamona: uma monocomponente, polimerizada em contato com o ar, e outra bicomponente, polimerizada pelo processamento do pré-polímero com o poliól. Estas resinas foram desenvolvidas pelo Grupo de Química Analítica e Tecnologia de Polímeros do Instituto de Química de São Carlos da USP. A utilização destas resinas para a melhoria das características elétricas se justifica pelos ótimos resultados apresentados como dielétrico sólido (GONZAGA et al., 1998).

Um dos aspecto considerados nesta pesquisa é o de que a mamona da espécie Ricinus communis, classe Dicotiledônea, ordem Geraneaces e família Euforbaceaes, constitui um vegetal típico de clima tropical (IGNÁCIO, 1999; PASCON, 1999). No territorial brasileiro, devido a sua grande extensão e suas características climáticas, encontra-se uma das grandes reservas mundiais deste produto, que apresenta um grande potencial óleoquímico, o qual pode garantir o fornecimento de polióis e pré-polímeros a partir de ácidos graxos em grande escala.

Alguns fatores positivos para o desenvolvimento dessa pesquisa são:

- custo: valor consideravelmente baixo da resina e da madeira, devido a que a 
mamona é de fácil obtenção na agricultura brasileira, assim como o Pinus;

- facilidade de obtenção: a resina e a madeira são facilmente encontradas, respectivamente, em indústrias químicas e madeireiras;

- boas propriedades da madeira e da resina: elétricas, químicas e mecânicas.

Como a madeira a ser utilizada no compósito é de reflorestamento e a resina é proveniente do óleo de mamona, o material obtido será ecologicamente correto, o que atribui à pesquisa um grande apelo ecológico, seguindo as tendências de países europeus, como a Noruega, que possuem leis severas de restrições ambientais ao uso de espécies nativas (P\&D, 2006).

Um dos fatores que motivaram esse trabalho foi a verificação do excelente desempenho da madeira em ensaios de Nível Básico de Isolamento (NBI) de cruzetas, e que o NBI da madeira melhorava aproximadamente $34 \%$ quando esta era impregnada com resina poliuretana derivada do óleo de mamona, além de apresentar um aumento de até $30 \%$ nas propriedades mecânicas de flexão e de ruptura (ALTAFIM et al., 2005; SILVA et al., 2004). Outro aspecto relevante é o ótimo poder de impermeabilização da resina. Atualmente, as cruzetas de madeira impregnadas com resina poliuretana encontram-se instaladas, e em serviço, na empresa distribuidora de energia ELEKTRO - Campinas/SP.

Justifica-se, dessa forma, a criação de um isolador híbrido de madeira impregnada com resina poliuretana derivada do óleo de mamona, procurando realçar as características elétricas, mecânicas e de impermeabilização citadas com novas descobertas e nova metodologia de impregnação.

Serão expostos, neste trabalho, os conceitos fundamentais sobre isoladores, madeiras e resinas poliuretanas derivadas do óleo de mamona. Será analisada a impregnação da madeira da espécie Pinus Taeda através de ensaios em amostras, para verificar a pro- 
fundidade, a direção das fibras e as condições necessárias para que a impregnação ocorra da melhor forma possível, além de observar e comparar o desempenho das resinas monocomponente e bicomponente frente à impregnação. Também serão realizados ensaios mecânicos e elétricos na madeira impregnada para sua caracterização.

Para tanto, a redação desta dissertação foi dividida em cinco capítulos, expostos a seguir.

No capítulo 2, encontra-se uma análise crítica das principais pesquisas sobre:

- isoladores elétricos e seus principais problemas nos sistemas elétricos de potência, descrevendo seus vários tipos, modelos e características;

- madeira e suas principais propriedades, em que são apresentadas as características da madeira, bem como as vantagens e desvantagens de sua utilização;

- óleo de mamona e resinas poliuretanas, apresentando informações sobre o óleo de mamona e as resinas monocomponentes e bicomponentes derivadas do mesmo.

O capítulo 3 apresenta um processo inovador de impregnação das resinas poliuretanas monocomponente e bicomponente derivada do óleo de mamona na madeira da espécie Pinus Taeda.

Os procedimentos e ensaios realizados para a caracterização elétrica e mecânica do compósito madeira-resina poliuretana, visando à análise da viabilidade de sua utilização como material para fabricação de isoladores elétricos, estão descritos no capítulo 4.

As considerações finais, juntamente com as descrições de trabalhos futuros para a continuação dessa importante pesquisa sobre a utilização do compósito madeira-resina poliuretana para a fabricação de isoladores elétricos estão expostas no capítulo 5. 


\section{Capítulo 2}

\section{ANÁLISE BIBLIOGRÁFICA}

Para melhor conhecer o problema dos isoladores elétricos e criar subsídios para seu projeto, segue uma análise crítica dos estudos relevantes sobre o assunto e seus principais problemas nos sistemas elétricos de potência. Devido a que o novo compósito proposto nesta pesquisa envolve a utilização da madeira e das resinas poliuretanas derivadas do óleo de mamona, também serão expostos alguns dos principais estudos sobre os mesmos.

\subsection{ISOLADORES ELÉTRICOS E SEUS PRINCIPAIS PRO- BLEMAS}

As linhas aéreas de transmissão de energia elétrica consistem, fundamentalmente, de duas partes distintas: uma parte ativa, composta pelos cabos condutores; e uma parte passiva, constituída pelos isoladores, ferragens e estruturas, que asseguram o afastamento dos condutores do solo e entre si (FUCHS, 1982).

De acordo com a NBR5472 (1986), isolador elétrico é um elemento destinado a isolar eletricamente e a suportar mecanicamente um equipamento, um condutor, ou outros isoladores. Neste contexto, quando em serviço em linhas de transmissão, linhas de distribuição e subestações, os isoladores devem assegurar o suporte mecânico, rígido 
ou flexível para os condutores elétricos, já que estes são submetidos a solicitações mecânicas que lhes são transmitidas pelos cabos condutores. As solicitações são divididas em (FUCHS, 1977; SARAIVA, 1988; LOOMS, 1990):

a) forças verticais, devidas ao próprio peso dos condutores - nos países de clima frio, é acrescido o peso da capa de gelo que se forma em torno dos mesmos;

b) forças horizontais axiais, no sentido dos eixos longitudinais das linhas, necessárias para que os condutores se mantenham suspensos sobre o solo;

c) forças horizontais transversais, em sentido tangencial aos eixos longitudinais das linhas, devidas à ação da pressão do vento sobre os próprios cabos.

Os isoladores também devem possuir características elétricas que dificultem a passagem de correntes elétricas, pois são submetidos a solicitações de natureza elétrica e devem resistir às mais elevadas tensões possíveis nas linhas de transmissão (FUCHS, 1977; SARAIVA, 1988; LOOMS, 1990):

a) tensão normal e sobretensões em freqüência industrial;

b) surtos de sobretensão de manobra;

c) sobretensões causadas por descargas atmosféricas.

Os surtos de sobretensão de manobra, embora sejam fenômenos de curta duração, podem atingir níveis de tensão bastante elevados entre fase e terra, da mesma forma, as sobretensões causadas por descargas atmosféricas podem ser muito elevadas e ainda possuírem intensidades variadas.

A caracterização elétrica de um material isolante normalmente é feita através da medida da resistividade elétrica superficial e volumétrica e de sua rigidez dielétrica definidas no Anexo A deste trabalho. Os valores de resistividade volumétrica de materiais isolantes sólidos e líquidos usados em engenharia são de aproximadamente $10^{7}$ a $10^{9}$ R.cm 
para baixo grau de isolação, e de aproximadamente $10^{16}$ a $10^{18}$ Л.cm para alto grau de isolação. Entretanto, esses valores são fortemente influenciados pela umidade e pela temperatura, diminuindo consideravelmente quando ambas aumentam (TAREEV, 1965).

Os isoladores elétricos, de um modo geral, podem ser classificados quanto às seguintes naturezas: nível de tensão, tipo de material de fabricação ou número de partes, como exposto a seguir (BONOMO, 2003).

a) Níveis de tensão: Isolador para extra alta, alta, média e baixa tensão.

b) Tipo de material de fabricação, figura 2.1: Porcelana, vidro e material não cerâmico ou material polimérico - entre os materiais poliméricos mais utilizados estão a borracha de silicone, o EPDM (Etileno Polipropileno Dieno Monômero) e a resina epóxi.
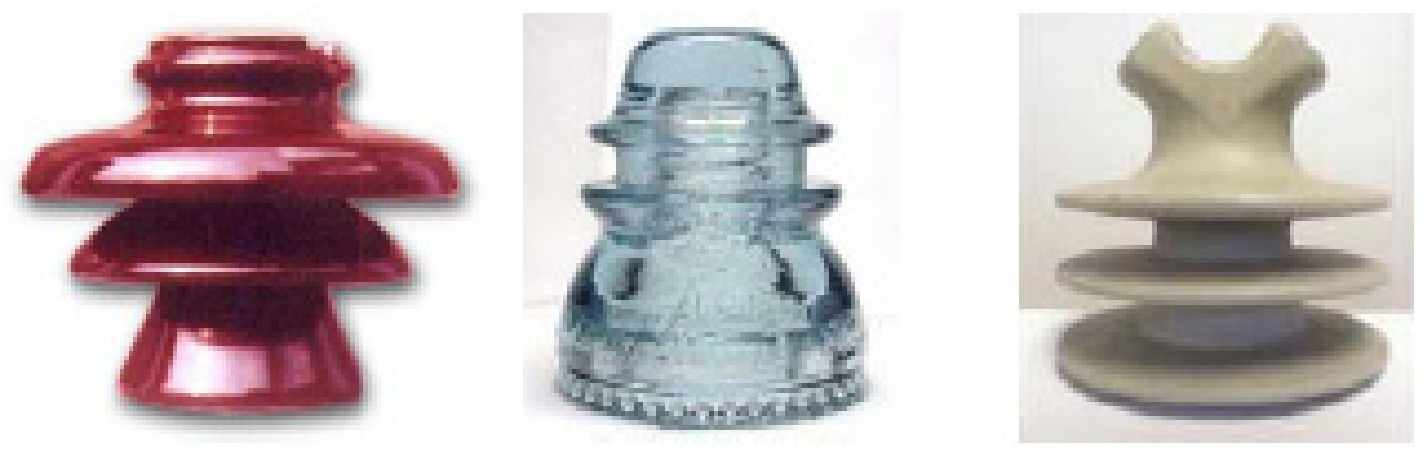

Figura 2.1: Isoladores de porcelana, vidro e polimérico, respectivamente.

c) Número de partes, figura 2.2: Monocorpos e multicorpo; esse último é muito utilizado em linhas de distribuição, sua construção de multipartes reduz a vulnerabilidade a danos, pois, mesmo com uma concha quebrada, um isolador multicorpo pode resistir normalmente a tensões de linha, durante um tempo considerável, sem dificuldade. 


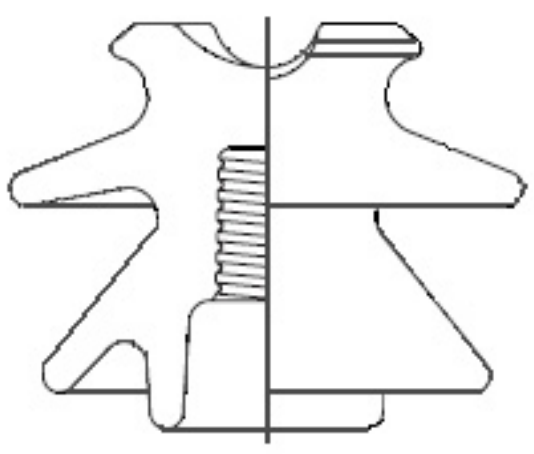

(a)

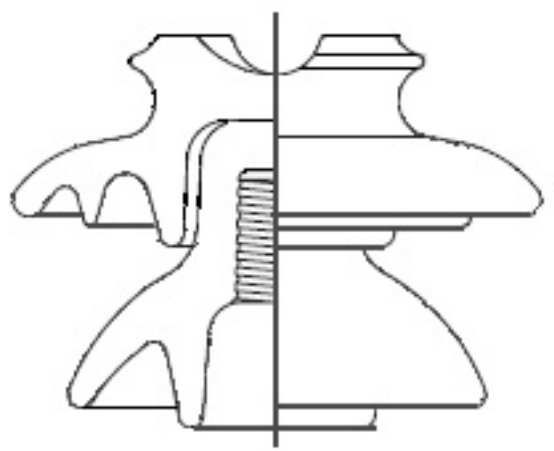

(b)

Figura 2.2: Isoladores tipo pino: (a) monocorpo e (b) multicorpo. Fonte: http://www.pigsa.com.br:8080/iso9002.htm

A tabela 2.1 apresenta a opinião do mercado sobre os diferentes tipos de materiais usados para a fabricação de isoladores elétricos, segundo Isoladores Santana.

Tabela 2.1: Opinião do mercado sobre os diferentes tipos de materiais usados para a fabricação de isoladores elétricos.

\begin{tabular}{|c|c|c|}
\hline ISOLADOR & VANTAGENS & LIMITAÇÕES \\
\hline Porcelana & $\begin{array}{l}\text { Longo histórico de uso. } \\
\text { Desempenho conhecido. }\end{array}$ & $\begin{array}{l}\text { Defeitos ocultos. } \\
\text { Suscetível ao vandalismo. } \\
\text { Peso. }\end{array}$ \\
\hline Vidro & $\begin{array}{l}\text { Longo histórico de uso. } \\
\text { Desempenho conhecido. } \\
\text { Defeitos facilmente } \\
\text { visualizáveis. }\end{array}$ & $\begin{array}{l}\text { Frágil. } \\
\text { Peso. } \\
\text { Atrativo para o vandalismo }\end{array}$ \\
\hline Poliméricos & $\begin{array}{l}\text { Bom comportamento sob } \\
\text { contaminação. } \\
\text { Peso: são mais leves. } \\
\text { Menos suscetível ao } \\
\text { vandalismo e manuseio. }\end{array}$ & $\begin{array}{l}\text { Fragilidade do núcleo não } \\
\text { solucionada. } \\
\text { Efeito do tempo no } \\
\text { processo de envelhecimento. } \\
\text { Pode ter defeitos ocultos. }\end{array}$ \\
\hline
\end{tabular}

FONTE: http://www.abceram.org.br/asp/49cbc/pdf/49cbc_santana.pdf - Acesso em: 16 de março de 2007. 
Em linhas de transmissão os tipos de isoladores mais utilizados são:

a) isoladores de suspensão e de ancoragem de vidro - isolam eletricamente as linhas da terra e sustentam mecanicamente os cabos aéreos de transporte de energia fixados nas estruturas metálicas de concreto ou de madeira, nas tensões de $69 \mathrm{kV}$ até 500 $\mathrm{kV}$. A figura 2.3 apresenta exemplos deste tipo de isolador;

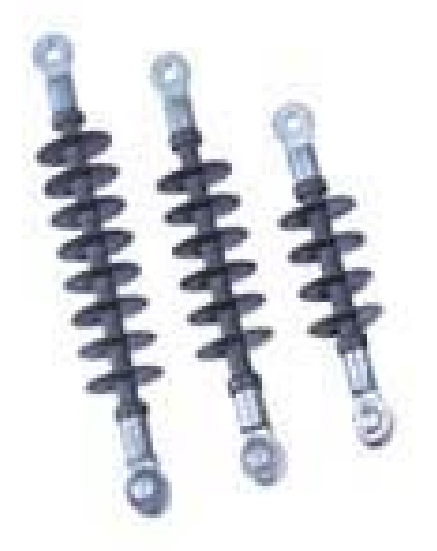

Figura 2.3: Isoladores de suspensão e de ancoragem de vidro

b) isoladores de suspensão de porcelana - são produzidos por processo úmido a partir de matérias primas selecionadas, com queima das peças cerâmicas em fornos elétricos e a gás;

Os tipos de isoladores mais utilizados em linhas de distribuição são:

a) isolador de disco de vidro - isolador de cadeia em forma de disco côncavoconvexo, com ferragens integrantes em ambas as faces (NBR5472, 1986).

b) isolador bastão de porcelana - compreende uma haste de forma aproximadamente cilíndrica, com ou sem saias ou frisos, com vínculos integrantes, fixados externamente em cada extremidade (NBR5472, 1986) - figura 2.4; 


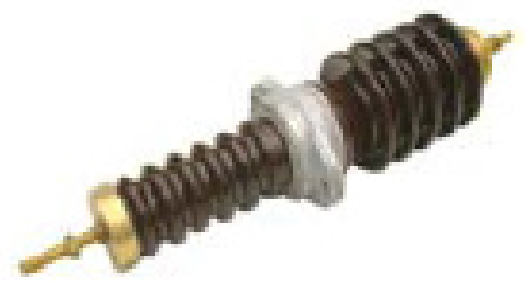

Figura 2.4: Isolador do tipo bastão.

c) isolador de suspensão de porcelana - usado em cadeias de ancoragem ou fim-de-linha;

d) isolador de pino - isolador rígido com corpo isolante, ou dois ou mais corpos ligados permanentemente entre si, projetados para serem instalados rigidamente numa estrutura de suporte, por meio de um pino não integrante que penetra no interior do seu corpo isolante (NBR5472, 1986) - um exemplo desse tipo de isolador é mostrado na figura 2.5

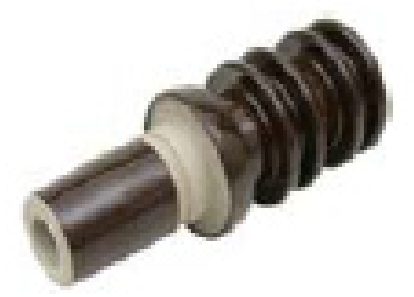

Figura 2.5: Isolador do tipo pino.

e) isolador pilar - isolador rígido, com um corpo isolante, ou dois ou mais corpos ligados entre si, projetados para serem instalados rigidamente numa estrutura de suporte, por meio de uma base metálica integrante (NBR5472, 1986) - figura 2.6; 


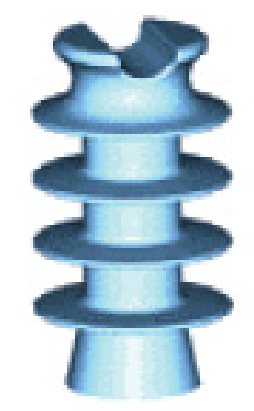

Figura 2.6: Isolador do tipo pilar.

f) isolador castanha de porcelana - projetado para converter o esforço de tração exercido por um condutor ou estai, em esforço de compressão simétrica no corpo do isolador (NBR5472, 1986) - mostrados na figura 2.7;

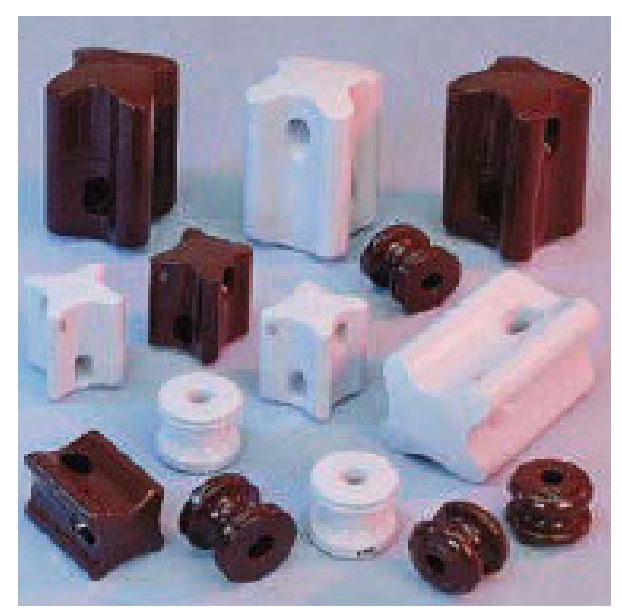

Figura 2.7: Isoladores do tipo castanha e roldana.

Em subestações e instalações industriais, os tipos de isoladores mais utilizados são:

a) isolador suporte de porcelana - projetado para assegurar suporte rígido a uma parte viva (NBR5472, 1986); 
b) isolador pedestal - suporte para exterior dotado de campânula ${ }^{1}$ com furos, rosqueada na extremidade superior, e um pedestal com furos lisos correspondentes na extremidade inferior NBR5472 (1986) - figura 2.8;

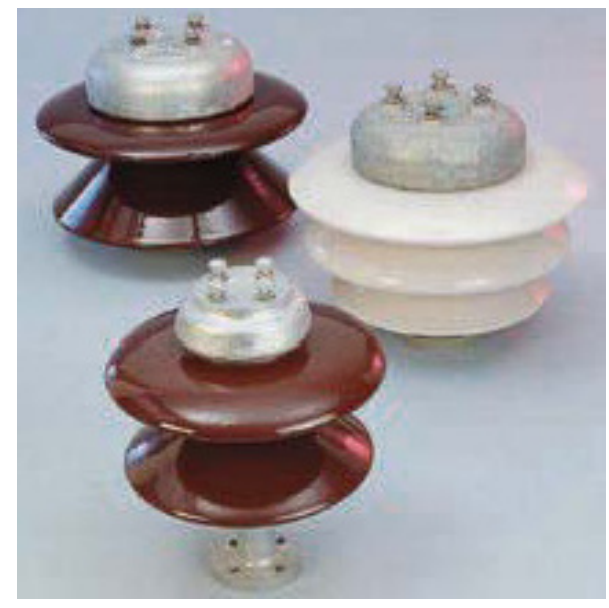

Figura 2.8: Isoladores do tipo pedestal.

Isoladores também podem ser híbridos, ou seja, compostos por diferentes tipos de materiais como, por exemplo, interior de cerâmica, saia de elastômero e superfície coberta por selante (LOOMS, 1988). Tal composição tem a finalidade de aproveitar as melhores qualidades de cada tipo de material utilizado.

Isoladores híbridos requerem dois critérios de aceitação: (i) propriedades elétricas satisfatórias, inclusive capacidade de isolação, e resistência a trilhamento e erosão durante descargas elétricas na superfície, e (ii) desempenho mecânico seguro em longo prazo (HOULGATE, 1996).

\footnotetext{
${ }^{1}$ Campânula: Ferragem integrante fixada externamente em uma ou nas duas extremidades de um isolador, cobrindo parte do corpo do mesmo (NBR5472, 1986).
} 


\subsubsection{Problemas relacionados a isoladores em serviço}

O isolamento elétrico é assegurado por sua resistividade superficial e rigidez dielétrica, externa e interna. Quando ocorre o rompimento dielétrico do ar que envolve o isolador, há uma descarga de contorno, ou seja, uma descarga de ruptura externa ao isolador, entre as partes que são, normalmente, submetidas à tensão de serviço, caracterizando uma falha externa. Uma descarga de ruptura através do material isolante do isolador pode causar a perda permanente de sua rigidez dielétrica, com risco de perfuração - o que caracteriza uma falha interna (NBR5472, 1986).

O formato dos isoladores com saias ou saliências garante o aumento do caminho percorrido pela corrente de fuga sobre a superfície do dielétrico, dificultando a ocorrência de curtos-circuitos ocasionados por arcos elétricos (MURAKAMI, 2002).

As formas características dos isoladores se devem à necessidade de assegurar uma distribuição balanceada de potenciais e, conseqüentemente, dos gradientes no ar, de maneira que se assegurem tensões de descarga apropriadas.

\section{I - Problemas de exposição dos isoladores externos}

Isoladores externos estão constantemente sujeitos a flashover, o que pode acarretar sérios problemas, tais como trilhamento e erosão. O conhecimento da distribuição de campo elétrico no isolador pode aprofundar a compreensão destes fenômenos; assim, é importante analisar a distribuição de campo elétrico ao longo de um isolador sob condições secas e durante chuva (HARTINGS, 1994).

Isoladores externos dependem da isolação da superfície, atingida pela umidade, intempéries e contaminação. $\mathrm{O}$ acúmulo de poluentes sobre a superfície dos isoladores favorece a formação de uma camada constituída por substâncias que, diluídas em água 
decorrente de condensação na superfície dos isoladores, produzem soluções condutoras o que contribui para uma redução drástica da rigidez dielétrica superficial, com risco de centelhamento e, conseqüentemente, falhas no sistema elétrico (MELLO et al., 2001).

Por isso, é importante realizar testes para determinar o desempenho de isoladores externos poluídos sob flashover, especialmente se estes são substancialmente hidrófilos (SWIFT et al., 2006).

O envelhecimento de isoladores externos deve ser analisado considerando não somente a quantidade de poluição, mas também os fatores ambientais. Estes fatores incluem: umidade média, nível de radiação ultravioleta (UV), velocidade do vento e chuva (NADERIAN et al., 2004).

Três propriedades específicas devem ser observadas em materiais isolantes externos (FOURMIGUÉ \& NOEL, 1996):

a) resistência à erosão e trilhamento quando submetidos a arco;

b) tempo antes da perda da hidrofobicidade quando submetidos a um ambiente molhado, por exemplo, névoa ou chuva;

c) velocidade da transferência de hidrofobicidade para a camada de poluição.

Além disso, isoladores externos são expostos ao vandalismo. A porcelana, material clássico dos isoladores externos, é frágil e sua exposição ao vandalismo pode causar fratura direta - quando um projétil rompe o isolador - ou fratura indireta, quando rachaduras internas antecipam uma perfuração ou rompimento elétrico (LOOMS, 1988).

A solução para os problemas de exposição tem seguido três linhas principais (LOOMS, 1988):

a) melhorar a forma geométrica, tanto para evitar a fuga de corrente na superfície do dielétrico quanto para diminuir a característica de retenção de poluição e umidade; 
b) mudar a natureza da superfície para vencer a contaminação e umidade;

c) reduzir a fragilidade, isto é, a suscetibilidade a fraturas, por meio da troca do material.

\section{II - Problemas de corrosão em isoladores}

Um dos problemas para as empresas concessionárias do setor elétrico brasileiro é a corrosão de isoladores (figura 2.9), principalmente, devido ao elevado custo de serviço da troca de isoladores corroídos, pois além de envolver recursos necessários com o isolador propriamente dito, ainda são necessários recursos com a equipe de manutenção e equipamentos, e os reparos quase sempre são realizados com a linha de transmissão energizada (MELLO et al., 2003).

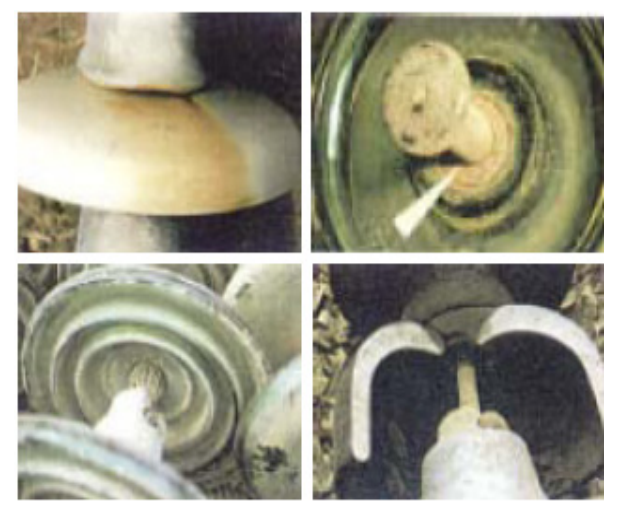

Figura 2.9: Danos típicos da corrosão em isoladores.

A ocorrência de perfuração no isolador é ocasionada devido à pequena espessura da porcelana na região do berço do isolador para o pino de aço, e também como conseqüência de sobretensões de origem atmosférica. Como o campo elétrico nessa região é muito intenso, a porcelana pode sofrer perfuração (MURAKAMI, 2002).

Já as trincas e rupturas da porcelana são resultados do aquecimento por descargas e centelhamentos dos diferentes materiais empregados, e por diferentes coeficientes 
de dilatação (MURAKAMI, 2002) - como pode ser visto na figura 2.10.

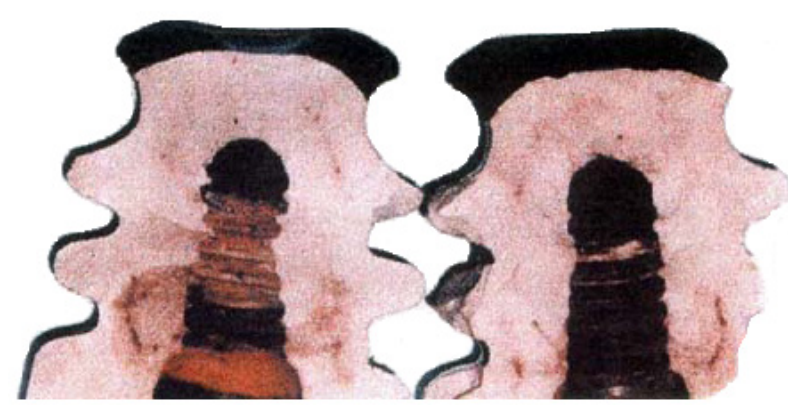

Figura 2.10: Causa de ruptura de isolador.

Os defeitos citados, geralmente, provocam fuga de corrente, interrupções transitórias e interrupções permanentes, e podem causar o rompimento de condutores. Esses defeitos em isoladores também contribuem para o surgimento de focos de radiointerferências, que perturbam os sinais de comunicações e, atualmente, é uma das preocupações das concessionárias de energia elétrica do país (MURAKAMI, 2002).

\section{III - Conclusão dos problemas em isoladores}

Como visto anteriormente, vários problemas afetam os isoladores elétricos, mas alguns deles podem ser superados utilizando, como material de fabricação do isolador, o compósito madeira-resina poliuretana, proposto neste trabalho.

Maiores valores de NBI possibilitam reduzir o impacto do fenômeno flashover, que pode provocar trilhamento e erosão. Espera-se que o isolador de madeira seja mais resistente a essas conseqüências, já que a madeira possui NBI elevado.

Os problemas relacionados à umidade e às intempéries que atingem a isolação da superfície do isolador são amenizados com a impregnação da madeira com resina poliuretana derivada do óleo de mamona, pois a resina impermeabiliza a madeira, aumentando sua hidrofobicidade e impedindo que a mesma seja atacada por organismos vivos, como 
fungos e insetos.

A região de contato do pino com o berço do isolador também será impregnada com a resina poliuretana; dessa forma, a corrosão do pino de aço do isolador poderá ser reduzida, pois a camada superficial de resina diminui a corrosão (SOUZA et al., 2004).

\subsection{MADEIRA E SUAS PRINCIPAIS PROPRIEDADES}

A madeira é um material isolante e estrutural altamente versátil usado em linhas de transmissão, com tensão de até $345 \mathrm{kV}$, como, por exemplo, postes e cruzetas, por ser abundante, de baixo custo e facilmente processado (TAREEV, 1965; IEEESTD751, 1991).

A madeira é um importante material de engenharia, e em muitos casos, é bastante útil em diversos avanços tecnológicos. Um dos principais atributos que mantém a madeira na vanguarda de matérias-primas é sua disponibilidade em muitas espécies, tamanhos, formas, e condições de suprir quase toda a demanda.

Em âmbito molecular, a madeira é composta de celulose, lignina, hemiceluloses, e quantias secundárias ( $5 \%$ a 10\%) de extratos, sais, águas e outras substâncias contidas em sua estrutura celular (TORGOVNIKOV, 1993). Variações nas características e volume destes componentes, além de diferenças na estrutura celular fazem com que a madeira seja classificada pesada ou leve, dura ou flexível, e dura ou macia.

As propriedades de uma única espécie são relativamente constantes dentro de certos limites; assim, a classificação da madeira através de espécies nem sempre pode ser adequada. Para usufruir das vantagens da madeira, em aplicações práticas, da melhor e 
efetiva maneira, deve-se considerar suas características específicas e propriedades físicas.

\subsubsection{Fisiologia da madeira}

O tronco é a parte útil da árvore para a produção de peças de madeira, conforme pode ser visualizado na figura 2.11. É formado por:

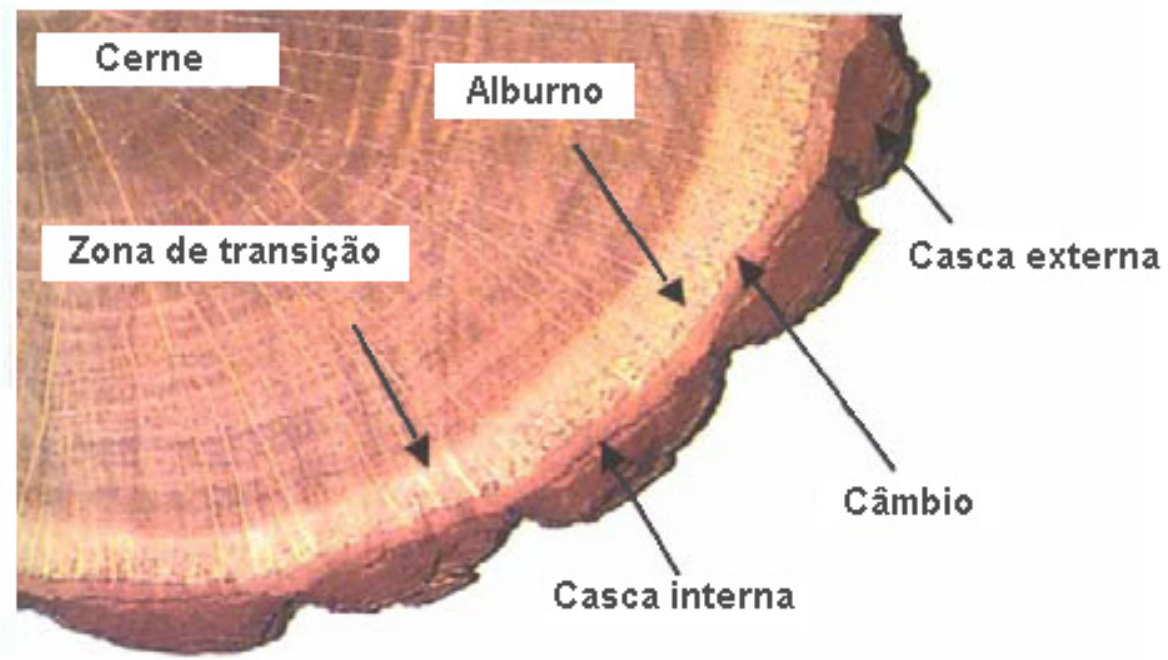

Figura 2.11: Corte transversal de um tronco de madeira de carvalho mostrando as distintas formações (SILVA, 2006).

- casca: protege o lenho e é o veículo da seiva elaborada; pode ser dividida em: uma parte externa formada de tecido morto, com espessura que varia bastante de acordo com a espécie e idade da árvore; e uma parte interna fina, constituída de tecido vivo, mole e úmido, com atividade fisiológica e condutora da seiva elaborada;

- cambio vascular: fina camada de tecido vivo, cituada dentro da casca interna, forma a madeira e células da casca; só pode ser visto por microscópio;

- alburno: situado entre o câmbio vascular e o cerne, possui tanto células vivas quanto células mortas e tem como função principal o armazenamento de alimento para a árvore; nas camadas exteriores, perto do cambio vascular, o alburno controla o transporte 
de água ou seiva (MOTA, 2006);

- cerne: parte interior, mais dura e compacta, constituída exclusivamente por células mortas, formado por uma mudança gradual no alburno; inativo (MOTA, 2006);

- medula: caroço pequeno de tecido localizado no centro do tronco da árvore, onde se inicia o crescimento de madeira;

- raios: orientam horizontalmente o tecido do plano radial da árvore, conectam várias camadas de cerne com a casca para armazenamento e transferência de alimento (FPL, 1999).

A madeira tem propriedades mecânicas diferentes com respeito a seus três eixos principais, por causa da orientação das células da madeira e a maneira como a árvore cresce. Estes eixos são: longitudinal, ou axial, em relação ao caule, ou seja, na direção das fibras; radial em relação aos anéis de crescimento; e tangencial aos anéis de crescimento (IEEESTD751, 1991)- figura 2.12.

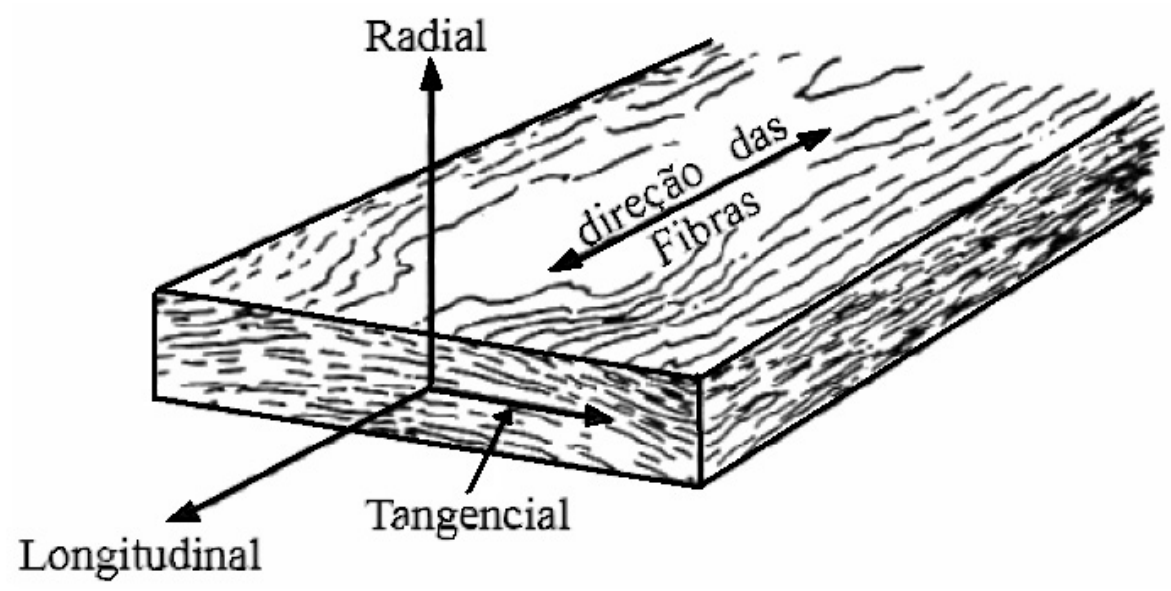

Figura 2.12: Três principais eixos da madeira (SMITH, 1990). 


\subsubsection{Propriedades mecânicas da madeira}

A estrutura molecular da celulose e da lignina são responsáveis por grande parte das características físicas e de resistência mecânica da madeira. Tais estruturas representam cerca de $90 \%$ das substâncias componentes da madeira: $60 \%$ a $70 \%$ de celulose e $15 \%$ a $35 \%$ de lignina - interligando a celulose e preenchendo os espaços vazios da estrutura da madeira (HELLMEISTER, 1973).

A rigidez e a dureza da madeira podem ser atribuídas à lignina; uma maior porcentagem de lignina representa diminuição de absorção de água. A água da madeira começa a evaporar logo após o corte, até atingir uma umidade de equilíbrio com as condições do ambiente. A madeira quando "seca ao ar", à temperatura de $25^{\circ} \mathrm{C}$ e umidade relativa de 65\%, possui umidade que oscila em torno de 12\% (HELLMEISTER, 1973).

As características que facilitam o reconhecimento da madeira, em geral, são: cor, dureza, disposição das fibras e densidade. As madeiras moles apresentam vasos abertos e fibras longas e grossas, sinais característicos de um tecido celular mole que constitui uma madeira leve, frágil e capaz de acumular uma grande quantidade de água em estado livre ${ }^{2}$. Nas madeiras duras, as quais possuem vasos pequenos e fibras curtas e finas, acontece o contrário: são compactas e resistentes (ERNITZ, 1955).

A madeira é altamente higroscópica, ou seja, é suscetível à umidade. Com a queda da umidade, desde a madeira verde até o ponto de saturação, em torno de $25 \%$, não há redução da resistência mecânica, porém, para teores de umidade abaixo do ponto de saturação das fibras, é bastante significativa a influência da redução da umidade. A madeira úmida contrai ao secar, o que pode provocar deformações e rachaduras em peças

\footnotetext{
${ }^{2}$ Seiva contida nos vazios dos traqueídes, vasos e fibras. Pode circular livremente sem afetar a forma e dimensões da madeira (HELLMEISTER, 1973)
} 
feitas com esse tipo de material (ERNITZ, 1955; TAREEV, 1965).

Quanto às propriedades mecânicas, o esforço que uma peça de madeira pode suportar é afetado de forma expressiva pela direção da carga aplicada, em relação à direção das fibras, à duração da carga, da massa específica, do teor de umidade e da temperatura da madeira.

Considerando seu peso, a madeira possui algumas propriedades mecânicas bastante boas. A resistência à tração de vários tipos de madeiras está entre 70 e 130 MPa, sua massa específica é de, aproximadamente, 0,5 a $0,8 \mathrm{~g} / \mathrm{cm}^{3}$, e, em alguns casos, mais que $1 \mathrm{~g} / \mathrm{cm}^{3}$. Para efeito de comparação, observe que o aço possui resistência à tração entre 400 e $500 \mathrm{MPa}$ e massa específica de $7,8 \mathrm{~g} / \mathrm{cm}^{3}$. Assim, a resistência à tração da madeira não é menor que o aço se referido ao seu peso volumétrico em vez de suas dimensões (TAREEV, 1965).

A madeira seca tem boas propriedades isolantes térmicas, acústicas e elétricas. É resistente à oxidação, ácido, água salgada e outros agentes corrosivos, possui boa resistência de choque, pode ser tratada com preservativos e retardantes de fogo, e também pode ser combinada com quase qualquer outro material.

\subsubsection{Propriedades elétricas da madeira}

Condutividade, constante dielétrica e fator de potência dielétrico são as mais importantes propriedades elétricas da madeira (FPL, 1999).

\section{I - Condutividade}

A condutividade de um material determina a corrente elétrica que flui quando este material é colocado sob uma determinada tensão gradiente. A condutividade elétrica 
da madeira, ou sua recíproca resistividade, varia ligeiramente com a tensão aplicada e dobra para cada aumento de temperatura de $10^{\circ} \mathrm{C}$; também varia bastante com o teor de umidade, especialmente abaixo do ponto de saturação das fibras (FPL, 1999).

O teor de umidade da madeira vai de próximo de zero até a saturação das fibras, sendo que com as fibras saturadas a condutividade elétrica aumenta na ordem de $10^{10}$ a $10^{13}$ vezes. A resistividade é de, aproximadamente, $10^{14}$ a $10^{16} \Omega \cdot \mathrm{m}$ para madeira seca e de $10^{3}$ a $10^{4} \Omega \cdot \mathrm{m}$ para madeira com fibras saturadas. Como o teor de umidade aumenta até a saturação das fibras para a completa saturação da estrutura de madeira, o aumento adicional em condutividade é menor e irregular, geralmente chegando a menos que uma centena (FPL, 1999). Dessa forma, em comparação com diversos materiais refratários, que são ótimos isolantes com resistividade na ordem de $10^{10} \Omega . m$, a madeira apresenta boa resistividade (MOTA, 2006).

A resistividade elétrica da madeira decresce rapidamente com o aumento do teor de umidade, como pode ser observado na tabela 2.2 (COUTINHO, 1999; KOLLMANN \& CÔTÉ, 1984).

Tabela 2.2: Resistividade tangencial: valores médios.

\begin{tabular}{cc}
\hline $\begin{array}{c}\text { TEOR DE UMIDADE } \\
(\%)\end{array}$ & $\begin{array}{c}\text { RESISTIVIDADE } \\
(\mathrm{M} \Omega . c m)\end{array}$ \\
\hline 7 & 22000 \\
10 & 600 \\
15 & 40 \\
25 & 0,5 \\
\hline
\end{tabular}

Fonte: COUTINHO, 1999.

A figura 2.13 ilustra a variação da resistência elétrica com o teor de umidade ao longo da madeira, baseada em testes realizados em várias espécies domésticas. A variabi- 
lidade entre as espécies testadas é ilustrada pela área sombreada. Os valores de resistência foram obtidos utilizando um medidor de umidade padrão a $27^{\circ} \mathrm{C}$. A condutividade é maior ao longo das fibras do que na direção normal às fibras e ligeiramente maior na direção radial do que na direção tangencial (FPL, 1999).

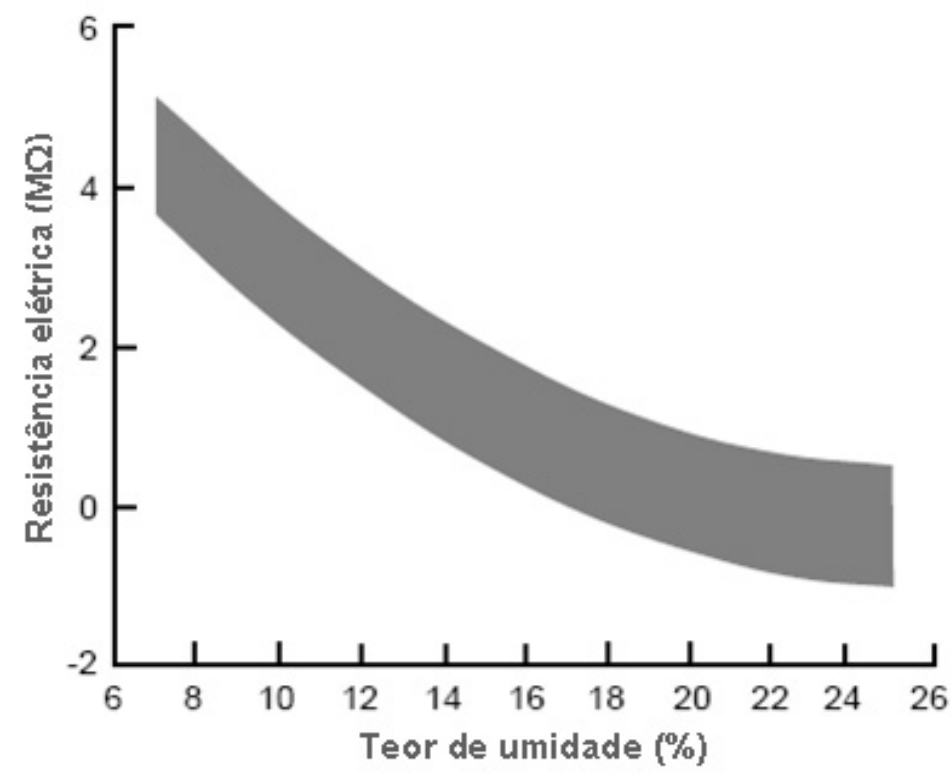

Figura 2.13: Variação da resistência elétrica da madeira com o teor de umidade de algumas espécies norte-americanas. (FPL, 1999).

Para um determinado grau de umidade, a resistividade depende da espécie, direção e massa volumétrica da madeira. A resistividade na direção tangencial é de 2 a 4 vezes maior do que na direção longitudinal, e um pouco superior à resistividade na direção radial (COUTINHO, 1999).

\section{II - Constante dielétrica $(\epsilon)$}

A constante dielétrica de um material não-condutor determina a quantidade de energia elétrica potencial, na forma de polarização induzida, que é armazenada em um determinado volume do material quando colocado em um campo elétrico. Representa a relação da permissividade dielétrica do material com a permissividade do vácuo. De acordo 
com testes práticos, a constante dielétrica de um material é a relação da capacitância de um capacitor que utiliza um material dielétrico e a capacitância do mesmo capacitor usando o ar como dielétrico (FPL, 1999).

A constante dielétrica da madeira seca está entre 2 a 5 vezes a constante dielétrica do ar, e decresce lentamente, mas constantemente, com o aumento da freqüência do campo aplicado. O aumento da temperatura ou do teor de umidade eleva o valor da constante dielétrica - o que mostra uma interação positiva moderada entre estes dois fatores. Há uma intensa interação negativa entre umidade e freqüência. A $20 \mathrm{~Hz}$, a constante dielétrica pode variar, aproximadamente, de 4 para madeira seca a 1.000 .000 para madeira úmida; a $1 \mathrm{kHz}$, aproximadamente, de 4 quando seca a 5.000 quando úmida; e a $1 \mathrm{MHz}$, aproximadamente, de 3 quando seca a 100 quando úmida, aproximadamente. A constante dielétrica da madeira é maior para a polarização na direção paralelo do que na direção perpendicular às fibras (FPL, 1999).

Para freqüência e teor de umidade acima de $10^{3} \mathrm{~Hz}$ e $10 \%$, respectivamente, os valores da constante dielétrica dependem, em grande parte, da espécie e da densidade da árvore. Estes valores diferem consideravelmente um do outro, e a dependência desses valores com o teor de umidade tem o caráter de uma função exponencial (TORGOVNIKOV, 1993).

A figura 2.14 apresenta a relação da constante dielétrica nas direções paralela e perpendicular às fibras com o teor de umidade de madeiras do tipo coníferas - como as árvores do gênero Pinus. Observe que, para teor de umidade entre $20 \%$ e 30\%, a taxa de aumento na constante dielétrica é maior do que a taxa de aumento do teor de umidade (TORGOVNIKOV, 1993). 


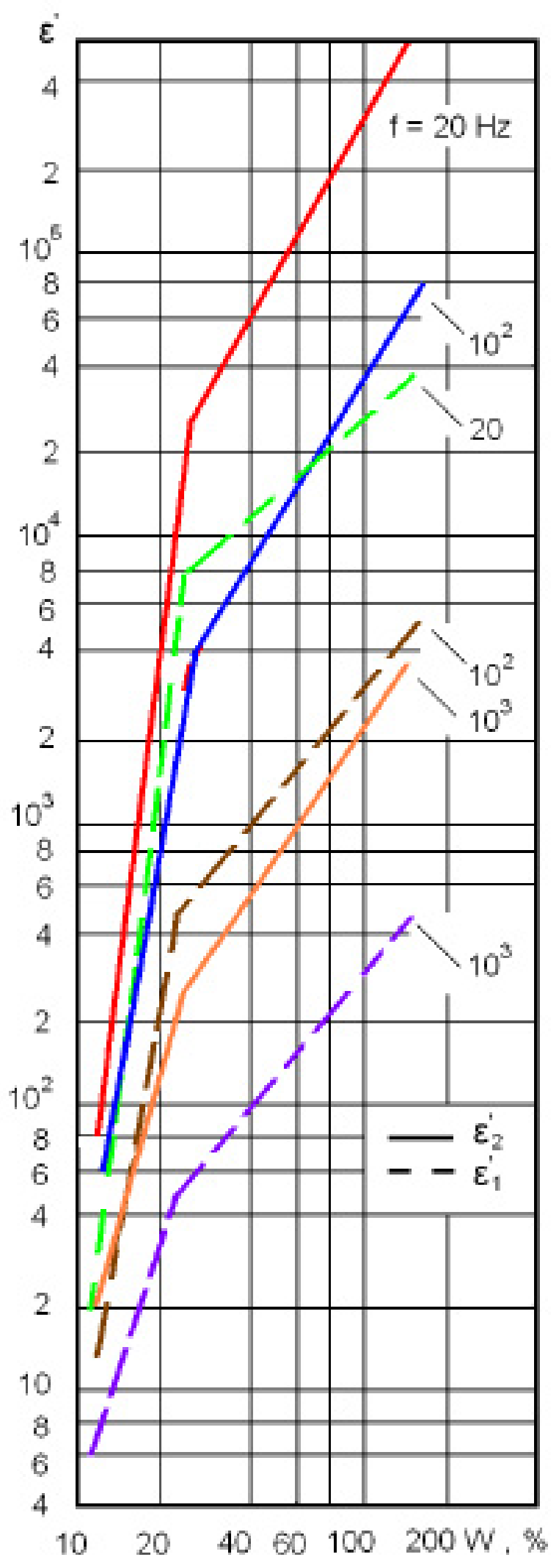

Figura 2.14: Relação da constante dielétrica com a umidade de madeiras do tipo coníferas, nas freqüências entre 20 e $1000 \mathrm{~Hz}$ (densidade $=0,4-0,5 \mathrm{~g} / \mathrm{cm}^{3}, \mathrm{t}=20-25^{\circ} \mathrm{C}$ ) (TORGOVNIKOV, 1993). 


\section{III - Fator de potência dielétrica}

O fator de potência de um material não-condutor determina a fração de energia armazenada que é dissipada na forma de calor quando realizado um ciclo completo de polarização/depolarização (FPL, 1999).

Quando um não-condutor é colocado em um campo elétrico, absorve e armazena energia potencial. A quantidade de energia armazenada por volume de unidade depende da constante dielétrica e da magnitude do campo aplicado. Um dielétrico ideal libera toda a energia para o circuito elétrico externo quando o campo é retirado, mas os dielétricos reais dissipam alguma energia em forma de calor. O fator de potência é uma medida da porção da energia armazenada convertida em calor. Os valores do fator de potência estão sempre entre 0 e 1 (FPL, 1999).

O fator de potência da madeira varia de aproximadamente 0,01 , para madeiras secas e baixa densidade, para até 0,95 para madeiras densas e com altos níveis de umidade. O fator de potência, geralmente, é maior para campos elétricos ao longo do que através das fibras (FPL, 1999).

O fator de potência da madeira é afetado por vários fatores, inclusive a freqüência, o teor de umidade e a temperatura.

\subsubsection{Vantagens e desvantagens do uso da madeira}

É possível citar, dentre muitas, as principais vantagens do uso da madeira (COUTINHO, 1999):

- encontrada em grandes quantidades e a preço relativamente baixo; o crescente número de áreas de reflorestamento, que torna o material disponível; 
- fácil trabalhabilidade com ferramentas simples e posibilidade de ser retrabalhada várias vezes;

- baixa massa volumétrica e elevada resistência mecânica;

- permite ligações e emendas fáceis de executar;

- boa resistência ao choque, ou seja, tenacidade, com nível de umidade não muito baixo - a madeira não estilhaça quando submetida a choques bruscos que romperiam ou rachariam outros materiais;

- boas condições naturais de isolamento elétrico, térmico e absorção acústica.

Em contraposição, apresenta algumas desvantagens que devem ser cuidadosamente consideradas (COUTINHO, 1999):

- material fundamentalmente heterogêneo e anisotrópico;

- para espécies de reflorestamento, é vulnerável aos agentes externos e apresenta durabilidade limitada quando não são tomadas medidas preventivas;

- sensível ao ambiente, aumentando ou diminuindo de dimensões com as variações de umidade.

Alguns dos processos desenvolvidos para anular as características negativas da madeira no seu estado natural são:

- a degradação das suas propriedades e o aparecimento de tensões internas decorrentes de alterações da umidade são anulados pelos processos desenvolvidos de secagem artificial controlada;

- a deterioração da madeira em ambientes que favoreçam o desenvolvimento de seus principais predadores é contornada com tratamentos de preservação;

- a heterogeneidade e a anisotropia próprias de sua constituição fibrosa orientada, assim como a limitação das suas dimensões, são resolvidas pelos processos de transfor- 
mação nos laminados, contraplacados e aglomerados de madeira (URIARTT, 1992).

A impregnação da madeira com alguns tipos de óleo, verniz e resina melhora sua força de isolação e reduzem sua higroscopicidade. Peças de madeira podem ser impregnadas somente depois de terem sido trabalhadas, devido a que as camadas mais profundas de madeira não são impregnadas igualmente às camadas superficiais; assim, se uma peça impregnada for perfurada, a umidade vai facilmente penetrar a madeira (TAREEV, 1965).

\subsubsection{Fatores que influenciam as características da madeira}

A escolha da madeira de uma determinada espécie lenhosa para um determinado uso, somente poderá ser realizada com economia e segurança, conhecendo-se os valores médios que definem o seu comportamento físico e sua resistência às solicitações mecânicas. É necessário levar em consideração todos os fatores que influenciam a variação das características do material, como os fatores naturais, decorrentes da própria natureza do material, e os fatores tecnológicos, decorrentes da técnica de execução dos ensaios (COUTINHO, 1999).

Alguns fatores naturais que influenciam as características da madeira são (COUTINHO, 1999):

a) Espécie botânica da madeira - a estrutura anatômica e a constituição do tecido lenhoso, as principais responsáveis pelo comportamento físico-mecânico do material, variam de espécie para espécie lenhosa. A partir deste ponto de vista é necessária a perfeita identificação botânica da espécie a ser qualificada.

b) Massa volumétrica do material - a massa volumétrica aparente é um índice da distribuição ou concentração de material existente no tecido lenhoso. Permite estimar va- 
lores de outras propriedades com ela relacionadas por aplicação de fórmulas determinadas experimentalmente, por correlação.

c) Localização da peça no lenho - as alterações do tecido lenhoso e a massa volumétrica são evidentes, conforme as diferentes zonas do lenho.

d) Presença de defeitos - a presença de defeitos, tais como nós, fendas, fibras torcidas, entre outros, depende de sua distribuição, dimensões e, principalmente, de sua localização - provoca consideráveis anomalias no comportamento físico-mecânico da peça.

e) Umidade - a madeira é constituída por fibras de paredes celulósicas hidrófilas; o grau de umidade determina profundas alterações nas propriedades do material.

Os fatores tecnológicos que influenciam a variação dos resultados são aqueles que resultam do procedimento dos ensaios: forma e dimensões dos corpos de prova, orientação das forças aplicadas em relação aos anéis de crescimento e velocidade de aplicação das cargas. Esses fatores dizem respeito à distribuição de tensões internas nas peças, variáveis conforme sua forma e dimensões (COUTINHO, 1999).

A resistividade elétrica é um fator fundamental para controlar o campo elétrico dentro da madeira. Uma baixa resistividade aumenta a capacidade de reduzir o campo elétrico dentro da estrutura da madeira e a umidade afeta diretamente sua resistividade elétrica. Condições ambientais, como umidade relativa de ar e temperatura atmosférica, afetam a porcentagem de umidade e, conseqüentemente, a resistividade elétrica da madeira (GUNATILAKE et al., 2004). 


\subsection{RESINAS POLIURETANAS DERIVADAS DO ÓLEO DE MAMONA}

As poliuretanas foram desenvolvidas por Otto Bayer em 1937 (VILAR, 1993). As resinas poliuretanas apresentam bastante versatilidade em vários segmentos industriais: podem ser encontradas como elastômero de alta flexibilidade ou de maior dureza (WOODS, 1990).

O termo poliuretana se aplica à classe de polímeros que contém ligação uretana, mesmo que existam outras ligações presentes. Diferentes de outros polímeros, de unidades monoméricas, as poliuretanas não contêm unidades de uretano repetidas de modo regular e não têm uma forma empírica que seja representativa de um todo. Uma poliuretana típica, além dos grupos uretano, pode conter hidrocarbonetos alifáticos e aromáticos, grupos éster, éter, uréia, amida, entre outros (SILVESTRE, 2001).

Algumas vantagens apresentadas pelas poliuretanas são: processabilidade; flexibilidade de formulação; versatilidade de temperatura de cura e controle de pico exotérmico na transição líquido-gel; excelentes propriedades estruturais; ausência de emissão de vapores irritantes ou tóxicos; bom poder de adesão; e baixo custo.

As resinas poliuretanas podem derivar de fontes naturais, como o petróleo e os óleos vegetais. Estes óleos podem ser retirados de vegetais como soja, milho, açafrão, girassol, canola, amendoim, oliva e mamona (PETROVIC, 1999) apud (SILVA et al., 2003).

O início do desenvolvimento das poliuretanas derivados de óleo de mamona ocorreu na década de 40 (VILAR, 1993). Segundo a Empresa de Pesquisa Agropecuária S.A. (EMBRAPA) da Bahia e a Secretaria da Agricultura, a mamona mais comum no Brasil é a espécie Ricinus Communis L. - planta oleaginosa, arbustiva, da família das 
Euforbáceas.

O óleo de mamona é obtido da semente da espécie Ricinus Communis, encontrada em regiões tropicais e subtropicais, portanto, muito abundante no Brasil. Sua estrutura está apresentada no esquema 1 da figura 2.15.

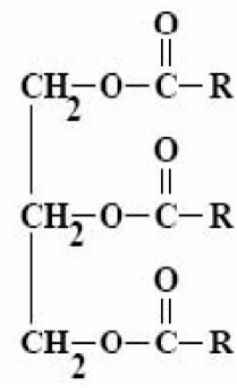

onde:

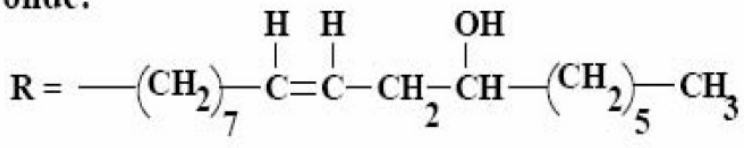

Figura 2.15: Estrutura do óleo de mamona.

É uma das poucas fontes naturais que se aproximam de um composto puro. O ácido ricinoléico está presente em cerca de $90 \%$ dos ácidos graxos presentes na composição dos triglicerídeos do óleo de mamona, sendo os $10 \%$ restantes constituídos de ácidos graxos não hidroxilados, como os ácidos oléicos e linoléicos.

A presença, em sua estrutura molecular, do grupo hidroxila no $12^{\circ}$ carbono, difere o ácido ricinoléico da grande maioria dos ácidos graxos presentes na natureza, fazendo da triglicéride do ácido ricinoléico um poliol natural trifuncional (SILVESTRE, 2001). A composição média do óleo de mamona é apresentada na TABELA 2.3.

O ácido ricinoléico atribui, ao óleo de mamona, propriedades únicas e grande versatilidade devido aos grupos $\mathrm{OH}$ e à ligação dupla, que são sítios distintos de reação para a preparação de vários derivados industriais. As reações podem ser efetuadas isoladamente ou em combinação, possibilitando a obtenção de muitos derivados (SILVESTRE, 2001). Por causa deste grupo de hidroxila polar, ele é compatível com uma grande variedade de resinas naturais e sintéticas (HEMERLY, 1981). 
Tabela 2.3: Composição média do óleo de mamona.

\begin{tabular}{lc}
\hline COMPONENTE & PERCENTAGEM \\
\hline Ácido ricinoléico & 89,5 \\
Ácido palmítico & 1,0 \\
Ácido linoléico & 4,2 \\
Ácido linolênico & 0,3 \\
Ácido dihidroxiesteárico & 0,7 \\
Ácido estereático & 1,0 \\
Ácido oléico & 3,0 \\
Ácido eicosanáico & 0,3 \\
\hline
\end{tabular}

Fonte: (PLEPIS, 1991)

Conforme sua finalidade, o óleo de mamona tem uma característica de acidez, umidade e outros índices, representados na tabela 2.4 .

Tabela 2.4: Características de diferentes tipos de óleo de mamona (ARAUJO, 1992).

\begin{tabular}{|c|c|c|c|c|c|c|c|c|}
\hline PRODUTO & COR & ACID. & VISC. & DENS. & I.I. & I.OH. & I.SAP. & P.CONG. \\
\hline AA-Padrão & $1+$ & 2,0 & 7,5 & 0,959 & 86 & 164 & 180 & -10 \\
\hline AA-USP & $1-$ & 2,0 & 7,5 & 0,959 & 86 & 164 & 180 & -10 \\
\hline Cristal O & $1-$ & 2,0 & 7,5 & 0,959 & 86 & 164 & 180 & -10 \\
\hline C. Crown & $1-$ & 2,0 & 7,5 & 0,959 & 86 & 164 & 180 & -10 \\
\hline DB Oil & $1+$ & 0,6 & 7,5 & 0,959 & 86 & 164 & 180 & -10 \\
\hline \#1 Oil & $2+$ & 2,0 & 7,5 & 0,959 & 86 & 158 & 180 & -10 \\
\hline ACID. & - & \multicolumn{7}{|c|}{ Acidez do óleo de mamona. } \\
\hline VISC. & - & \multicolumn{7}{|c|}{ Viscosidade a $25^{\circ} \mathrm{C}[\mathrm{cP}]$} \\
\hline DENS. & - & \multicolumn{7}{|c|}{ Densidade a $25^{\circ} \mathrm{C}\left[\mathrm{g} / \mathrm{cm}^{3}\right]$. } \\
\hline I.I. & - & \multicolumn{7}{|c|}{ Índice de Iodo. } \\
\hline I.OH. & - & \multicolumn{7}{|c|}{ Índice de Hidroxila. } \\
\hline I.SAP. & - & \multicolumn{7}{|c|}{ Índice de Saponificação. } \\
\hline P.CONG. & - & \multicolumn{7}{|c|}{ Ponto de congelamento $\left[{ }^{o} \mathrm{~F}\right]$. } \\
\hline
\end{tabular}

O óleo de mamona foi usado por um longo tempo como padrão absoluto para viscosidade, o que confirma a uniformidade e confiabilidade de suas propriedades físicas (MURAKAMI, 2002). 


\subsubsection{Resina poliuretana monocomponente}

Com o avanço da tecnologia de polímeros, o Instituto de Química de São Carlos (IQSC), da Universidade de São Paulo (USP), desenvolveu um polímero monocomponente derivado do óleo de mamona com processo de cura pela umidade do ar.

Este polímero foi processado com o auxílio de um reator carregado com óleo de mamona e um antioxidante para manter a mistura sem alterar a cor, devido à oxidação ou polimerização oxidativa do óleo vegetal. Simultaneamente, adicionou-se $30 \%$ de solventes, xileno e acetato de etil glicol, em proporções balanceadas, considerando-se o volume da mistura.

O processo foi mantido sob atmosfera de gás inerte, com controle térmico e um procedimento adequado para adição de reagentes até total dissolução (CARLO, 2003). Esta resina pode ser utilizada sobre superfícies molhadas e aplicada com pincel, rolos, spray ou imersão (AZAMBUJA, 2006).

Conforme avaliações realizadas nas propriedades relativas à aparência, cor, solubilidade em solventes, viscosidade, teor de sólidos e eficiência da adesividade, a poliuretana monocomponente derivada do óleo de mamona com cura pela umidade do ar pode ser considerada um produto estável e de fácil aplicação (CARLO, 2003).

Avaliações cromatográficas determinaram teores de TDI iguais a $0,6 \%$, o que classifica o produto como "nocivo à saúde do aplicador". Entretanto, os baixos teores de isocianato (NCO) contidos no Tolueno Diisocianto (TDI), classificam a poliuretana como "não tóxica"(CARLO, 2003).

De acordo com o fabricante, KEHL $\cap$ Indústria e Comércio LTDA, a resina poliuretana monocomponente possui tempo de secagem ao toque em torno de 30 minutos; dependendo da temperatura ambiente e umidade, seu tempo de cura é de 24 horas . A 
viscosidade desta resina é de aproximadamente $5,313 \mathrm{cP}$ a $20^{\circ} \mathrm{C}$ e sua densidade está entre 0,9 e 1,0 $\mathrm{g} / \mathrm{cm}^{3}$ (VICINO, 2007).

\subsubsection{Resina poliuretana bicomponente}

A resina poliuretana bicomponente derivada do óleo de mamona utilizada nesse estudo é formada por dois componentes: um pré-polímero com terminação isocianato e um poliol. Quando curados por poliadição, esses dois componentes reagem entre si, resultando em um composto poliuretano. Na mistura dos componentes, quanto maior for a proporção do poliol, mais flexível fica a estrutura da resina. Enquanto que, se houver maior concentração de pré-polímero, mais rígida se torna a sua estrutura.

A polimerização final ocorre em torno de 24 horas e sua secagem ao toque varia entre 10 e 30 minutos, dependendo da umidade e temperatura ambiente. Possui viscosidade de $7,5 \mathrm{cP}$ e densidade de $0,959 \mathrm{~g} / \mathrm{cm}^{3}$ ambas a $25^{\circ} \mathrm{C}$ (ARAUJO, 1992).

Quando aplicada em uma matriz, se impregna nos poros e posteriormente se polimeriza, formando um filme altamente compacto sobre a superfície, capaz de promover o encapsulamento do material suporte - protegendo e evitando a penetração de agentes agressivos.

Esta resina poliuretana é totalmente isenta de solventes e não agressiva ao meio ambiente ou ao homem, ou seja, por não possuir em sua composição materiais voláteis e metais pesados, são completamente atóxicas.

As poliuretanas vegetais diferem muito das derivadas de petróleo. Sua matéria prima é proveniente de recursos vegetais renováveis, e são bastante resistentes aos agentes agressivos, tais como, ácidos, álcalis e bases. Diferentes das poliuretanas de petróleo, não são inflamáveis e, quando queimadas, não emitem gases tóxicos. 


\subsubsection{Reação de polimerização}

Denomina-se uretano ou uretana o produto da reação química entre um grupo hidroxila e um grupo isocianato (WULTZ, 1849) apud (NETO, 1997) - apresentado no esquema da figura 2.16 .

A polimerização das poliuretanas ocorre quando um composto com dois ou mais isocianatos em uma estrutura reage com um poliol, ou seja, um álcool polifuncional (NETO, 1997) - conforme esquema da figura 2.17.

A reação de polimerização é exotérmica e sua velocidade depende da estrutura do isocianato e do poliol. A reatividade do isocianato depende da influência dos grupos vizinhos e da configuração da molécula (SILVESTRE, 2001).

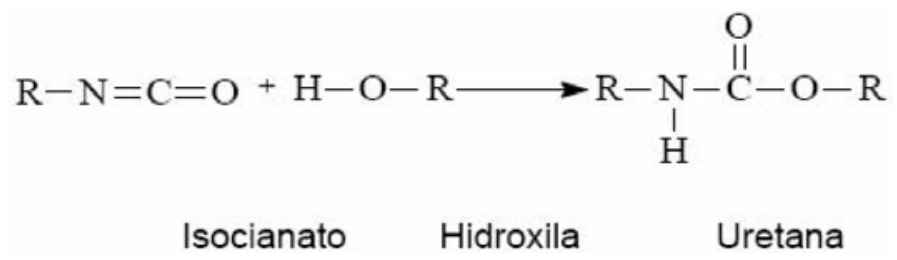

Figura 2.16: Estrutura do uretano.

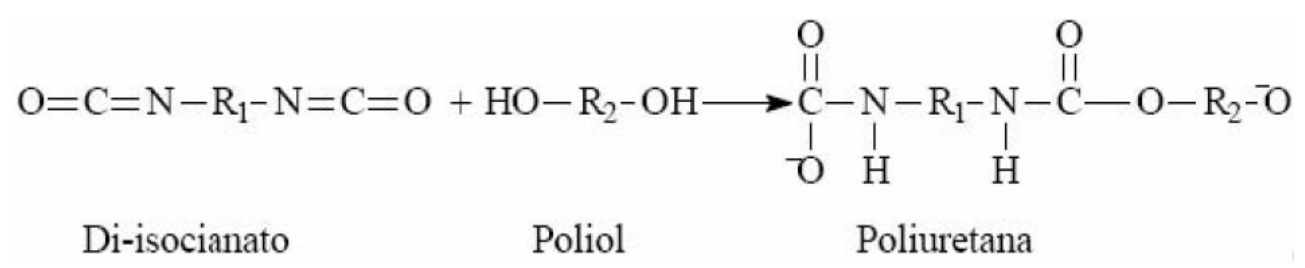

Figura 2.17: Polimerização da poliuretana.

Geralmente é feita uma pré-polimerização, que consiste na reação de um di ou poliisocianato com um poliol, em proporções determinadas previamente para a obtenção do teor de isocianato livre desejado. Esta pré-polimerização é necessária devido à alta 
reatividade dos compostos contendo grupos isocianatos. A reação de polimerização ocorre pela mistura do pré-polímero com o poliol final, gerando uma poliuretana de alto peso molecular (SILVA, 2003).

\section{I - Poliol}

Os isocianatos e os compostos hidroxilados ou polióis são componentes importantes na síntese das poliuretanas. Existe uma grande variedade de polióis que podem ser utilizados na manufatura de poliuretanas, como, por exemplo, os compostos naturais como o óleo de mamona, que contém três grupos hidroxila que produzem polímeros entrecruzados (SILVESTRE, 2001).

A maioria dos polióis possui a forma de poliéteres ou poliésteres. Os fatores principais na determinação das propriedades do polímero são: massa molecular, funcionalidade e estrutura do poliol. Poliésteres e poliéteres produzem poliuretanas com propriedades térmicas e tolerância a substâncias corrosivas diferentes. As poliuretanas derivadas de poliéster são mais estáveis e menos facilmente oxidáveis.

Os polióis são desenvolvidos com estrutura molecular e funcionalidade necessária para reagir com um pré-polímero ou um diisocianato comercial, e podem gerar poliuretanas com propriedades específicas. A escolha do poliol, especialmente pelo tamanho e flexibilidade de sua estrutura molecular e sua funcionalidade, controla, em grande parte, o grau de entrecruzamento obtido no polímero formado na reação poliol com isocianato (PLEPIS, 1991).

\section{II - Pré-polímero}

Geralmente é feita uma pré-polimerização com um poliol, aumentando sua massa 
molecular, deixando uma porcentagem de isocianato livre para reagir com o poliol final, devido à alta reatividade dos compostos contendo grupos isocianatos.

Os compostos contendo grupos isocianatos são encontrados em duas classes distintas (NETO, 1997):

a) aromáticos - os mais utilizados são o difenilmetano diisocianato (MDI) e o tolueno diisocianato (TDI);

b) alifáticos - o hexametileno diisocianato (HDI) e o isofurona diisocianato (IPDI) são mais utilizados.

O pré-polímero utilizado neste trabalho foi sintetizado a partir do MDI - esquema da figura 2.18 - e de um poliol derivado de óleo de mamona, devido à sua alta resistência a produtos químicos impedir que substâncias agressivas infiltrem a madeira (PINTO \& TAKAGI, 2005).

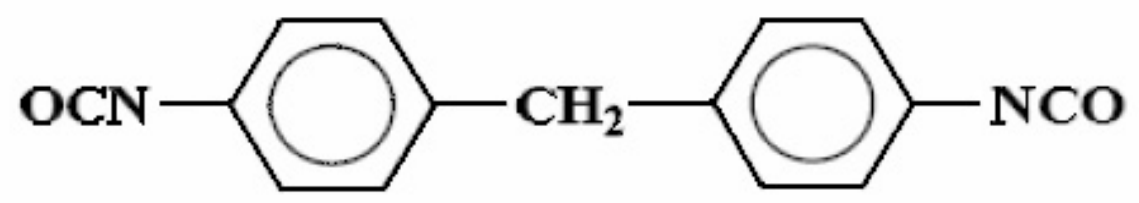

Figura 2.18: Estrutura do difenilmetano diisocianato (MDI).

\subsubsection{Conclusão da Bibliografia}

De acordo com a análise bibliográfica, constatou-se que o compósito proposto é um material inovador, com grandes expectativas de aplicações elétricas, aproveitando as melhores características elétricas e mecânicas da madeira e das resinas poliuretanas. 


\section{Capítulo 3}

\section{CARACTERIZAÇÃO DA MADEIRA IMPREGNADA COM AS RESINAS POLIURETANAS}

Diversos testes de impregnação foram realizados previamente com a resina poliuretana em duas das espécies de madeira de reflorestamento mais comumente encontradas no Brasil, o Pinus Elliottii e o Pinus Taeda. Estes testes preliminares apontaram o Pinus Taeda como o mais adequado para a utilização nesta pesquisa, pois apresentou maior impregnação. O Pinus Elliottii não apresentou boa impregnação, devido à presença de grande quantidade de resina natural da própria espécie que impede a penetração da resina poliuretana; por isso, foi descartado.

Este capítulo apresenta a impregnação em amostras de madeira da espécie $P i$ nus Taeda com resina poliuretana monocomponente e bicomponente derivada do óleo de mamona.

A resina poliuretana monocomponente possui uma coloração bastante transparente quando aplicada à madeira; sendo assim, foi necessária a utilização de colorante na resina para possibilitar a visualização da impregnação. Foram testadas as seguintes cargas: pó fluorescente para biscuit e porcelana fria, tinta para caneta tinteiro Sheaffer Skrip@ e tinta a óleo Classic Acrilex.

O pó fluorescente e a tinta para caneta tinteiro não se misturaram completa- 
mente à resina, a carga não penetrou na madeira e foi filtrada por ela. A tinta a óleo para tela apresentou-se como melhor opção para a coloração da resina - carga, portanto, escolhida para a coloração.

Após vários testes com a resina bicomponente, a proporção de pré-polímero e poliol que apresentou a melhor consistência física para ser utilizada na impregnação foi de 1:1,5 e o tempo de processamento $\left(t_{p}\right)$ mais adequado foi de 3 minutos.

O tempo de manuseio da resina bicomponente é de até 6 minutos, e seu tempo de cura total é de 24 horas à temperatura ambiente (MURAKAMI, 2002). A resina monocomponente também possui tempo de cura de aproximadamente 24 horas à temperatura ambiente; entretanto, seu tempo de manuseio é bem maior.

As amostras foram acondicionadas em condições normais de temperatura e umidade relativa de ar, e tomou-se o cuidade de não expô-las à umidade excessiva, devido ao material possuir propriedade higroscópica.

\subsection{PREPARAÇÃO DAS AMOSTRAS PARA IMPREGNAÇÃO}

Como visto anteriormente, altos teores de umidade diminuem a resistividade elétrica da madeira e também são prejudiciais à impregnação, pois os espaços que poderiam ser preenchidos pela resina estão ocupados pela água.

Antes de realizar o procedimento de impregnação, deve-se medir o teor de umidade das peças de madeira das quais serão retirados os corpos-de-prova (CPs) para verificar a necessidade de secagem das mesmas.

Existem vários métodos para se determinar o teor de umidade da madeira; no entanto, os mais utilizados são: método por pesagens, método químico e aparelhos elétricos. 
Fez-se uso do método por pesagens, pois, além de ser o mais utilizado, é o método recomendado pela norma NBR7190 (1997). Para atender aos objetivos de caracterização simplificada da madeira, segundo a norma citada, devem-se realizar os ensaios em, no mínimo, seis CPs retirados de peças diferentes.

Para a determinação do teor de umidade das sete peças a serem utilizadas nos ensaios elétricos e mecânicos foram retirados sete CPs de cada peça de seção transversal retangular, com dimensões nominais de $2,0 \mathrm{~cm} \times 3,0 \mathrm{~cm}$ e comprimento de $5,0 \mathrm{~cm}$ ao longo das fibras (NBR7190, 1997) - figura 3.1.
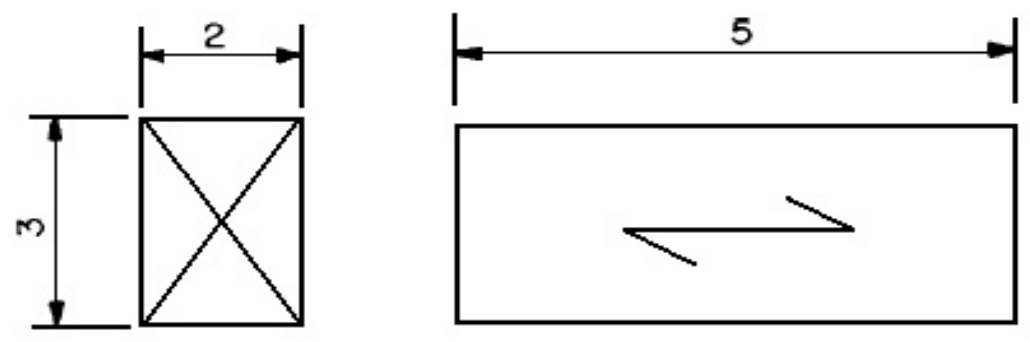

Figura 3.1: CP para determinação da umidade da madeira, valores em centímetros $(\mathrm{cm})$.

O teor de umidade da madeira corresponde à relação entre a massa da água contida na mesma e a massa da madeira seca, dada pela equação 3.1

$$
U=\frac{m_{i}-m_{s}}{m_{s}} \times 100
$$

onde

$m_{i}$ é a massa inicial da madeira, em gramas;

$m_{s}$ é a massa da madeira seca, em gramas.

Para a determinação da umidade da madeira, primeiramente, é determinada a massa inicial $\left(m_{i}\right)$ do CP com exatidão de $0,01 \mathrm{~g}$, em seguida, o CP é colocado na 
estufa com temperatura máxima de $103^{\circ} \mathrm{C} \pm 2{ }^{\circ} \mathrm{C}$ - neste trabalho utilizou-se uma estufa Quimis. Aumenta-se gradualmente a temperatura da estufa, aproximadamente $10^{\circ} \mathrm{C}$ a cada 2 horas, até atingir os $103^{\circ} \mathrm{C}$ - procedimento necessário para evitar que ocorram rachaduras nos CPs.

A massa do CP deve ser medida a cada 6 horas, durante a secagem, até que a variação entre duas medidas consecutivas seja menor ou igual a $0,5 \%$ da última massa medida; assim, esta será a massa seca $\left(m_{s}\right)$ (NBR7190, 1997).

Com os valores da massa inicial e da massa seca conhecidos, a umidade à base seca pode ser obtida através da equação 3.1.

De acordo com testes de impregnação realizados, a umidade da madeira deve ser menor que $12 \%$, uma vez que esta é a umidade de equilíbrio da madeira à umidade relativa do ar menor que 65\%, conforme a norma NBR7190 (1997) - lembrando que níveis de umidade muito baixos diminuem a tenacidade da madeira (COUTINHO, 1999).

As peças com umidade acima de $12 \%$ deverão passar por um processo de secagem em estufa à temperatura de $100^{\circ} \mathrm{C}$. A massa das amostras deve ser medida a cada 30 minutos, até alcançar a massa referente à umidade de $12 \%$ - calculada a partir da equação 3.1.

Como pode ser observado na tabela 3.1, somente a peça 2 apresentou umidade superior a $12 \%$ e, portanto, peça precisou passar pelo processo de secagem em estufa até atingir tal umidade. 
Tabela 3.1: Resultado da medição da umidade das amostras.

\begin{tabular}{cc}
\hline PEÇA & $\begin{array}{c}\text { UMIDADE (\%) } \\
(\%)\end{array}$ \\
\hline 1 & 10,58 \\
2 & 12,26 \\
3 & 9,23 \\
4 & 9,27 \\
5 & 11,66 \\
6 & 10,43 \\
7 & 9,42 \\
\hline
\end{tabular}

\subsection{PROCESSO INOVADOR PARA IMPREGNAÇÃO DA MA- DEIRA}

A impregnação da madeira com as resinas poliuretanas monocomponente e bicomponente proposta nesta pesquisa é realizada com a imersão da madeira, sob vácuo, nas resinas poliuretanas.

Foi utilizado um processo inovador para o processamento da resina bicomponente, em que todo o processamento do pré-polímero com o poliol ocorre sob vácuo, já que, até então, o vácuo era utilizado somente após a mistura do pré-polímero com o poliol. Para tanto, fez-se uso de um agitador a vácuo, desenvolvido pelo Laboratório de Alta Tensão (LAT) da Escola de Engenharia de São Carlos (EESC/USP), conectado a uma bomba de vácuo com revestimento em PTFE - Marconi MA-057/1 - figura 3.2.

Segue abaixo o procedimento inovador utilizado para a preparação da resina bicomponente.

1. Em um recipiente plástico de $500 \mathrm{ml}$, a resina é preparada na proporção de 1:1,5 de pré-polímero e de poliol, respectivamente; para tal procedimento é utilizada uma 
balança de precisão Toledo, precisão de $10^{-3} \mathrm{~kg}$, conforme apresenta a figura 3.3.

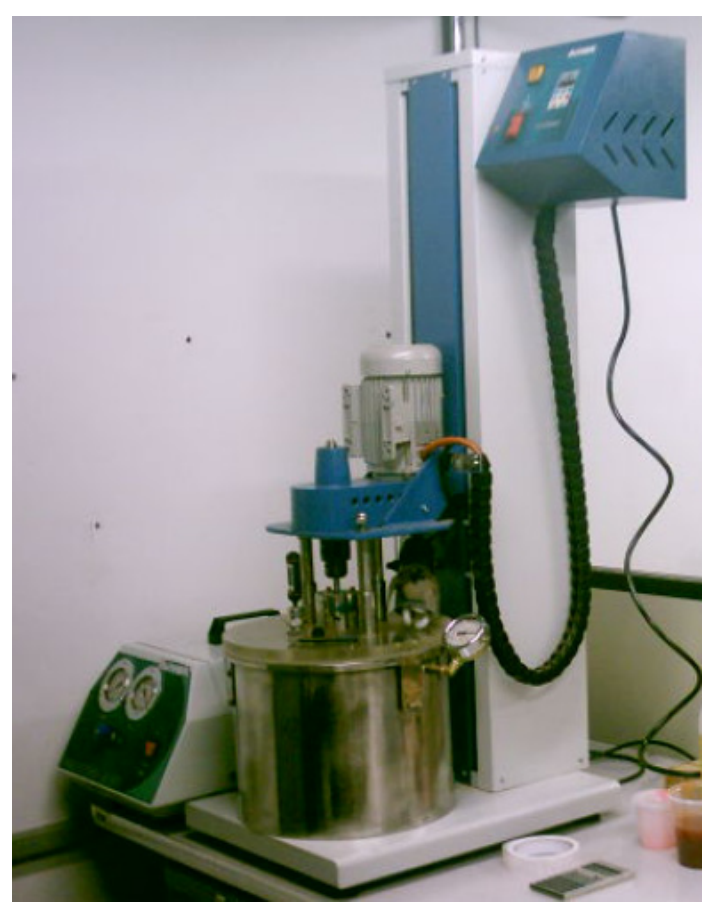

Figura 3.2: Agitador a vácuo.

2. A mistura preparada é colocada dentro do agitador, conforme apresenta a figura 3.4, permanecendo sob vácuo de $\pm 635 \mathrm{mmHg}$ durante o tempo de processamento da resina $\left(\mathrm{t}_{p}\right)$ - que é igual a 3 minutos.

3. O vácuo é retirado da máquina e o agitador, suspenso; a resina bicomponente está pronta para ser utilizada na impregnação.

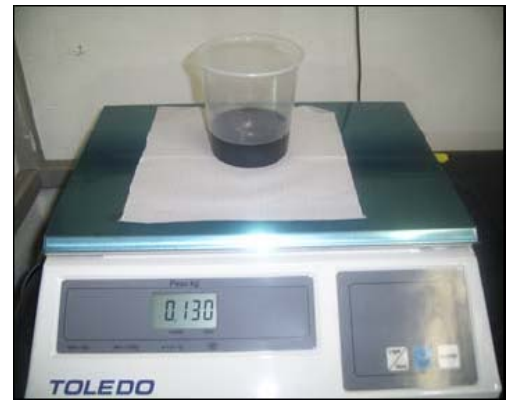

Figura 3.3: Pesagem do pré-polímero na balança de precisão Toledo.

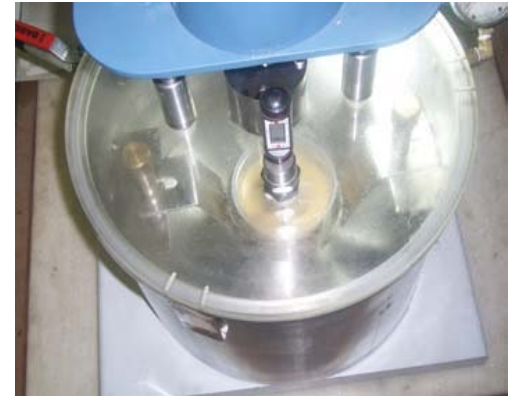

Figura 3.4: Processamento do prépolímero/poliol no agitador a vácuo. 
A resina monocomponente é utilizada diretamente, dispensando qualquer processo para sua preparação; porém, devido à transparência desta resina, sua aplicação na madeira requer a utilização de um corante para visualizar e medir a profundidade da impregnação. O corante deve ser misturado à resina monocomponente sob vácuo, na proporção de 1:145, ou seja, para cada 145 gramas de resina é adicionado 1 grama de carga.

Para verificar a influência do corante na profundidade da impregnação da resina monocomponente na madeira foi realizada a medida da profundidade da impregnação com a resina bicomponente com e sem carga. A resina bicomponente é mais viscosa do que a monocompenente; portanto, se o corante não dificultar a impregnação com a resina bicomponente, conseqüentemente, não influenciará a impregnação com a monocomponente. Os resultados das impregnações estão apresentados na tabela 3.2; a temperatura ambiente no momento dos ensaio era de $23^{\circ} \mathrm{C}$ e a umidade relativa do ar $46 \%$.

A partir dos resultados da tabela 3.2 é possível observar que a carga não influenciou na impregnação da resina na madeira, devido à pequena quantidade de carga (1:145) frente à quantidade de resina.

O procedimento para a impregnação da madeira com as resinas poliuretanas está detalhado abaixo.

1. As amostras de madeira Pinus Taeda são previamente cortadas nas dimensões desejadas e secadas em estufa, quando necessário.

2. As peças são completamente imersas na resina e submetidas ao vácuo durante o tempo de impregnação $\left(\mathrm{t}_{i m p}\right)$. Após vários testes, optou-se por um $\mathrm{t}_{i m p}$ igual a 4 minutos - dado que o tempo de manuseio da resina bicomponente, após seu processamento, é de 
6 minutos. A resina é forçada - pela redução da pressão atmosférica proporcionada pelo vácuo - a preencher os poros e cavidades da madeira.

Tabela 3.2: Resultados da Impregnação longitudinal às fibras da espécie Pinus Taeda com resina bicomponente sem e com carga.

\begin{tabular}{ccccc}
\hline \multirow{2}{*}{ Amostra } & \multicolumn{2}{c}{ Impregnação longitudinal às fibras $(\mathbf{m m})$} \\
\multicolumn{2}{c}{ Sem carga } & \multicolumn{2}{c}{ Com carga } \\
& Mínima & Máxima & Mínima & Máxima \\
\hline I & 2,0 & 7,0 & 0,5 & 4,0 \\
II & 2,2 & 5,5 & 2,5 & 4,1 \\
III & 1,9 & 3,0 & 2,5 & 4,0 \\
IV & 3,1 & 3,9 & 2,0 & 5,1 \\
V & 2,2 & 6,0 & 3,0 & 5,8 \\
VI & 2,8 & 6,0 & 3,9 & 7,2 \\
VII & 2,0 & 4,0 & 2,1 & 4,9 \\
\hline \multirow{2}{*}{ MÉDIA } & \multicolumn{3}{c}{3,69} \\
\hline
\end{tabular}

3. O vácuo é removido rapidamente, o que diminui a possibilidade de surgimento de bolhas.

4. As amostras são retiradas da resina e mantidas suspensas durante todo o tempo de cura, para que o excesso de resina escorra, conforme figura 3.5. Transcorrido o tempo de cura, a impregnação está completa - figura 3.6. 


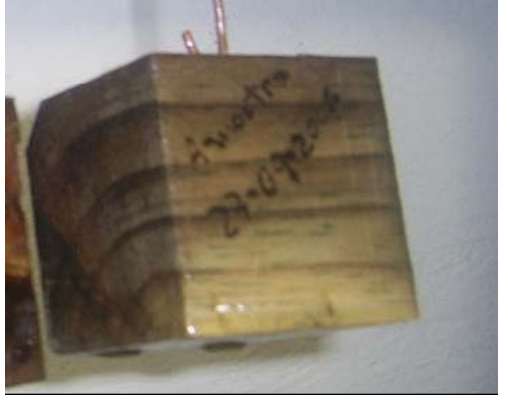

Figura 3.5: Amostra de madeira impregnada suspensa.

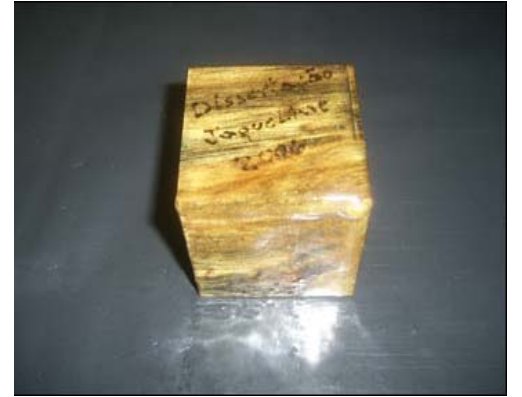

Figura 3.6: Amostra de madeira impregnada com resina poliuretana.

\subsection{RESULTADOS E ANÁLISE DAS IMPREGNAÇÕES}

As amostras foram analisadas com o auxílio de uma lupa (Carl Zeiss - Citoval

2, Germany). Para visualizar a impregnação foram realizados cortes nos corpos de prova na direção longitudinal às fibras; para facilitar a visualização com a lupa, a face cortada foi lixada com lixas $\mathrm{n}^{\circ} 120,220,320,400,600,1200$ e 2000, consecutivamente.

A medida da profundidade da amostra foi realizada com o auxílio de uma lupa, de uma escala semelhante à mostrada na figura 3.7, e de um paquímetro.

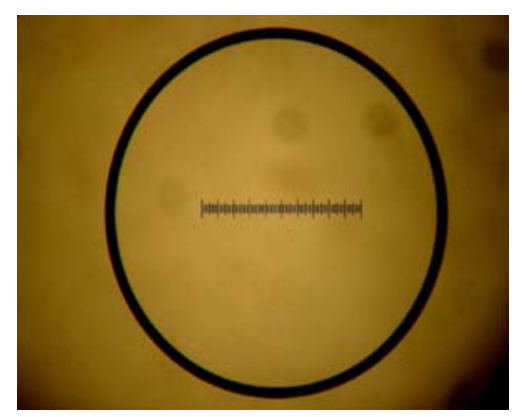

Figura 3.7: Escala equivalente a $1 \mathrm{~mm}$ para medir impregnação, ampliada 32x.

Na impregnação com a resina poliuretana monocomponente, observou-se a necessidade de realizar novamente o processo, pois a camada superficial de resina que se 
formou no CP, na primeira impregnação, foi muito fina.

\subsubsection{Impregnação dos CPs com a resina poliuretana monocom- ponente}

Os resultados da impregnação das sete peças de Pinus Taeda com a resina poliuretana monocomponente com carga estão apresentados na tabela 3.3; a temperatura ambiente no momento da primeira impregnação era de $18,1^{\circ} \mathrm{C}$ e a umidade relativa do ar, $52 \%$, na segunda impregnação, $22,6^{\circ} \mathrm{C}$ e $40 \%$, respectivamente.

Tabela 3.3: Resultados da Impregnação longitudinal às fibras da espécie Pinus Taeda com resina monocomponente com carga.

\begin{tabular}{cccc}
\hline \multirow{2}{*}{ Peça } & \multicolumn{3}{c}{ Impregnação longitudinal $(\mathbf{m m})$} \\
& Mínima & Máxima & Média \\
\hline I & 2,59 & 4,21 & 3,40 \\
II & 2,93 & 4,54 & 3,74 \\
III & 2,77 & 4,49 & 3,63 \\
IV & 2,66 & 4,59 & 3,62 \\
V & 2,79 & 4,76 & 3,77 \\
VI & 2,84 & 4,06 & 3,45 \\
VII & 3,17 & 4,93 & 4,05 \\
\hline \multirow{2}{*}{ Média } & & & 3,67 \\
Desvio-padrão & & & 0,22 \\
\hline
\end{tabular}

As figuras 3.8 a 3.14 apresentam a impregnação com a resina monocomponente. 


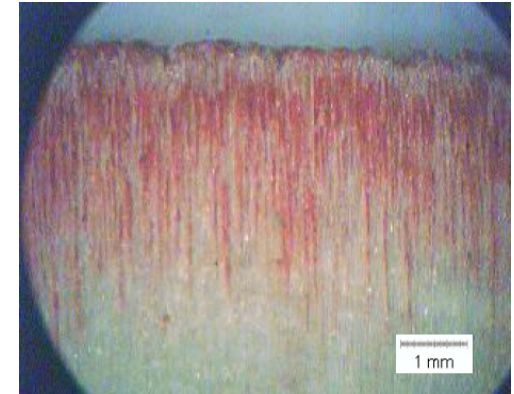

Figura 3.8: Amostra I - profundidade da impregnação longitudinal às fibras da madeira impregnada com resina monocomponente.

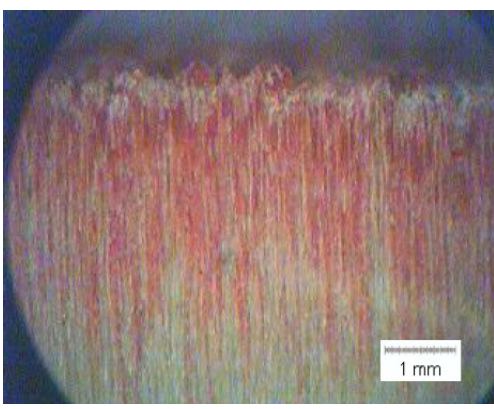

Figura 3.10: Amostra III - profundidade da impregnação longitudinal às fibras da madeira impregnada com resina monocomponente.

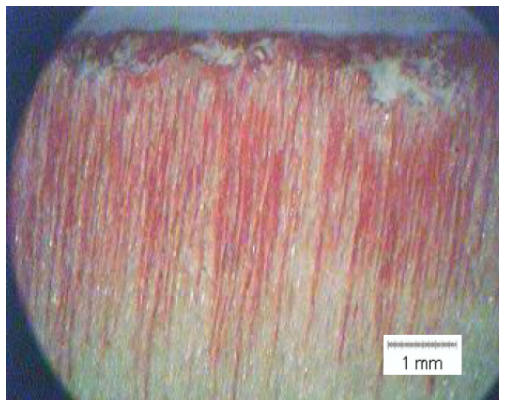

Figura 3.12: Amostra V - profundidade da impregnação longitudinal às fibras da madeira impregnada com resina monocomponente.

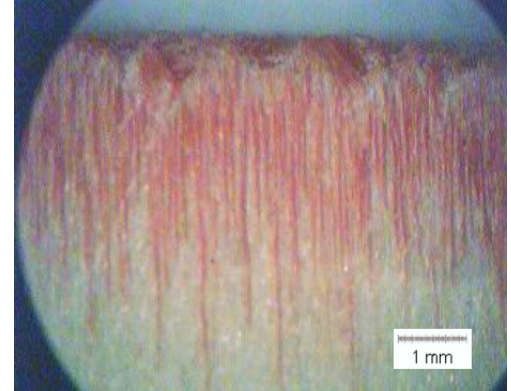

Figura 3.9: Amostra II - profundidade da impregnação longitudinal às fibras da madeira impregnada com resina monocomponente.

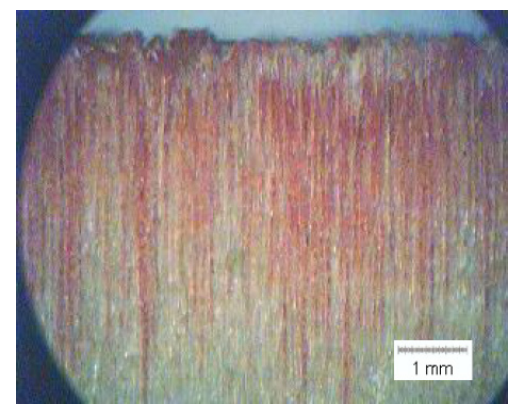

Figura 3.11: Amostra IV - profundidade da impregnação longitudinal às fibras da madeira impregnada com resina monocomponente.

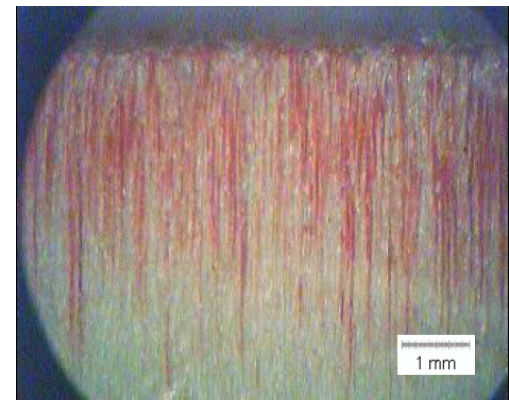

Figura 3.13: Amostra VI - profundidade da impregnação longitudinal às fibras da madeira impregnada com resina monocomponente. 


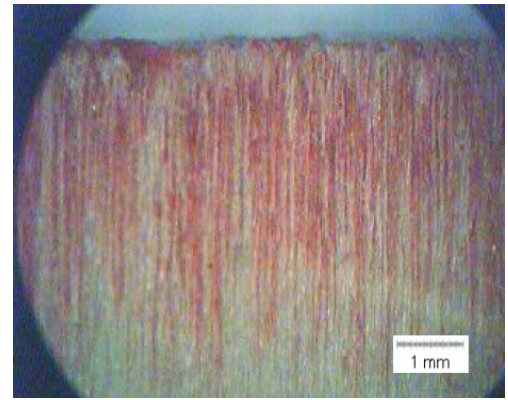

Figura 3.14: Amostra VII - profundidade da impregnação longitudinal às fibras da madeira impregnada com resina monocomponente.

\subsubsection{Impregnação dos CPs com a resina poliuretana bicompo- nente}

Os resultados da impregnação das sete peças de Pinus Taeda com a resina poliuretana bicomponente sem carga estão apresentados na tabela 3.4; a temperatura ambiente no momento do ensaio era de $21,9^{\circ} \mathrm{C}$, e a umidade relativa do ar, $48 \%$.

As figuras 3.15 a 3.21 apresentam a impregnação com a resina bicomponente.

Tabela 3.4: Resultados da Impregnação longitudinal às fibras da espécie Pinus Taeda com resina bicomponente sem carga.

\begin{tabular}{cccc}
\hline \multirow{2}{*}{ Peça } & \multicolumn{3}{c}{ Impregnação longitudinal $(\mathbf{m m})$} \\
& Mínima & Máxima & Média \\
\hline I & 2,43 & 4,20 & 3,31 \\
II & 2,46 & 4,01 & 3,24 \\
III & 3,09 & 4,60 & 3,84 \\
IV & 2,70 & 5,29 & 2,59 \\
V & 2,63 & 4,06 & 3,34 \\
VI & 1,96 & 3,60 & 2,78 \\
VII & 3,30 & 4,90 & 4,10 \\
\hline Média & & & 3,31 \\
Desvio-padrão & & & 0,53 \\
\hline
\end{tabular}




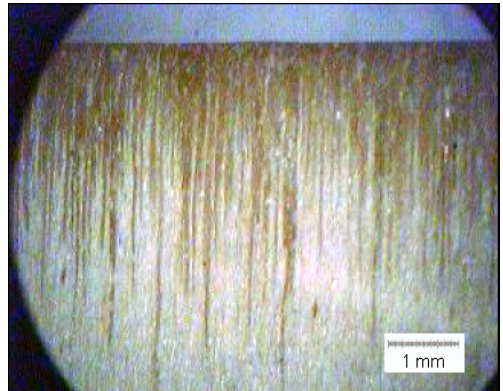

Figura 3.15: Amostra I - profundidade da impregnação longitudinal às fibras da madeira impregnada com resina bicomponente.

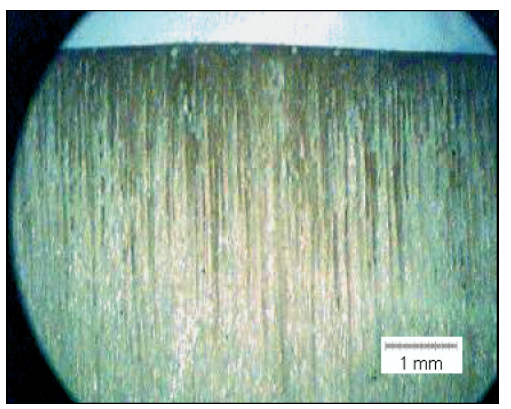

Figura 3.17: Amostra III - profundidade da impregnação longitudinal às fibras da madeira impregnada com resina bicomponente.

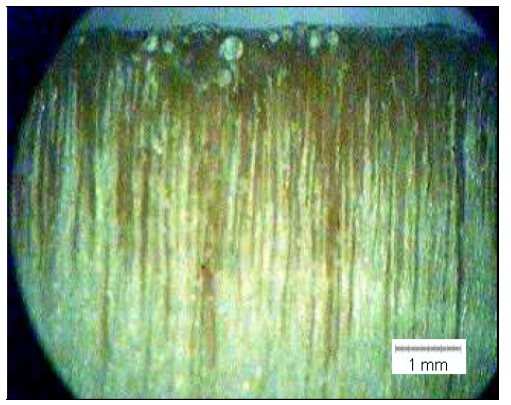

Figura 3.19: Amostra V - profundidade da impregnação longitudinal às fibras da madeira impregnada com resina bicomponente.

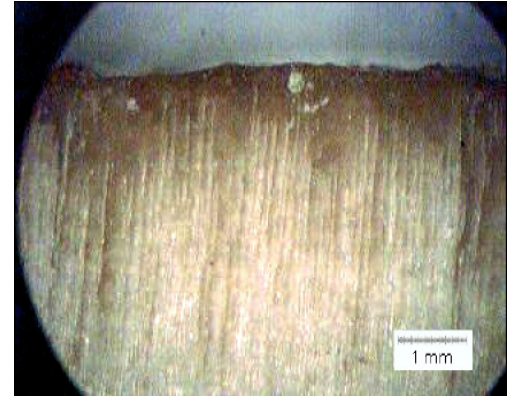

Figura 3.16: Amostra II - profundidade da impregnação longitudinal às fibras da madeira impregnada com resina bicomponente.

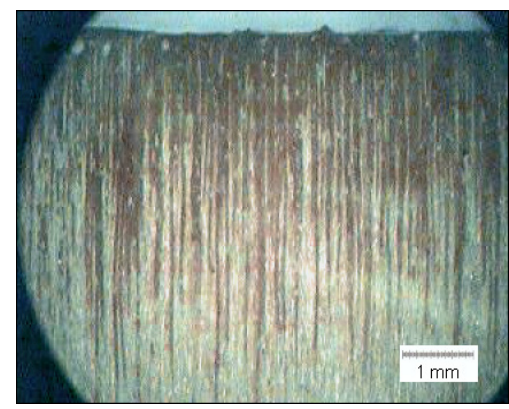

Figura 3.18: Amostra IV - profundidade da impregnação longitudinal às fibras da madeira impregnada com resina bicomponente.

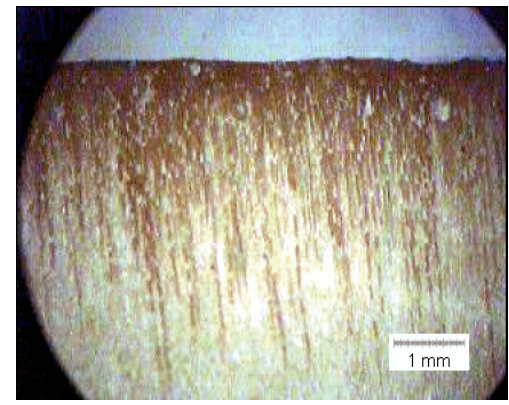

Figura 3.20: Amostra VI - profundidade da impregnação longitudinal às fibras da madeira impregnada com resina bicomponente. 


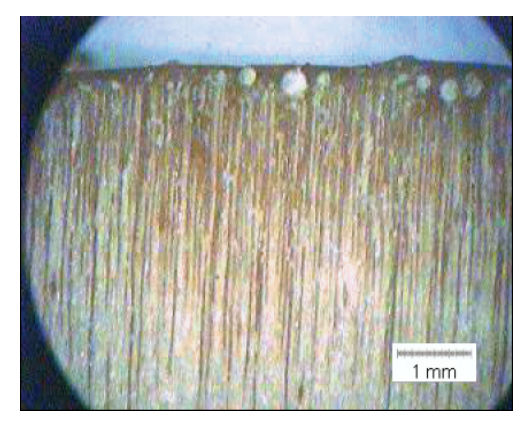

Figura 3.21: Amostra VII - profundidade da impregnação longitudinal às fibras da madeira impregnada com resina bicomponente.

\subsubsection{Análise estatística dos resultados}

$\mathrm{Na}$ análise dos resultados empregaram-se procedimentos estatísticos, pois o desvio-padrão $\left(S_{m}\right)$ - indicador estatístico de volatilidade - mede a dispersão dos valores obtidos em torno da sua média. Quando se determina o $S_{m}$ a partir de um número de amostras $(\mathrm{n})$ finito $(\mathrm{n}<30)$, a distribuição dos desvios em torno da média não segue uma distribuição normal é necessário realizar a análise do intervalo de confiança da diferença das médias entre os conjuntos de dados, aos pares, para verificar a equivalência estatística entre eles.

Os resultados devem ser considerados estatisticamente equivalentes, se o zero pertencer ao intervalo de confiança $(0 \in \mu)$, caso o zero não pertença a esse intervalo, significa que os resultados são considerados estatisticamente não equivalentes (MEYER, 1972; LEAL, 1970). O intervalo de confiança da média é dado pela equação (3.2), com um nível de probabilidade de $95 \%$.

$$
\bar{x}_{n}-t_{\frac{\alpha}{2}, n-1} \frac{S_{m}}{\sqrt{n}} \leq \mu \leq \bar{x}_{n}+t_{\frac{\alpha}{2}, n-1} \frac{S_{m}}{\sqrt{n}}
$$

onde 
$\mu$ - intervalo de confiança;

$\bar{x}_{n}$ - média aritmética amostral da população;

$S_{m}$ - desvio padrão amostral dessa população;

$t_{\frac{\alpha}{2}, n-1}$ - valor tabelado da distribuição $t$ de student com $n-1$ grau de liberdade;

$\alpha$ - nível de confiança;

$n$ - número de amostras de cada grupo.

O número de amostras de cada impregnação, realizada neste trabalho, foi igual sete $(\mathrm{n}=7)$, as médias e os desvios-padrão apresentaram valores próximos; assim, foi necessário calcular o intervalo de confiança.

A tabela 3.5 apresenta a média das diferenças entre os conjuntos de dados da profundidade da impregnação das resinas poliuretanas monocomponente e bicomponente nos CPs, bem como seus devios-padrão e intervalos de confiança.

De acordo com o intervalo de confiança, a profundidade da impregnação da resina monocomponente e da bicomponente não são estatisticamente equivalentes, uma vez que o intervalo não contém o zero.

Tabela 3.5: Análise do intervalo de confiança entre os conjuntos de dados da profundidade da impregnação dos CPs com a resina poliuretana monocomponente e bicomponente.

Análise Estatística das Impregnações

\begin{tabular}{cc}
\hline $\bar{x}_{n}$ & 0,35 \\
$S_{m}$ & 0,03 \\
$\mu$ & $0,32 \leq \mu \leq 0,38$ \\
\hline
\end{tabular}




\subsection{CONCLUSÕES DA IMPREGNAÇÃO}

A resina monocomponente apresentou profundidade média de impregnação no Pinus Taeda de 3,67 mm, com desvio-padrão de 0,22 mm, e a resina bicomponente, de 3,31 mm, com desvio-padrão de $0,53 \mathrm{~mm}$, como pode ser observado nas tabelas 3.3 e 3.4 . Ou seja, os CPs impregnados com a resina monocomponente apresentaram profundidade de impregnação pouco maior que os impregnados com a resina bicomponente, em torno de $10 \%$. Testes preliminares de impregnação realizados em amostras de Pinus Elliotti impregnados com a resina bicomponente apontaram uma profundidade de impregnação média de $1,1 \mathrm{~mm}$.

A impregnação tangencial às fibras apresentou valores muito pequenos em relação à impregnação longitudinal às fibras, formando, praticamente, apenas uma camada superficial tanto de resina monocomponente - figura 5.2 - como de bicomponente - figura 5.3. Porém, observou-se que a camada de resina monocomponente possui maior aderência à madeira. 


\section{Capítulo 4}

\section{CARACTERIZAÇÃO MECÂNICA E ELÉTRICA DO COMPÓSITO MADEIRA-RESINA POLIURETANA}

Neste capítulo estão relacionados os procedimentos dos ensaios realizados para

a caracterização mecânica e elétrica do compósito madeira-resina poliuretana, visando à análise da viabilidade de sua utilização como material para a fabricação de isoladores elétricos.

Conforme recomenda a norma brasileira (NBR7190, 1997), o número de CPs que atendem aos objetivos de caracterização simplificada da madeira é seis; assim os ensaios mecânicos e elétricos utilizarão sete CPs.

Os ensaios foram realizados em amostras impregnadas com as resinas poliuretanas monocomponente e bicomponente, e em amostras não impregnadas a título de comparação.

\subsection{ENSAIOS MECÂNICOS NAS AMOSTRAS IMPREGNA- DAS}

Nos próximos itens serão apresentados os procedimentos e os resultados dos ensaios mecânicos realizados nos CPs de Pinus Taeda impregnados com as resinas poliuretanas monocomponente e bicomponente, ambas derivadas do óleo de mamona. 


\subsubsection{Procedimentos dos ensaios mecânicos nas madeiras impreg- nadas.}

Os procedimentos dos ensaios mecânicos respeitaram as orientações da Associação Brasileira de Normas Técnicas (ABNT) (NBR7190, 1997).

Nos ensaios mecânicos são evidenciados alguns fatores importantes, tais como, acondicionamento das amostras, métodos de medição, precisão correspondente e dimensões dos CPs.

As amostras foram acondicionadas em condições normais de temperatura e umidade relativa de ar, e tomou-se o cuidado de não expô-las à umidade excessiva, devido ao material possuir propriedade higroscópica.

\section{I - Dureza}

A dureza da madeira é medida nas direções paralela $\left(f_{H 0}\right)$ e normal $\left(f_{H 90}\right)$ ás fibras. O ensaio foi realizado em sete CPs com seção quadrada de 5,0 cm, e de $15,0 \mathrm{~cm}$ ao longo das fibras, conforme apresenta a figura 4.1 .
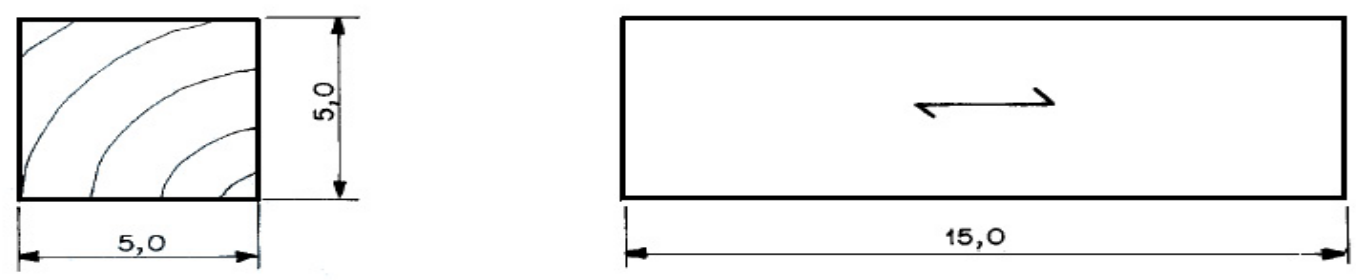

Figura 4.1: CP para ensaio de dureza, valores em $\mathrm{cm}$.

Para a determinação da dureza da madeira $\left(f_{H}\right)$, dada em MPa, foi utilizado o método Janka, que considera a força que produz a penetração de uma semi-esfera de aço com área diametral de $1 \mathrm{~cm}^{2}$, dada pela equação 4.1: 


$$
f_{H}=\frac{F_{\max }}{A_{\text {transversal }}}
$$

onde

$F_{\text {max }}$ é a máxima força aplicada ao CP necessária à penetração de uma semiesfera de seção diamentral, com $1 \mathrm{~cm}^{2}$ de área na profundidade, igual ao seu raio, em Newtons (N);

$A_{\text {transversal }}$ é a área da seção diametral da esfera, igual a $1 \mathrm{~cm}^{2}$, em centímetros quadrados $\left(\mathrm{cm}^{2}\right)$.

As medidas dos lados do CP devem ser feitas com paquímetros com sensibilidade de 0,1 mm. Deve ser utilizado um dispositivo especial entre o atuador e o CP para aplicar o carregamento, conforme a figura 4.2

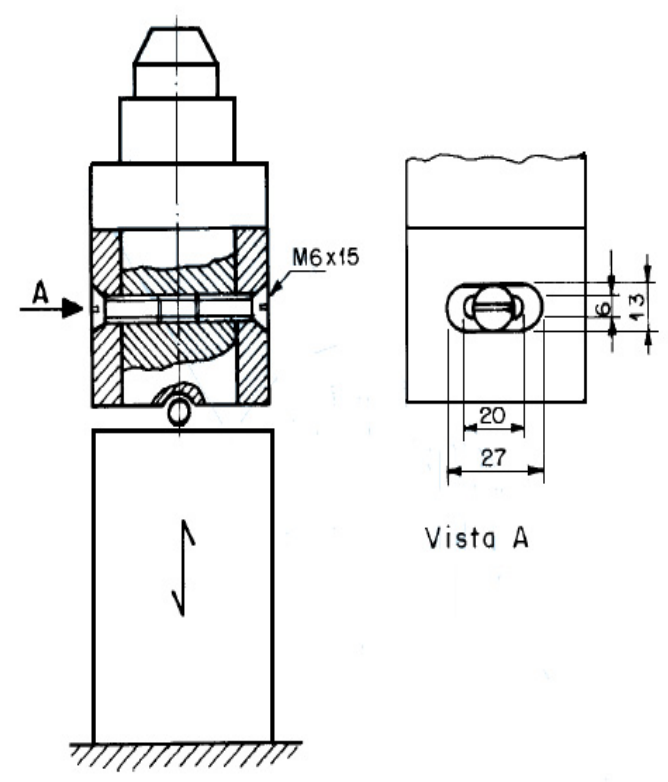

Figura 4.2: Arranjo de ensaio para dureza Janka.

O carregamento deve ser monotônico crescente, aplicado até que a esfera penetre a uma profundidade igual ao seu raio, em um período de pelo menos 1 minuto. 


\section{II - Compressão paralela às fibras}

O ensaio de compressão paralela é realizado para determinar a resistência e a rigidez mecânica à compressão paralela às fibras da madeira.

A resistência à compressão paralela às fibras $\left(f_{c 0}\right)$ é dada em MPa e obtida pela máxima tensão de compressão que pode atuar em um CP com seção transversal quadrada de 5,0 cm de lado e $15,0 \mathrm{~cm}$ de comprimento - figura 4.3 - dada pela fórmula 4.2 :

$$
f_{c 0}=\frac{F_{c 0, \max }}{A}
$$

onde:

$F_{c 0, \text { max }}$ é a máxima força de compressão aplicada ao CP durante o ensaio, em $\mathrm{N}$;

A é a área inicial da seção transversal comprimida, em $m^{2}$.
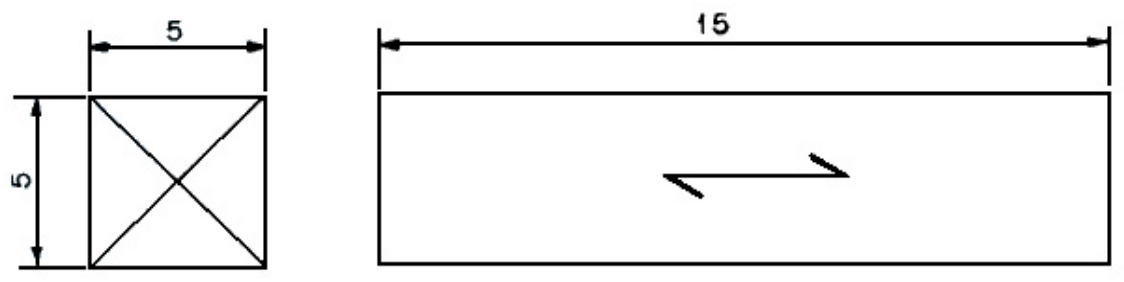

Figura 4.3: CP para ensaio de compressão paralela, valores em $\mathrm{cm}$.

\section{III - Compressão normal às fibras}

O ensaio de compressão normal $\left(f_{c 90}\right)$ é realizado para determinar a resistência e a rigidez mecânica à compressão normal às fibras da madeira. As dimensões do CP para este ensaio estão apresentadas na figura 4.4. 


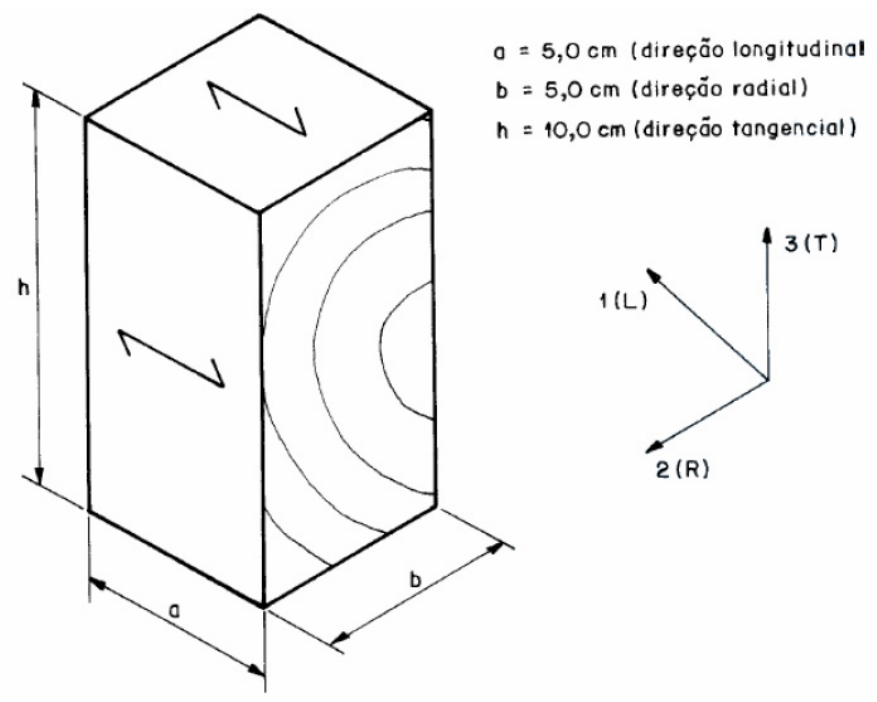

Figura 4.4: CP para o ensaio de compressão normal às fibras.

\section{IV - Flexão}

O ensaio de flexão é realizado para a determinação da resistência e da rigidez mecânica da madeira à flexão.

A resistência da madeira à flexão $\left(f_{M}\right)$, dada em MPa, é um valor convencional, obtido pela máxima tensão que pode atuar em um CP no ensaio de flexão simples, calculado com a hipótese de a madeira ser um material elástico, dada pela equação 4.3.

$$
f_{M}=\frac{M_{\max }}{W_{e}}
$$

onde:

$M_{\max }$ é o máximo momento aplicado ao CP, em Newtons-metro (N.m);

$W_{e}$ é o módulo de resistência elástico da seção transversal do $\mathrm{CP}$, dado por $b h^{2} / 6$, em metros cúbicos $\left(m^{3}\right)$. 


\subsubsection{Resultados dos ensaios mecânicos}

Os CPs ensaiados foram de três tipos: sem impregnação, impregnados com resina poliuretana monocomponente e impregnados com resina poliuretana bicomponente.

Para a realização dos ensaios mecânicos foi utilizada uma máquina universal AMSLER no Laboratório de Madeiras e de Estruturas de Madeira (LAMEM), do Departamento de Engenharia de Estruturas, EESC, USP. A aplicação da carga nos ensaios foi contínua, com velocidade constante. Alguns resultados foram descartados, devido aos CPs apresentarem nós ou erros de medição.

Os resultados dos ensaios mecânicos realizados apresentaram valores muito próximos e o número de amostras foi menor ou igual a $7(n \leq 7)$. Assim, para verificar a existência de equivalência estatística entres eles, calculou-se o intervalo de confiança da diferença das médias entre os resultados obtidos nos ensaios mecânicos, com nível de probabilidade de $95 \%$, dos seguintes grupos de amostras:

- A: CPs sem impregnação;

- B: CPs impregnados com a resina monocomponente; e

- C: CPs impregnados com a resina bicomponente.

\section{I - Dureza}

As fotografias das figuras 4.5 e 4.6 mostram o ensaio de dureza na direção paralela e normal às fibras da madeira sendo realizado. 


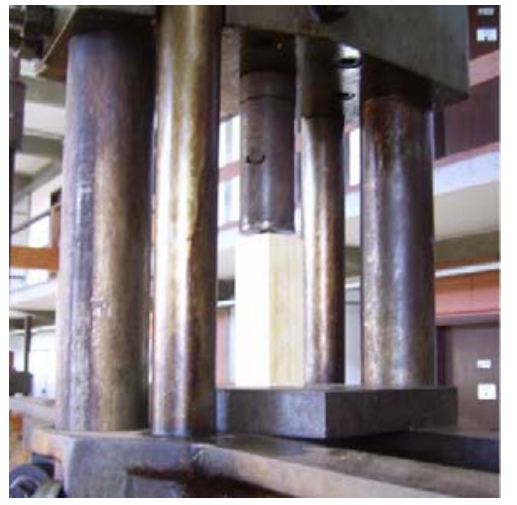

Figura 4.5: Ensaio de dureza na direção paralela às fibras.

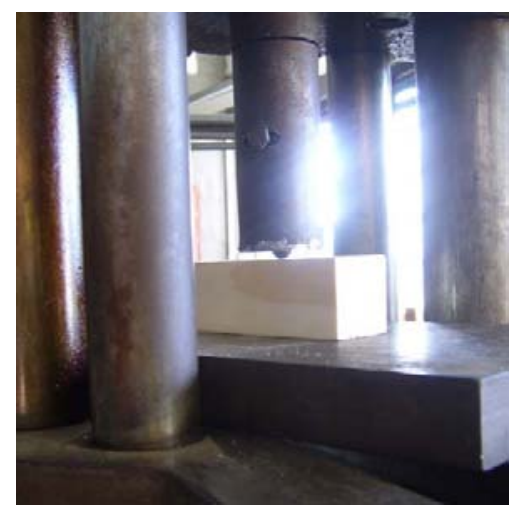

Figura 4.6: Ensaio de dureza na direção normal às fibras.

A tabela 4.1 apresenta os resultados dos ensaios de dureza nas direções paralela às fibras.

Tabela 4.1: Resultados do ensaio de dureza na direção paralela às fibras $-f_{H 0}$.

\begin{tabular}{|c|c|c|c|}
\hline $\mathrm{CP}$ & $\begin{array}{c}\text { Sem } \\
\text { impregnação } \\
\text { [MPa] }\end{array}$ & $\begin{array}{c}\text { Impregnação } \\
\text { monocomponente } \\
{[\mathrm{MPa}]}\end{array}$ & $\begin{array}{l}\text { om resina } \\
\text { bicomponente } \\
{[\mathrm{MPa}]}\end{array}$ \\
\hline I & 32,34 & 39,20 & 43,12 \\
\hline II & 33,32 & 41,16 & 41,16 \\
\hline III & 43,12 & 46,06 & 49,00 \\
\hline IV & 42,14 & 55,86 & 53,90 \\
\hline $\mathrm{V}$ & 30,38 & 45,08 & 50,96 \\
\hline VI & 22,54 & 55,86 & 37,24 \\
\hline VII & 49,98 & 60,76 & 52,92 \\
\hline$f_{H 0}$ (médio) & 36,26 & 49,14 & 46,90 \\
\hline$S_{m}$ & 13,16 & 8,30 & 6,41 \\
\hline
\end{tabular}

A tabela 4.2 apresenta o intervalo de confiança entre os conjuntos de dados A B, A - C e B - C dos resultados do ensaio de dureza na direção paralela às fibras. 
Tabela 4.2: Intervalo de confiança entre os conjuntos de dados A - B, A - C e B - C dos resultados do ensaio de dureza na direção paralela às fibras.

\begin{tabular}{cccc}
\hline \multicolumn{4}{c}{ Diferença entre os conjuntos de dados: } \\
CP & A - B & A - C & B - C \\
& {$[\mathrm{MPa}]$} & {$[\mathrm{MPa}]$} & {$[\mathrm{MPa}]$} \\
\hline \multirow{2}{*}{ I } & $-6,86$ & $-10,78$ & $-3,92$ \\
II & $-7,84$ & $-7,84$ & 0,00 \\
III & $-2,94$ & $-5,88$ & $-2,94$ \\
IV & $-13,72$ & $-11,76$ & 1,96 \\
V & $-14,70$ & $-20,58$ & $-5,88$ \\
VI & $-33,32$ & $-14,70$ & 18,62 \\
VII & $-10,78$ & $-2,94$ & 7,84 \\
\hline \multirow{2}{*}{$\bar{x}_{n}$} & $-12,88$ & $-10,64$ & 2,24 \\
$S_{m}$ & 9,89 & 5,86 & 8,52 \\
$\mu$ & $-21,72 \leq \mu \leq-4,04$ & $-15,88 \leq \mu \leq-5,40$ & $-5,37 \leq \mu \leq 9,85$ \\
\hline
\end{tabular}

A tabela 4.3 apresenta os resultados do ensaio de dureza nas direção normal às fibras da madeira.

Tabela 4.3: Resultados do ensaio de dureza na direção normal às fibras $-f_{H 90}$.

\begin{tabular}{|c|c|c|c|}
\hline $\mathrm{CP}$ & $\begin{array}{c}\text { Sem } \\
\text { impregnação } \\
\text { [MPa] }\end{array}$ & $\begin{array}{c}\text { Impregnação } \\
\text { monocomponente } \\
{[\mathrm{MPa}]}\end{array}$ & $\begin{array}{l}\text { om resina } \\
\text { bicomponente } \\
{[\mathrm{MPa}]}\end{array}$ \\
\hline $\mathrm{I}$ & 13,72 & 19,60 & 19,60 \\
\hline II & 12,74 & 18,62 & 19,60 \\
\hline III & 15,69 & 29,40 & 31,36 \\
\hline IV & 11,76 & 18,62 & 17,64 \\
\hline $\mathrm{V}$ & 12,74 & 15,68 & 12,74 \\
\hline$f_{H 90}$ (médio) & 13,33 & 20,38 & 20,19 \\
\hline$S_{m}$ & 1,49 & 5,25 & 6,85 \\
\hline
\end{tabular}

A tabela 4.4 apresenta o intervalo de confiança entre os resultados dos conjuntos de dados $\mathrm{A}$ - B, A - C e B - C do ensaio de dureza na direção normal às fibras. 
De acordo com as tabelas 4.2 e 4.4, os intervalos de confiança dos resultados entre os grupos de amostras A - B e A - C, tanto do ensaio de dureza paralela quanto de dureza normal, não contém o zero, portanto, não são estatísticamente equivalentes, já o intervalo de confiança entre os grupos de amostras B - C contém o zero, ou seja, são estatísticamente equivalentes.

Tabela 4.4: Intervalo de confiança entre os os conjuntos de dados A - B, A - C e B - C dos resultados do ensaio de dureza na direção normal às fibras.

\begin{tabular}{cccc}
\hline \multicolumn{4}{c}{ Diferença entre os conjuntos de dados: } \\
CP & $\begin{array}{c}\text { A - B } \\
{[\mathrm{MPa}]}\end{array}$ & $\begin{array}{c}\text { A C } \\
{[\mathrm{MPa}]}\end{array}$ & {$[\mathrm{MPa}]$} \\
\hline I & 5,88 & $-5,88$ & 0,00 \\
II & 5,88 & $-6,86$ & $-0,98$ \\
III & $-13,71$ & $-15,67$ & $-1,96$ \\
IV & $-6,86$ & $-5,88$ & 0,98 \\
V & $-2,94$ & 0,00 & 2,94 \\
\hline $\bar{x}_{n}$ & $-7,05$ & $-6,86$ & 0,20 \\
$S_{m}$ & 4,00 & 5,63 & 1,89 \\
$\mu$ & $-11,66 \leq \mu \leq-2,45$ & $-13,33 \leq \mu \leq-0,39$ & $-1,97 \leq \mu \leq 2,36$ \\
\hline
\end{tabular}

\section{II - Compressão paralela às fibras}

A tabela 4.5 apresenta os resultados do ensaio de compressão paralela às fibras da madeira e a tabela 4.6 o intervalo de confiança entre os conjuntos de dados A - B, A C e B - C dos resultados do ensaio de compressão paralela às fibras. 
Tabela 4.5: Resultados do ensaio de compressão na direção paralela às fibras da madeira $-f_{c 0}$.

\begin{tabular}{|c|c|c|c|}
\hline $\mathrm{CP}$ & $\begin{array}{c}\text { Sem } \\
\text { impregnação } \\
\text { [MPa] }\end{array}$ & $\begin{array}{c}\text { Impregnação } \\
\text { monocomponente } \\
{[\mathrm{MPa}]}\end{array}$ & $\begin{array}{l}\text { bicom resina } \\
\text { biconponte } \\
\text { [MPa] }\end{array}$ \\
\hline $\mathrm{I}$ & 30,47 & 38,95 & 39,89 \\
\hline II & 36,46 & 39,67 & 36,48 \\
\hline III & 36,37 & 39,68 & 39,61 \\
\hline IV & 36,89 & 37,36 & 36,38 \\
\hline $\mathrm{V}$ & 49,90 & 56,85 & 49,94 \\
\hline$f_{c 0}$ (médio) & 38,02 & 42,50 & 40,46 \\
\hline$S_{m}$ & 7,15 & 8,08 & 5,55 \\
\hline
\end{tabular}

Tabela 4.6: Intervalo de confiança entre os resultados dos conjuntos de dados A - B, A C e B - C do ensaio de compressão na direção paralela às fibras dos CPs.

\begin{tabular}{cccc}
\hline \multicolumn{4}{c}{ Diferença entre os conjuntos de dados: } \\
CP & A - B & A - C & B - C \\
& {$[\mathrm{MPa}]$} & {$[\mathrm{MPa}]$} & {$[\mathrm{MPa}]$} \\
\hline \multirow{2}{*}{ I } & $-8,48$ & $-9,42$ & $-0,94$ \\
II & $-3,21$ & $-0,02$ & 3,19 \\
III & $-3,31$ & $-3,24$ & 0,07 \\
IV & $-0,47$ & 0,51 & 0,98 \\
V & $-6,95$ & $-0,04$ & 6,91 \\
\hline \multirow{2}{*}{$\bar{x}_{n}$} & $-4,08$ & $-2,44$ & 2,04 \\
$S_{m}$ & 3,21 & 4,17 & 3,12 \\
$\mu$ & $-8,17 \leq \mu \leq-0,80$ & $-7,24 \leq \mu \leq 2,36$ & $-1,54 \leq \mu \leq 5,63$ \\
\hline
\end{tabular}

Como pode ser observado na tabela 4.6, o intervalo de confiança entre os conjuntos de resultados do ensaio de compressão paralela às fibras da madeira A - B não contém o zero, sendo assim, não evidencia-se equivalência estatística entre esses grupos de amostras. Porém, os intervalos de confiança entre as amostras A - C e B - C, contém 
o zero, ou seja, esses grupos de amostras são estatísticamente equivalentes.

\section{III - Compressão normal às fibras}

A tabela 4.7 apresenta os resultados do ensaio de compressão na direção normal às fibras da madeira - figura 4.7.

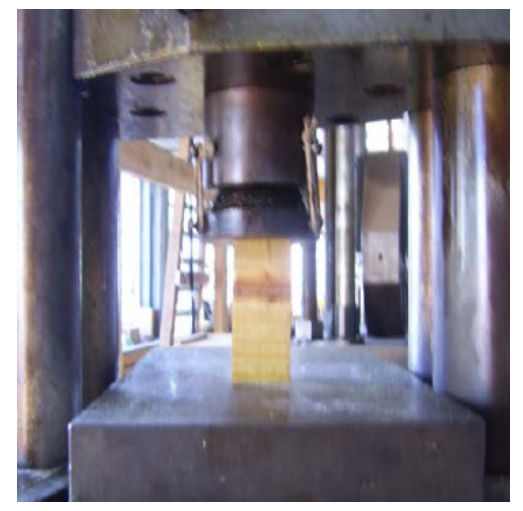

Figura 4.7: Ensaio de compressão normal.

Tabela 4.7: Resultados do ensaio de compressão na direção normal às fibras da madeira $-f_{c 90}$.

\begin{tabular}{|c|c|c|c|}
\hline $\mathrm{CP}$ & $\begin{array}{c}\text { Sem } \\
\text { impregnação } \\
{[\mathrm{MPa}]}\end{array}$ & $\begin{array}{c}\text { Impregnação } \\
\text { monocomponente } \\
{[\mathrm{MPa}]}\end{array}$ & $\begin{array}{l}\text { om resina } \\
\text { bicomponente } \\
\text { [MPa] }\end{array}$ \\
\hline $\mathrm{I}$ & 6,70 & 5,95 & 6,74 \\
\hline II & 4,32 & 5,65 & 8,17 \\
\hline III & 7,14 & 11,81 & 8,38 \\
\hline IV & 6,62 & 7,63 & 7,94 \\
\hline $\mathrm{V}$ & 6,19 & 7,73 & 7,36 \\
\hline VI & 5,82 & 10,37 & 6,68 \\
\hline$f_{c 90}($ médio $)$ & 6,13 & 8,19 & 7,54 \\
\hline$S_{m}$ & 1,00 & 2,44 & 0,73 \\
\hline
\end{tabular}

A tabela 4.8 apresenta o intervalo de confiança entre os conjuntos de dados A - 
$\mathrm{B}, \mathrm{A}$ - C e B - C dos resultados do ensaio de compressão na direção normal às fibras dos CPs. Onde evidenciou-se equivalência estatística entre os grupos de amostras B - C, uma vez que seu intervalo de confiança contém o zero, o que não ocorre quando comparados os grupos de amostras A - B e A - C.

Tabela 4.8: Intervalo de confiança entre os conjuntos de dados A - B, A - C e B - C dos resultados do ensaio de compressão normal às fibras dos CPs.

\begin{tabular}{cccc}
\hline \multicolumn{4}{c}{ Diferença entre os conjuntos de dados: } \\
CP & A e B & A e C & B e C \\
& {$[\mathrm{MPa}]$} & {$[\mathrm{MPa}]$} & {$[\mathrm{MPa}]$} \\
\hline \multirow{2}{*}{} & 0,75 & $-0,04$ & $-0,79$ \\
II & $-1,33$ & $-3,85$ & $-2,52$ \\
III & $-4,67$ & $-1,24$ & 3,43 \\
IV & $-1,01$ & $-1,32$ & $-0,31$ \\
V & 1,54 & $-1,17$ & 0,37 \\
VI & $-4,55$ & $-0,86$ & 3,69 \\
\hline $\bar{x}_{n}$ & $-2,06$ & $-1,41$ & 0,65 \\
$S_{m}$ & 1,79 & 1,28 & 2,24 \\
IC & $-3,84 \leq \mu \leq-0,27$ & $-2,69 \leq \mu \leq-0,13$ & $-1,81 \leq \mu \leq 3,10$ \\
\hline
\end{tabular}

\section{IV - Flexão}

A tabela 4.9 apresenta os resultados do ensaio de flexão - figura 4.8 - realizado nos CPs do Pinus Taeda sem e com impregnação com as resinas monocomponte e bicomponente e a figura 4.9 um CP que foi submetido ao ensaio de flexão.

O intervalo de confiança entre os grupos de amostras A - B, A - C e B - C dos resultados do ensaio de flexão é exposto na tabela 4.10. 
Tabela 4.9: Resultados do ensaio de flexão $-f_{M}$.

\begin{tabular}{|c|c|c|c|}
\hline $\mathrm{CP}$ & $\begin{array}{c}\text { Sem } \\
\text { impregnação } \\
{[\mathrm{MPa}]}\end{array}$ & $\begin{array}{c}\text { Impregnação } \\
\text { monocomponente } \\
{[\mathrm{MPa}]}\end{array}$ & $\begin{array}{l}\text { bom resina } \\
\text { bicomponente } \\
\text { [MPa] }\end{array}$ \\
\hline I & 22,05 & 25,73 & 24,07 \\
\hline II & 15,80 & 25,17 & 20,95 \\
\hline III & 12,50 & 24,44 & 29,22 \\
\hline IV & 18,19 & 23,52 & 26,83 \\
\hline $\mathrm{V}$ & 23,09 & 20,95 & 23,70 \\
\hline$f_{M}$ (médio) & 18,33 & 23,96 & 24,95 \\
\hline$S_{m}$ & 4,38 & 1,88 & 3,17 \\
\hline
\end{tabular}

Tabela 4.10: Intervalo de confiança entre os conjuntos de dados A - B, A - C e B - C dos resultados do ensaio de flexão dos CPs.

\begin{tabular}{cccc}
\hline \multicolumn{4}{c}{ Diferença entre os conjuntos de dados: } \\
CP & A e B & A e C & B e C \\
& {$[\mathrm{MPa}]$} & {$[\mathrm{MPa}]$} & {$[\mathrm{MPa}]$} \\
\hline \multirow{2}{*}{} & $-3,78$ & $-2,02$ & 1,66 \\
II & $-9,37$ & $-5,15$ & 4,22 \\
III & $-11,94$ & $-16,72$ & $-4,78$ \\
IV & $-5,33$ & $-8,64$ & $-3,31$ \\
V & 2,14 & $-0,61$ & $-2,75$ \\
\hline \multirow{2}{*}{$\bar{x}_{n}$} & $-5,64$ & $-6,66$ & $-1,24$ \\
$S_{m}$ & 5,43 & 6,43 & 3,79 \\
$\mu$ & $-11,88 \leq \mu \leq 0,61$ & $-14,02 \leq \mu \leq 0,77$ & $-6,11 \leq \mu \leq 3,11$ \\
\hline
\end{tabular}

Os intervalos de confiança da tabela 4.10 contém o zero, o que evidencia equivalência estatística entre todos os grupos de resultados do ensaio de flexão. 


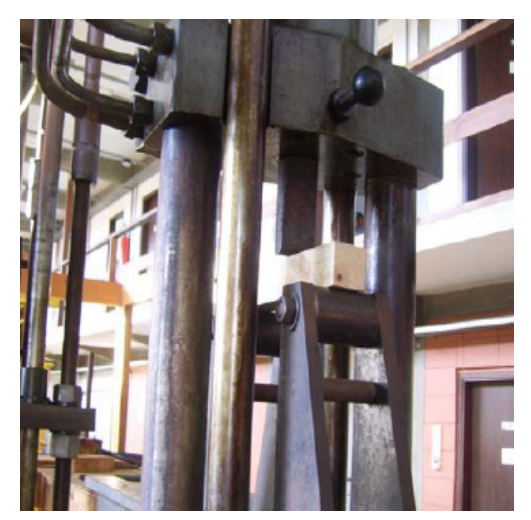

Figura 4.8: Ensaio de Flexão.

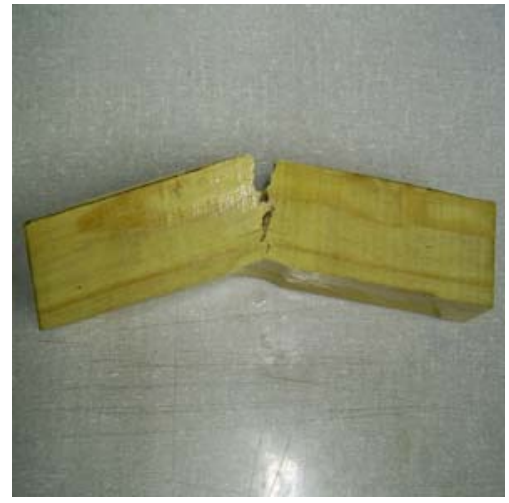

Figura 4.9: CP após ensaio de flexão.

\subsection{ENSAIOS ELÉTRICOS NAS AMOSTRAS IMPREGNADAS}

A seguir serão apresentados os procedimentos dos ensaios elétricos, segundo suas respectivas normas, realizados nos CPs de Pinus Taeda impregnados com as resinas poliuretanas monocomponente e bicomponente, bem como os resultados destes ensaios.

Nos ensaios elétricos, são evidenciados fatores importantes como acondicionamento das amostras, tensão aplicada nos ensaios, métodos de medição, precisão correspondente, tipos de eletrodos e dimensões dos CPs.

\subsubsection{Procedimentos dos ensaios elétricos nas madeiras impreg- nadas}

Os procedimentos dos ensaios elétricos acompanharam as orientações da ABNT, nas seguintes normas:

- NBR 5403: Determinação da resistividade volumétrica e superficial (NBR5403, 1983);

- NBR 5405: Determinação da rigidez dielétrica sob freqüência industrial (NBR5405, 1983). 


\section{I - Resistividade volumétrica e superficial}

A resistividade volumétrica caracteriza a resistência elétrica que o material oferece quando aplicada uma tensão contínua em um volume específico.

A resistividade superficial caracteriza a resistência que o material oferece ao longo da superfície diante de uma tensão contínua aplicada entre os eletrodos.

O esquema de medição da resistividade volumétrica e superficial é apresentado na figura 4.10 .

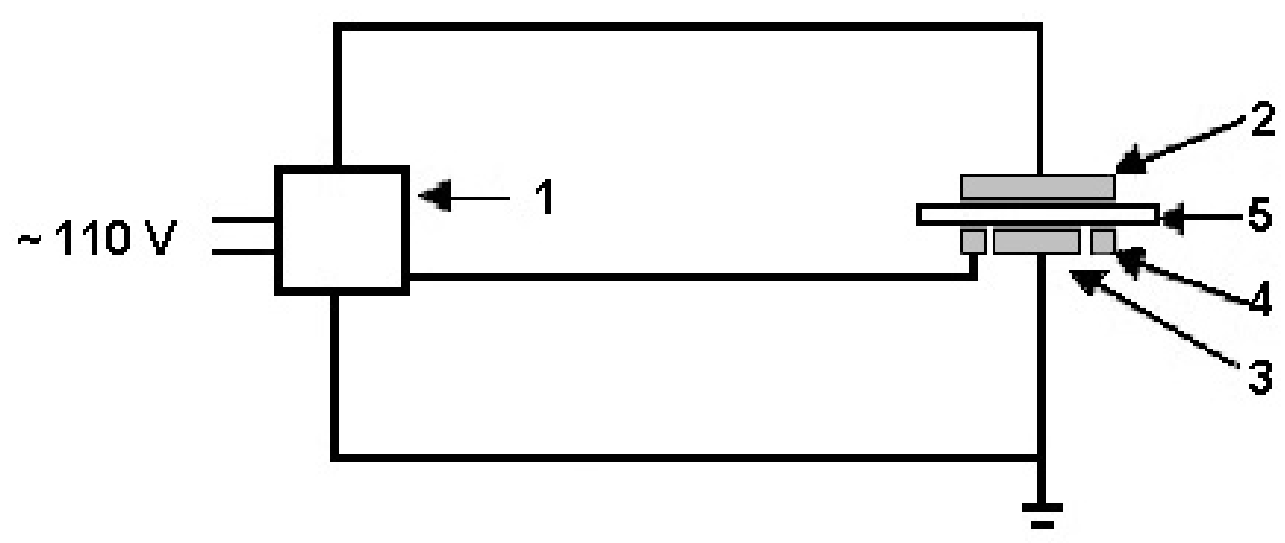

Figura 4.10: Esquema da montagem para a medição da resistividade volumétrica e superficial: 1 - medidor de resistividade volumétrica e superficial (ponte de resistência alta); 2eletrodo superior; 3 - eletrodo central; 4 - eletrodo de guarda; 5 - CP.

A mudança de resistividade com a temperatura e com a umidade pode ser significativa e deverá ser conhecida.

No momento do ensaio, as condições de temperatura ambiente e umidade relativa do ar eram de $21,8^{\circ} \mathrm{C}$ e $31 \%$, respectivamente.

Para comparar a resistividade volumétrica e superficial dos materiais, devem ser especificado o mesmo tempo de eletrificação para todas as das amostras. Nos ensaios realizados, utilizou-se 1 minuto de tempo de eletrificação e leitura. 
Nas figuras 4.11 e 4.12, encontram-se as fotografias do aparelho utilizado para medir a resistividade volumétrica e superficial - equipamento aferido conforme seu manual de instrução (AGILENT, 2001) -, e dos CPs de Pinus Taeda estudados.

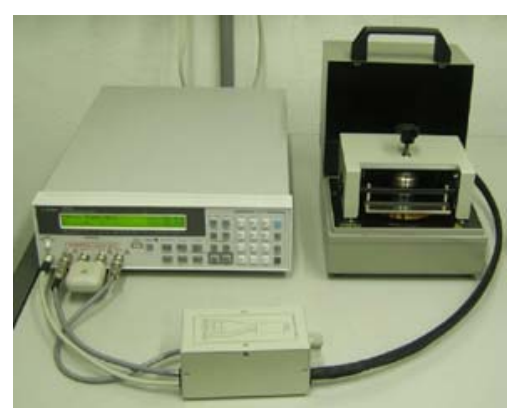

Figura 4.11: Agilent 16008B Resistivity Cell e Agilent 4339B High Resistance Meter - Equipamentos utilizados para medir a resistividade volumétrica e superficial.

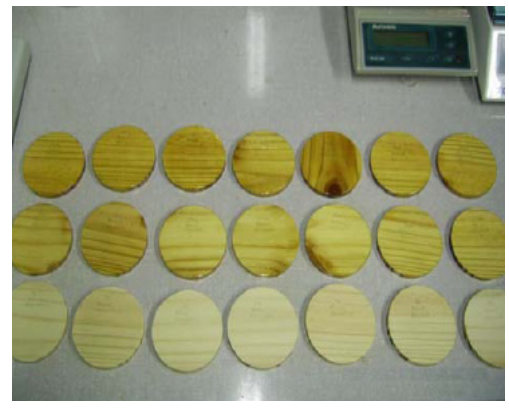

Figura 4.12: CPs de Pinus Taeda sem e com impregnação com as resinas monocomponente e bicomponente estudados nos ensaios de resistividade volumétrica.

\section{II - Rigidez dielétrica}

O ensaio elétrico realizado para determinar a rigidez dielétrica foi do tipo "tempo curto", em que se aumentou a tensão elétrica alternada aplicada a partir do zero, com taxa uniforme de $500 \mathrm{~V} / \mathrm{s}$ e com tempo médio de ensaio- entre 10 e 20 segundos -, quando ocorre a perfuração do material. O arranjo dos eletrodos juntamente com o CP para o ensaio de rigidez dielétrica podem ser vistos na figura 4.13. Para a realização deste ensaio foi utilizado um kit para ensaios de alta tensão da marca HAEFELY-TRENCH, composto por um transformador TEO 100/10, uma mesa de controle e um instrumento de medição DMI 551, apresentados na figura 4.14. 


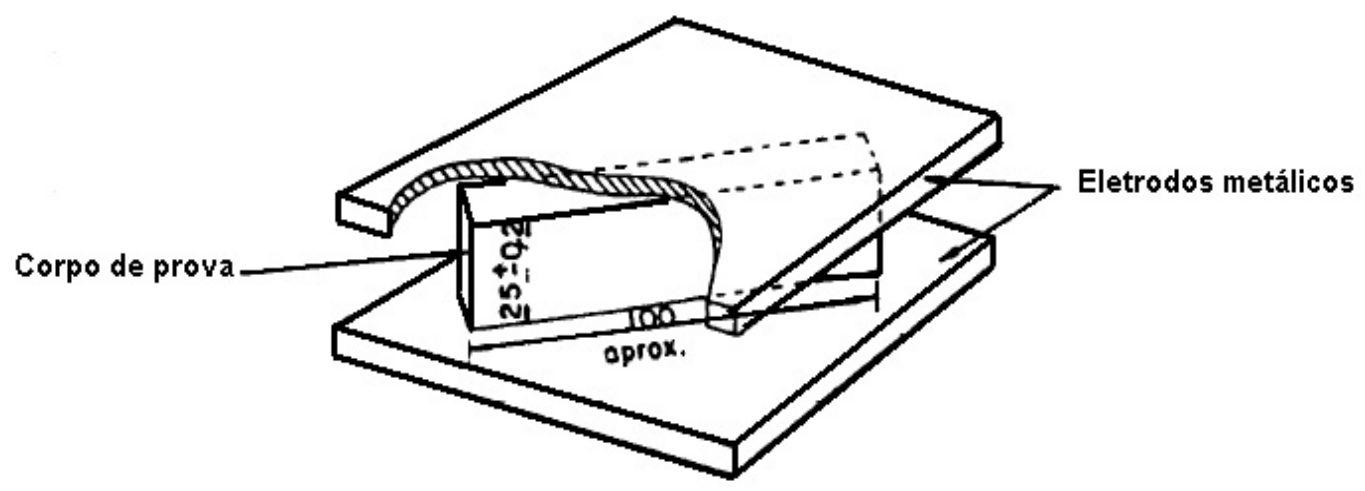

Figura 4.13: Arranjo dos eletrodos para ensaio ensaio de rigidez dielétrica.

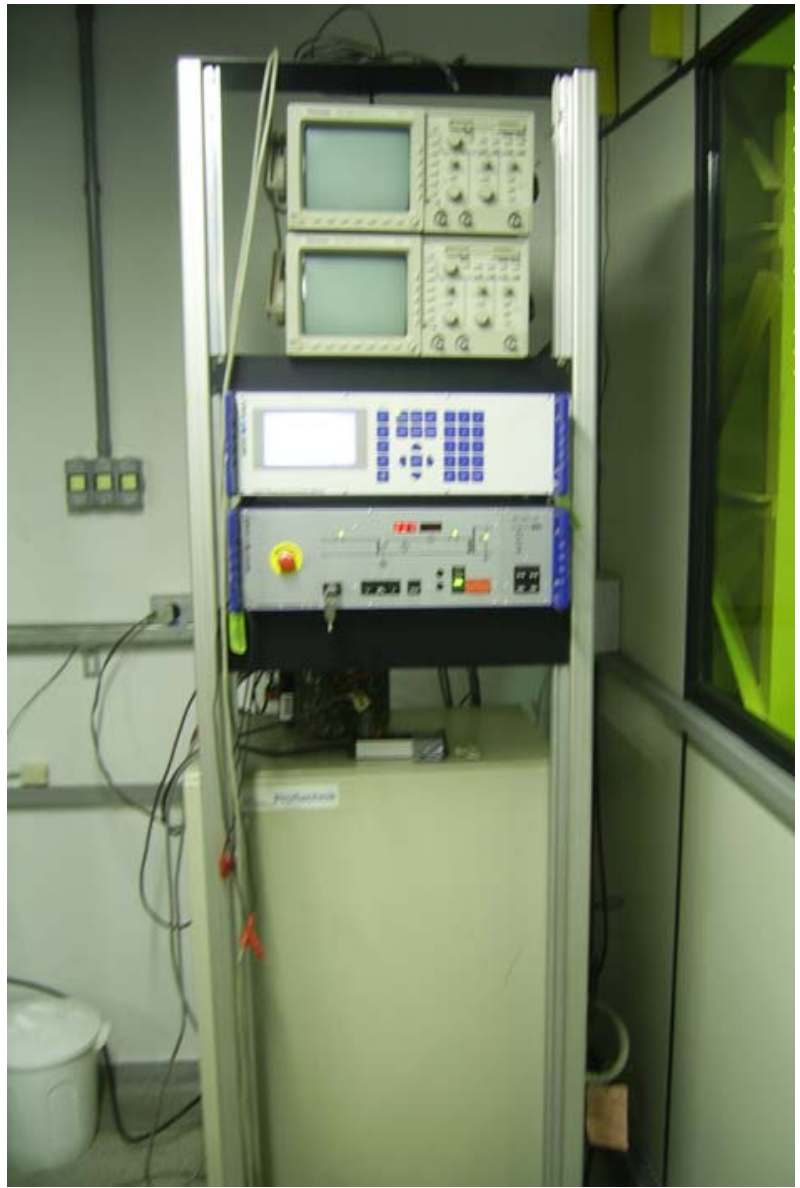

Figura 4.14: Kit para ensaios de alta tensão da marca HAEFELY-TRENCH. 


\subsubsection{Resultados dos ensaios elétricos}

A seguir estão apresentados os resultados dos ensaios de resistividade volumétrica, resistividade superficial e rigidez dielétrica.

\section{I - Resistividade volumétrica e superficial}

Os ensaios de resistividade volumétrica e superficial em CPs de Pinus Taeda sem e com impregnação com as resinas poliuretanas monocomponente e bicomponente foram realizados dentro dos seguintes parâmetros: tensão de saída de $500 \mathrm{~V}$, corrente limite de 0,5 $\mathrm{mA}$, tempo de carregamento de 1 minuto e escala de carga de $5 \mathrm{~kg}$. Os resultados desses ensaios encontram-se nas tabelas 4.11 e 4.12, respectivamente.

Tabela 4.11: Resultados do ensaio de resistividade volumétrica.

\begin{tabular}{|c|c|c|c|}
\hline $\mathrm{CP}$ & $\begin{array}{c}\text { Sem } \\
\text { impregnação } \\
{\left[10^{11} \Omega . c m\right]}\end{array}$ & $\begin{array}{c}\text { Impregnação } \\
\text { monocomponente } \\
{\left[10^{13} \Omega . c m\right]}\end{array}$ & $\begin{array}{l}\text { om resina } \\
\text { bicomponente } \\
{\left[10^{13} \Omega . \mathrm{cm}\right]}\end{array}$ \\
\hline $\mathrm{I}$ & 1,19 & 4,30 & 0,91 \\
\hline II & 3,07 & 7,74 & 4,12 \\
\hline III & 2,04 & 1,53 & 4,41 \\
\hline IV & 1,09 & 0,33 & 1,65 \\
\hline $\mathrm{V}$ & 8,06 & 0,37 & 1,21 \\
\hline VI & 1,62 & 3,08 & 13,97 \\
\hline VII & 1,76 & 1,38 & 2,86 \\
\hline $\bar{x}_{n}$ & 2,69 & 2,68 & 4,16 \\
\hline$S_{m}$ & 2,28 & 2,45 & 4,20 \\
\hline
\end{tabular}


Tabela 4.12: Resultados do ensaio de resistividade superficial.

\begin{tabular}{|c|c|c|c|}
\hline \multirow[b]{2}{*}{$\mathrm{CP}$} & \multirow{2}{*}{$\begin{array}{c}\text { Sem } \\
\text { impregnação } \\
{\left[10^{11} \Omega\right]}\end{array}$} & \multicolumn{2}{|c|}{ Impregnação com resina } \\
\hline & & $\begin{array}{c}\text { monocomponente } \\
{\left[10^{13} \Omega\right]}\end{array}$ & $\begin{array}{c}\text { bicomponente } \\
{\left[10^{14} \Omega\right]}\end{array}$ \\
\hline $\mathrm{I}$ & 3,16 & 2,79 & 2,81 \\
\hline II & 4,87 & 2,94 & 0,53 \\
\hline III & 1,60 & 1,15 & 1,19 \\
\hline IV & 3,29 & 1,88 & 6,67 \\
\hline $\mathrm{V}$ & 2,80 & 0,15 & 7,70 \\
\hline VI & 6,34 & 1,10 & 3,82 \\
\hline VII & 1,21 & 0,62 & 4,96 \\
\hline $\bar{x}_{n}$ & 3,24 & 1,52 & 3,95 \\
\hline$S_{m}$ & 1,66 & 0,98 & 2,48 \\
\hline
\end{tabular}

Os resultados do ensaio de resistividade volumétrica - tabela 4.11 - dos CPs impregnados com as resinas monocomponente e bicomponente foram muito próximos; assim, para verificar a equivalência estatística entre eles, calculou-se o intervalo de confiança.

Tabela 4.13: Intervalo de confiança entre os conjuntos de dados dos CPs impregnados com a resina monocomponente (B) e os impregnados com a resina bicomponente (C) dos resultados do ensaio de resistividade volumétrica.

\begin{tabular}{cc}
\hline CP & Diferença entre B e C $\left[10^{13} \Omega . c m\right]$ \\
\hline I & 3,39 \\
II & 3,62 \\
III & $-2,88$ \\
IV & $-1,32$ \\
V & $-0,84$ \\
VI & $-10,89$ \\
VII & $-1,48$ \\
\hline $\bar{x}_{n}$ & $-1,49$ \\
$S_{m}$ & 3,81 \\
IC & $-4,98 \leq \mu \leq 2,01$ \\
\hline
\end{tabular}

Como pode ser observado na tabela 4.10, o intervalo de confiança entre o B - C 
contém o zero, o que evidencia equivalência estatística entre este grupo de resultados do ensaio de resistividade volumétrica.

\section{II - Rigidez dielétrica}

No momento do ensaio de rigidez dielétrica, a temperatura ambiente e a umidade relativa do ar eram de $22,6^{\circ} C$ e $35 \%$, respectivamente. Os resultados dos ensaios realizados com a madeira não-impregnada e impregnada com as resinas poliuretanas monocomponente e bicomponente estão apresentados na tabela 4.14.

Tabela 4.14: Resultados do ensaio de rigidez dielétrica.

\begin{tabular}{|c|c|c|c|}
\hline $\mathrm{CP}$ & $\begin{array}{c}\text { Sem } \\
\text { impregnação } \\
{[\mathrm{kV}]}\end{array}$ & $\begin{array}{c}\text { Impregnação } \\
\text { monocomponente } \\
{[\mathrm{kV}]}\end{array}$ & $\begin{array}{l}\text { om resina } \\
\text { bicomponente } \\
{[\mathrm{kV}]}\end{array}$ \\
\hline $\mathrm{I}$ & 11,16 & 10,31 & 10,92 \\
\hline II & 9,99 & 10,31 & 10,54 \\
\hline III & 9,98 & 10,87 & 11,05 \\
\hline IV & 11,51 & 10,54 & 10,68 \\
\hline $\mathrm{V}$ & 11,06 & 10,84 & 10,98 \\
\hline $\bar{x}_{n}$ & 10,74 & 10,57 & 10,83 \\
\hline$S_{m}$ & 0,63 & 0,24 & 0,19 \\
\hline
\end{tabular}




\section{Capítulo 5}

\section{CONCLUSÕES E TRABALHOS FUTUROS}

Os resultados das impregnações com resinas poliuretanas monocomponente e bicomponente realizadas em amostras de madeira da espécie Pinus Taeda, previamente seca em estufa - quando necessário -, mostraram que as duas resinas utilizadas apresentaram performances similares quanto à profundidade da impregnação na madeira, sendo que, em média, a resina monocomponente apresentou profundidade apenas $10 \%$ maior do que a bicomponente.

A impregnação tangencial às fibras de ambas as resinas apresentou valores muito pequenos em relação à impregnação longitudinal às fibras, formando, praticamente, apenas uma camada superficial de resina. Assim, quando da fabricação dos isoladores, as fibras da madeira devem ser dispostas de tal forma a aproveitar ao máximo a impregnação longitudinal. Um exemplo de disposição das fibras pode ser visto na figura 5.1.

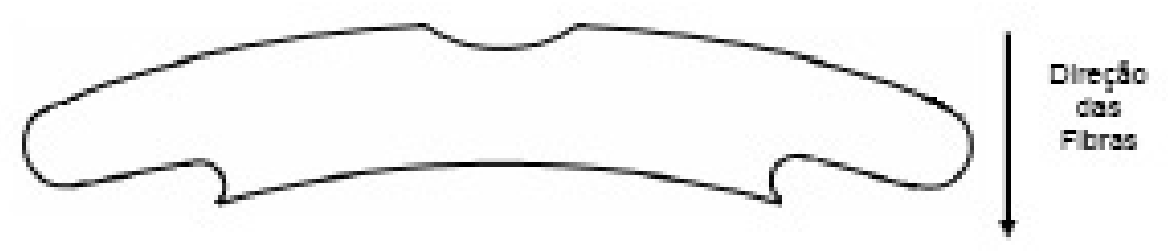

Figura 5.1: Direção das fibras no isolador proposto. 
As amostras impregnadas foram submetidas a ensaios mecânicos e elétricos visando sua caracterização.

Para uma melhor análise da impregnação no Pinus Taeda foi realizada a pesagem dos CPs, antes e após as impregnações; assim, foram analisadas 7 amostras de cada um dos 8 ensaios $(\mathrm{n}=56)$. Constatou-se uma impregnação média de $582,4 \mathrm{~g} / \mathrm{m}^{2}$ de resina bicomponente na madeira, com desvio-padrão de $196,3 \mathrm{~g} / \mathrm{m}^{2}$; e de $314,6 \mathrm{~g} / \mathrm{m}^{2}$ de resina monocomponente, com desvio-padrão de $108,5 \mathrm{~g} / \mathrm{m}^{2}$, apesar de esta não ser a unidade usual, observou-se que é a mais compatível com esta pesquisa. A quantidade de resina bicomponente impregnada foi, em média, 54\% superior à quantidade de resina monocomponente impregnada. Essa diferença ocorre, principalmente, devido a que a resina bicomponente forma uma camada superficial mais espessa do que a resina monocomponente, como pode ser observado nas figuras 5.2 e 5.3 .

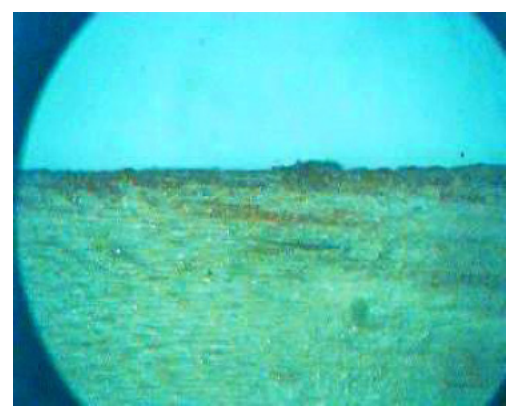

Figura 5.2: Impregnação com resina monocomponente na superfície tangencial às fibras da madeira, ampliada 40x.

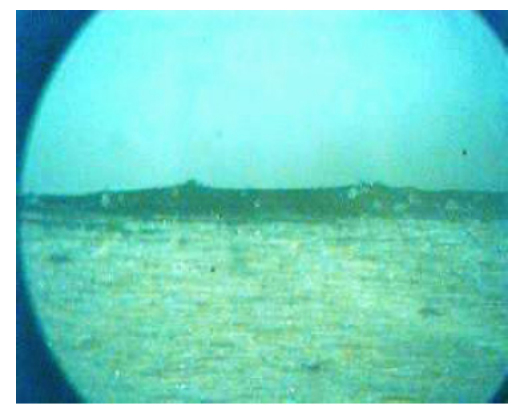

Figura 5.3: Impregnação com resina bicomponente na superfície tangencial às fibras da madeira, ampliada 40x.

Os ensaios mecânicos seguiram os parâmetros e metodologias da norma NBR7190 (1997) e tiveram como finalidade determinar a dureza e a resistência e rigidez mecânica à compressão e à flexão dos compostos madeira-resina poliuretana.

Observaram-se bons resultados nos ensaios mecânicos da madeira impregnada com ambas as resinas poliuretanas em comparação com a não-impregnada com exceção do ensaio de flexão, que não apresentou melhora significativa. Apesar de os resultados 
apresentados pelos CPs impregnados com a resina monocomponente terem sido ligeiramente superiores aos impregnados com a bicomponente, os valores médios e os desviospadrão foram próximos; assim, foi feita a análise do intervalo de confiança, para verificar a existência de equivalência estatística entre os grupos de amostras.

Segundo os intervalos de confiança - tabela 5.1 - os resultados dos ensaios mecânicos dos CPs impregnados com as resinas monocomponentes e bicomponentes são estatisticamente equivalentes, ou seja, ambas apresentaram desempenhos semelhantes e positivos com relação à madeira não-impregnada.

Tabela 5.1: Intervalo de confiança entre os conjuntos de dados A - B, A - C e B - C.

\begin{tabular}{|c|c|c|c|}
\hline \multirow[t]{2}{*}{ Ensaio } & \multicolumn{3}{|c|}{ Intervalo de Confiança } \\
\hline & $\mathrm{A}$ e $\mathrm{B}$ & $\mathrm{A}$ e $\mathrm{C}$ & $\mathrm{B}$ e $\mathrm{C}$ \\
\hline$f_{H 0}$ & $-21,72 \leq \mu \leq-4,04$ & $-15,88 \leq \mu \leq-5,40$ & $-5,37 \leq \mu \leq 9,85$ \\
\hline$f_{H 90}$ & $-11,66 \leq \mu \leq-2,45$ & $-13,33 \leq \mu \leq-0,39$ & $-1,97 \leq \mu \leq 2,36$ \\
\hline$f_{c 0}$ & $-8,17 \leq \mu \leq-0,80$ & $-7,24 \leq \mu \leq 2,36$ & $-1,54 \leq \mu \leq 5,63$ \\
\hline$f_{c 90}$ & $-3,84 \leq \mu \leq-0,27$ & $-2,69 \leq \mu \leq-0,13$ & $-1,81 \leq \mu \leq 3,10$ \\
\hline$f_{M}$ & $-11,88 \leq \mu \leq 0,61$ & $-14,02 \leq \mu \leq 0,77$ & $-6,11 \leq \mu \leq 3,11$ \\
\hline$R_{v}$ & - & - & $-4,98 \leq \mu \leq 2,01$ \\
\hline
\end{tabular}

A: CPs sem impregnação

B: CPs impregnados com a resina monocomponente

C: CPs impregnados com a resina bicomponente

Os ensaios de dureza paralela $\left(f_{H 0}\right)$ e normal $\left(f_{H 90}\right)$ e compressão paralela $\left(f_{c 0}\right)$ e normal $\left(f_{c 90}\right)$ não apresentaram equivalência estatística quando comparados os grupos de resultados dos CPs sem impregnação com os impregnados com a resina monocomponente, o que significa que esta resina melhorou essas características da madeira.

A diferença das médias dos resultados dos ensaios de dureza paralela e normal e de compressão normal também não evidenciaram equivalência estatística entre os CPs sem impregnação e impregnados com a resina bicomponente; porém, o ensaio de compressão 
paralela apresentou equivalência estatística, ou seja, a resina bicomponente, praticamente, não melhorou essa propriedade mecânica da madeira.

Os resultados do ensaio de flexão $\left(f_{M}\right)$ evidenciaram equivalência estatística entre todos os grupos de amostras, o que sugere que as resinas poliuretanas monocomponente e bicomponente não melhoraram, significativamente, esta propriedade da madeira.

Com os resultados dos ensaios mecânicos, pode-se concluir que a impregnação com ambas as resinas melhora as propriedades mecânicas de dureza, compressão normal e compressão paralela da madeira.

Os ensaios elétricos tiveram o objetivo de determinar a resistividade volumétrica $\left(R_{v}\right)$ e superficial $\left(R_{s}\right)$ e a rigidez dielétrica sob freqüência industrial dos compósitos madeira-resina poliuretana, de acordo com as normas NBR5403 (1983) e NBR5405 (1983).

As amostras impregnadas com as resinas monocomponente e bicomponente apresentaram resultados estatisticamente equivalentes no ensaio de resistividade volumétrica, da ordem de $10^{13} \Omega$, o que significa que as duas resinas apresentaram desempenhos semelhantes quanto a esta característica elétrica da madeira e melhoraram-a significativamente, pois o Pinus não-impregnado apresentou resistividade da ordem de $10^{11} \Omega . c m$.

Contudo, os ensaios de resistividade superficial apontaram para uma melhor performance da resina bicomponente em relação à monocomponente, pois os resultados da bicomponente foram da ordem de $10^{14} \Omega$ contra $10^{13} \Omega$ da monocomponente; ambas melhoraram bastante esta característica da madeira, quando comparada à madeira sem impregnação, uma vez que esta apresentou resultados da ordem de $10^{11} \Omega$.

Conclui-se, com os resultados dos ensaios de resistividade volumétrica e superficial, que ambos os compósitos madeira-resinas poliuretanas melhoraram essas características elétricas da madeira, com destaque aos resultados do ensaio de resistividade superficial 
da resina bicomponente.

Os resultados dos ensaios de rigidez dielétrica nas amostras não-impregnadas e impregnadas com as resinas poliuretanas não foram conclusivos, pois, o rompimento dielétrico ocorreu no ar, e não no CP, observou-se carbonização na superfície de algumas amostras - figura 5.4; assim, propõe-se alterar as dimensões dos CPs e eletrodos da norma NBR5405 (1983), de forma que o rompimento ocorra através do CP.

Para a continuidade desta pesquisa, propõe-se, como trabalhos futuros, estudos do compósito madeira-resina poliuretana buscando aproveitar as melhores características das duas resinas no mesmo CP. Como a resina monocomponente apresentou resultados mecânicos ligeiramente melhores, no caso da compressão paralela às fibras, convém realizar uma primeira impregnação com a resina monocomponente e uma segunda impregnação com a resina bicomponente, por esta ter apresentado melhor performance quanto à resistividade superficial.

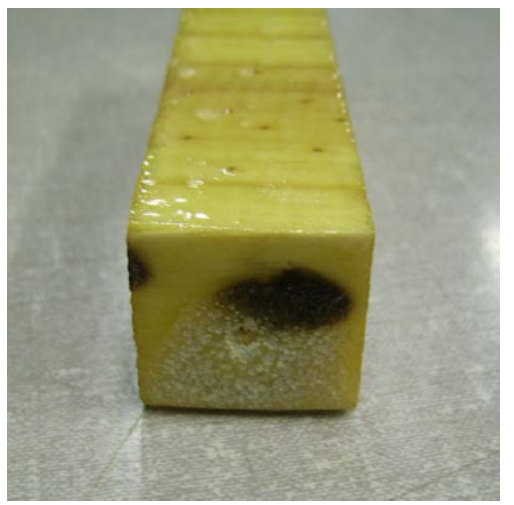

Figura 5.4: Corpo-de-prova impregnado com a resina bicomponente submetido ao ensaio de rigidez dielétrica.

Também propõe-se como trabalhos futuros o desenvolvimento de um isolador híbrido madeira-resina poliuretana composto de cinco discos sobrepostos, conforme a figura 5.5, respeitando as normas NBR7109 (1987) e NBR7110 (1998). Estes discos serão obtidos trabalhando a madeira da espécie Pinus Taeda com o auxilio de um torno. Cada disco 
será submetido aos processos de secagem em estufa - quando necessário - e impregnação com as resinas poliuretanas utilizados neste trabalho.

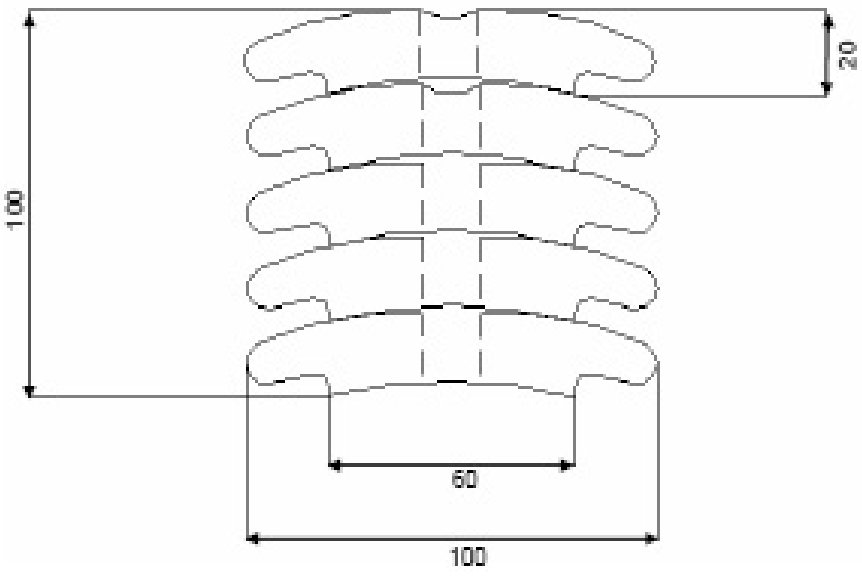

Figura 5.5: Isolador multicorpo proposto, valores em $\mathrm{mm}$. 


\section{REFERÊNCIAS BIBLIOGRÁFICAS}

AGILENT. User's Guide - Agilent 16451B High Resistence Meter. Japan, 2001.

Altafim, R. A. C., WOSchitz, R., RIBEIRO, C., MUHR, M., SIlla, J. F. R., CAlil, C. J., BASSO, H. C., SUMEREDER, C., Altafim, R. A. P., e SilveiriA, A. Prototypes of polymer-impregnated reforested wood crossarms subjected to partial discharge tests. Electrical Insulation Conference and Electrical Manufacturing Expo, v. 1, p. 225-228, 2005.

ARAUJO, L. C. R. Caracterização química, térmica e mecânica de poliuretanas elastoméricas baseadas em materiais oleoquímicos, 1992. 105 f. Dissertação (Mestrado em Química Analítica), Instituto de Física e Química de São Carlos, Universidade de São Paulo, São Carlos, 1992.

AZAMBUJA, M. A. Estudo experiemental de adesivos para fabricação de madeira laminada colada: avaliação da resistência de emendas, da durabilidade e de vigas, 2006. 128 f. Tese (Doutorado em Ciências e Engenharia de Materiais), Universidade de São Paulo, São Carlos, 2006.

BONOMO, A. Estudo sobre isoladores poliméricos à base de resinas poliuretanas para ambiente externo, 2003. 112 f. Dissertação (Mestrado em Engenharia Elétrica), Escola de Engenharia de São Carlos, Universidade de São Paulo, São Carlos, 2003.

BRUINS, P. R. Epoxy Resin Technology. New York: Interscience Publishers Copyright, john wiley \& sons inc edition, 1968.

CARLO, E. Desenvolvimento e caracterização de um poliuretano monocomponente baseado em óleo vegetal com processo de cura pela umidade do ar, 2003. 207 f. Dissertação (Mestrado em Ciências e Engenharia de Materiais), Universidade de São Paulo, USP, 2003.

CHERNEY, E. A., HACKAM, R., e KIM, S. H. Porcelain insulator maintenance with RTV silicone rubber coatings. IEEE Transactions on Power Delivery, v. 6, p. 11771181, jul , 1991.

CLARK, M., DYMOND, J., HAYWARD, J., MOORE, B., SNOPEK, D., STRANGES, N., e YOUNSI, K. Changing insulation systems - Benefits and problems. In IEEE International Symposium on Electrical Insulation, 2000, Anaheim, CA USA, 2000.

COUtinho, J. S. Madeiras. Porto, Pt: Faculdade de Engenharia da Universidade do Porto (FEUP), 1999. 
ERNITZ, A. Manual de Madeiras. Buenos Aires: Editora Alsina, 1955.

FEIO, A. O., MACHADO, J. S., e LOURENÇO, P. B. Caracterização da resistência da madeira de castanho à tracção paralela ao fio. In I Congresso Ibérico: A Madeira na Construção, 2004, GUIMARÃES, PT, 2004. 343-352.

FOURMIGUÉ, J. e NOEL, M. Testing methods for performance prediction of outdoor insulation housings. In ELECTRICAL INSULATION AND DIELECTRIC PHENOMENA, 1996, volume 2, San Francisco. IEEE Annual Report of the Conference, 1996. p. $451-454$.

FPL. Wood handbook: Wood as an engineering material. FOREST PRODUCTS LABORATORY. Madison: Department of Agriculture, Forest Service, 1999. Gen. Tech. Rep. FPL-GTR-113.

FUCHS, R. D. Transmissão de Energia Elétrica: linhas aéreas; teoria das linhas em regime permanente. Rio de Janeiro: Livros Técnicos e Científicos Editora S.A, 1977.

FUCHS, R. D. Projetos mecânicos das linhas aéreas de transmissão. Itajubá: Editora Edgard Blücher, Editora da Escola Federal de Engenharia de Itajubá, 1982.

GOnzaGA, D. P., Murakami, C. R., Chierice, G. O., e Altafim, R. A. C. ELECTRICAL CHARACTERIZATION OF CASTOR-OIL RESINS. In Conference Record of the 1998 IEEE International Symposium on Electrical Insulation, 1998, volume 1, Arlington, Virginia, USA, 1998. 181-185.

GORUR, R. S. e ORBECK, T. Surface dielectric behavior of under HV outdoor conditions. IEEE Transactions on Electrical Insulation, v. 26, p. 1064-1072 , 1991.

GUNATILAKE, A., WANG, Z., e COTTON, I. Use of wooden structures to reduce electric field under EHV transmission lines. In 39th International Universities Power Engineering Conference - UPEC, 2004, volume 1. IEEExplore, 2004. p. 223-227.

HALL, J. F. History and bibliography of polymeric insulators for outdoor applications. IEEE Transactions on Power Delivery, v. 8, n.1, p. 376 - 385 , 1993.

HARTINGS, R. Electric fields along a post insulator: ac-measurements and calculations. IEEE Transactions on Power Delivery, v. 9, n. 2, p. 912 - 918, april , 1994.

HELLMEISTER, J. C. Sobre a determinação das características físicas da madeira, 1973. 119 f. Tese (Doutorado em Engenharia de Estruturas), Escola de Engenharia de São Carlos, Universidade de São Paulo, São Carlos, 1973.

HEMERLY, F. X. Mamona: comportamento e tendências no Brasil. Empresa Brasileira de Pesquisa Agropecuária (EMBRAPA). Departamento de Informação e Documentação, 1981. Brasília.

HOUlGATE, R. Outdoor testing of nonceramic insulators. In IEE Colloquium on Review of Outdoor Insulation Materials, 1996, 1996.

IEEESTD751. IEEE STANDARD 751: Trial-Use Design Guide for Wood Transmission Structures. Transmission and Distribution Committee of the IEEE Power Engineering Societ, Piscataway, New Jersey, 1991. 
IGNÁCIO, H. Avaliação da poliuretana da mamona nas formas compactas e porosas no preenchimento de falha óssea: estudo experimental em cães, 1999. 92 f. Tese (Doutorado em Ciências e Engenharia de Materiais), Faculdade de Medicina de Ribeirão Preto, Universidade de São Paulo, Ribeirão Preto, 1999.

KIM, S., CHERNEY, E., e HACKAM, R. Suppression mechanism of leakage current on RTV coated porcelainand silicone rubber insulators. IEEE Transactions on Power Delivery, v.6, n.4, p. 1549-1556 , 1991.

KIM, S., CHERNEY, E., e HACKAM, R. Effects of filler level in RTV silicone rubber coatings used in HVinsulators. IEEE Transactions on Electrical Insulation, v. 27, n. 6, p. 1065-1072, dec , 1992.

KIM, S. H., CHERNEY, E. A., HACHAM, R., e RUTherFORD, K. G. Chemical changes at the surface of RTV silicone rubber coatings on insulators during dry band arcing. IEEE Transactions on Dielecrics and Electrical Insulation, v.1, n.1, p. 106-123, 1994.

KOLLMAnN, F. F. P. e CÔTÉ, W. A. J. Principles of wood science and technology: Solid wood, volume 1. New York: Springer-Velang, 1984.

KORITSKY, Y. Electrical engineering materials. Moscow: Mir publishers, 1970.

LEAL, J. Análise da variância. Curitiba: CCE/UFPR, 1970.

LIPTROT, F. J. An examination of the service performance of ceramic insulators. In IEE Colloquium on Review of Outdoor Insulation Materials, 1996, London, UK, 1996.

LOOMS, L. Hybrid outdoor insulator. IEEE Electrical Insulation Magazine, v. 4, n. 4, p. $11-15$, jul - aug , 1988.

LOOMS, L. S. T. Insulators for High Voltages. London: Peter Peregrinus Ltd, 1990. IEE Power Engineering, Series 7.

MANRICH, S. O emprego de madeiras brasileiras na obtenção de compósitos polímero-madeira, 1984. 184 f. Dissertação (Mestrado em Ciência e Engenharia dos Materiais), Centro de Ciências e Tecnologia, Universidade Federal de São Carlos, São Carlos, 1984.

MELlO, D. R., JR, R. T. D. C., BATISTA, J. T., e MELO, M. E. Avaliação do grau de poluição em instalações de transmissão, subestações e distribuição. In I Citenel, 2001, Brasília, 2001.

Mello, D. R., Meloni, A. E. M., JR, A. M., MAURICIO, M. R. D., e GARCIA, R. W. S. Desenvolvimento de um novo isolador antipoluição com perfil aberto. In II Citenel, 2003, volume 1, Salvador, BA, 2003. 67-72.

MEYER, J. A. Industrial use of wood-polymer materials: state of the art. Forest Products Journal, v.32, n.1, p. 24-29, jan , 1982.

MEYER, L. P. Probabilidade: aplicações à estatística. Rio de Janeiro: Livro Técnico S.A., 1972. 
MOTA, O. $1^{\circ}$ Caderno: A madeira como material de engenharia naval. Inovação na Construção Naval em Madeira e seus Compósitos - ICOM. Associações das Indústrias Marítimas - AIM. Portugal, 2006. Disponível em: <http: //www . carpinteriaderibeira . org/Documentacion.html> Acesso em: 07 de maio.

MURAKAMI, C. R. Aplicação das resinas poliuretanas derivadas de óleo de mamona, como materiais isolantes elétricos, 2002. $141 \mathrm{f}$. Tese (Doutorado em Engenharia Elétrica), Escola de Engenharia de São Carlos, Universidade de São Paulo, São Carlos, 2002.

MURAmoto, C. M., MEllo, D. R., e YOKOTA, H. Avaliação do desempenho de isoladores para sistemas de distribuição de energia. In Seminário Nacional de Qualificação de Materiais e Equipamentos do Setor de Energia Elétrica (SQME), 1997, Rio de Janeiro, 1997.

NADERIAN, A., SANAYE-PASAND, M., e MOHSENI, H. A review of artificial contamination withstand test methods of high voltage outdoor insulators. In IEEE International Symposium on Electrical Insulation, 2004, 2004. 284-287.

NBR5403. Determinação da resistividade volumétrica e superficial. ASSOCIAÇÃO BRASILEIRA DE NORMAS TÉCNICAS - ABNT, Rio de Janeiro, 1983.

NBR5405. Determinação da rigidez dielétrica sob freqüência industrial. ASSOCIAÇÃO BRASILEIRA DE NORMAS TÉCNICAS - ABNT, Rio de Janeiro, 1983.

NBR5456. Eletricidade geral: terminologia. ASSOCIAÇÃO BRASILEIRA DE NORMAS TÉCNICAS - ABNT, Rio de Janeiro, 1987.

NBR5472. Isoladores e buchas para eletrotécnica: terminologia. ASSOCIAÇÃO BRASILEIRA DE NORMAS TÉCNICAS - ABNT, Rio de Janeiro, 1986.

NBR7109. Isolador de Disco: Dimensões e Características. ASSOCIAÇÃO BRASILEIRA DE NORMAS TÉCNICAS - ABNT, Rio de Janeiro, 1987.

NBR7110. Isolador de pino de porcelana ou vidro: Padronização de dimensões e características. ASSOCIAÇÃO BRASILEIRA DE NORMAS TÉCNICAS - ABNT, Rio de Janeiro, 1998.

NBR7190. Projeto de estruturas e madeiras. ASSOCIAÇÃO BRASILEIRA DE NORMAS TÉCNICAS - ABNT, Rio de Janeiro, 1997.

NETO, S. C. Caracterizações físico-químicas de um poliuretano derivado de óleo de mamona utilizado para implantes ósseos, 1997. 127 f. Tese (Doutorado em Química Analítica), Instituto de Química de São Carlos, Universidade de São Paulo, São Carlos, 1997.

PASCON, E. A. Projeto biocompatibilidade dos materiais endodônticos: biocompabilidade da resina poliuretana derivada da mamona, 1999. $167 \mathrm{f}$. Tese (Doutorado em Odontologia - Reabilitação Oral), Faculdade de Odontologia de Ribeirão Preto, Universidade de São Paulo, Ribeirão Preto, 1999. 
P\&D, R. Revista Pesquisa e desenvolvimento da ANEEL, 2006. Disponível em: <http://www.aneel.gov.br/arquivos/pdf/Revista_PD.pdf> Acesso em 31 de novembro de 2006.

PETROVIC, Z. S. Thermosetting resins from vegetable oils. In ANNUAL TECHINCAL CONFERENCE, 1999, number 57, New York, 1999.

PINTO, J. e TAKAGI, E. M. Injeções flexíveis para selamento definitivo das infiltrações em túneis e estruturas enterradas. In Waterproofing of Underground Structures, Presentation SP6, 2005, São Paulo, 2005.

PLEPIS, A. M. G. Caracterização térmica e viscoelástica de resinas poliuretanas derivadas de óleo de mamona, 1991. 155 f. Tese (Doutorado em Química Analítica), Escola de Engenharia de São Calos, Universidade de São Paulo, São Carlos, 1991.

\section{RES/ANEEL024. RESOLUÇÃO ANEEL No 024, 2000.}

SARAIVA, D. B. Materiais elétricos, chapter Isolantes e dielétricos, pages 98-107. Guanabara Koogan, 1988.

SCHNEIDER, M. H. e WITT, A. E. History of wood polymer composite commercialization. Forest Products Journal, v.54, n.4, p. 19-24, apr , 2004.

SILVA, A. A. Compostos fenólicos em madeiras brasileiras, 2006. 114 f. Dissertação (Mestrado em Química analítica), Instituto de Química de São Carlos, Universidade de São Paulo, São Carlos, 2006.

SILVA, D. D., CHIERICE, G. O., GAlHIANE, M. S., CHAAR, J. S., e FILHO, E. V. M. Quantificação do linalol no óleo essencial da aniba duckei Korstermans utilizando uma nova coluna capilar polyh4-md em cromatografia gasosa. Revista Química Nova On Line, v.26, n.4, p. 461-465, 2003. Disponível em: <http://www.scielo.br/pdf/qn/ v26n4/16422.pdf>. Acesso em: 06 nov 2006.

Silva, J. F. R., AltAfim, R. A. C., RIBEIRO, C., BASSO, H. C., BUENO, B., SARTORI, J. C., ALTAFIM, R. A. P., LIMA, L., SILVEIRA, A., e HIRAKAWA, W. Cruzetas de Madeira Resinada como Alternativa para o Sistema Aéreo de Distribuição de Energia Elétrica. In Seminário Nacional de Distribuição de Energia Elétrica - SENDI, 2004, Brasília, 2004.

SILVA, R. V. Compósito de resina poliuretana derivada de óleo de mamona e fibras vegetais, 2003. 139 f. Tese (Doutorado em Ciências e Engenharia de Materiais ), Instituto de Física de São Carlos, Universidade de São Paulo, São Carlos, 2003.

SILVESTRE, G. D. F. Comportamento Mecânico do Poliuretano Derivado de Óleo de Mamona reforçado por Fibra de Carbono: Contribuição para o Projeto de Hastes de Implante de Quadril, 2001. 136 f. Dissertação (Mestrado em Engenharia Mecânica), Escola de Engenharia de São Carlos, Universidade de São Paulo, São Carlos, 2001.

SMITH, W. F. Principles of Materials Science and Engineering. New York: Mc Graw-Hill International, 2nd edition, 1990. 
SOUZA, M. E. P., ARIZA, E., BAllester, M., YOSHIDA, I. V. P., ROCHA, L. A., e FREIRE, C. M. A. Resistência à corrosão de aço galvanizado e de aço eletrodepositado com $\mathrm{ZnFe}$ revestido por resinas de silicone. 4a Jornada da Revista Corrosão e Protecção de Materiais, v.25, n.4, p. 121-125, nov , 2004.

STOLF, D. O. Influência da impregnação com estireno e com metacrilato de metila em propriedades físicas e mecânicas da madeira de Eucalyptus grandis e de Pinus caribaea var. hondurensis, 2005. Tese (Doutorado em Ciências e Engenharia de Materiais ), Instituto de Física de São Carlos, Universidade de São Paulo, São Carlos, 2005 .

SWIFT, D. A., SPELLMAN, C., e HADDAD, A. Hydrophobicity transfer from silicone rubber to adhering pollutants and its effect on insulator performance. IEEE Transactions on Dielectrics and Electrical Insulation, v.13, p. 820-829, Aug , 2006.

TAREEV, B. M. Materials for electrical engineering. Moscow: Higher School Publishing House Moscow, 1965.

TORGOVNIKOV, G. I. Dielectric Properties of Wood and Wood-Based Materials. Heidelberg, Heidelberg: Springer-Verlag, 1993.

URIARTT, L. A. F. B. A. A. Materiais de construção 2, chapter A madeira como material de construção. Livros técnicos e científicos editora, Rio de Janeiro, Brasil, 4 edition, 1992.

VICINO, J. R. L. Publicação eletrônica [mensagem pessoal]. Mensagem recebida por < ricardo@kehl.ind.br>, em 07 março, 2007.

VILAR, W. D. Química e tecnologia dos poliuretanos. Rio de Janeiro: Grupo Pronor, 1993.

WOODS, G. The ICI Polyurethanes book. New York: John Willey, 1990.

WULTZ, A. polimer. IEEE Transactions on Dielectrics and Electrical Insulation Justus Liebigs Ann. Chem., v.71, n.326 , 1849. 
APÊNDICE 


\section{Apêndice A}

\section{DEFINIÇÕES}

\section{A.1 Elétricas}

Segundo as normas técnicas brasileiras NBR5456 (1987) e NBR5403 (1983), seguem algumas definições importantes:

Rigidez dielétrica: Propriedade de um dielétrico de se opor a uma descarga de ruptura, ou seja, uma descarga que destrói localmente a propriedade isolante de um meio, medida pelo gradiente de potencial sob o qual se produz essa descarga. Rigidez dielétrica também pode ser expressa pelo campo elétrico máximo que o material suporta.

Resistividade: Inverso da condutividade, que é a grandeza escalar ou matricial cujo produto pelo campo elétrico é igual à densidade de corrente de condução, ou seja, resistividade é o grau de oposição que o material oferece à passagem de corrente elétrica. Pode ser volumétrica ou superficial.

Resistência volumétrica: Quociente da tensão contínua (VCC) aplicada entre dois eletrodos em contato em faces opostas com o corpo-de-prova e a corrente normal de equilíbrio entre os eletrodos, excluindo a corrente superficial e negligenciando a possibilidade do fenômeno de polarização nos eletrodos, sua unidade no sistema internacional 
(SI) é ohm $(\Omega)$. É a resistência oferecida pela isolação à corrente de fuga fluindo através de um material isolante (TAREEV, 1965; KORITSKY, 1970).

Resistividade volumétrica: Quociente entre o campo elétrico em corrente continua e a densidade de corrente normal de equilíbrio através do material isolante, dada em $\Omega . m$.

Resistência superficial: Quociente entre a tensão contínua aplicada entre dois eletrodos colocados na superfície do corpo-de- prova e a corrente entre os eletrodos em um dado tempo de eletrificação, negligenciando a possibilidade do fenômeno de polarização nos eletrodos. A corrente geralmente passa através de uma camada superficial do corpo-de-prova e associa-se à umidade ou a qualquer contaminação superficial, incluindo também uma componente através do volume do corpo-de-prova. É a resistência oferecida pela isolação à corrente de fuga fluindo pela superfície do isolante (TAREEV, 1965; KORITSKY, 1970).

Resistividade superficial: Quociente entre o campo elétrico em corrente contínua, e a densidade linear da corrente na camada superficial do material isolante; sua unidade SI é $\Omega$.

Resistência de isolamento: Quociente da tensão contínua aplicada entre dois eletrodos em contato com o corpo-de-prova e a corrente total entre os eletrodos. A resistência de isolamento depende da resistividade volumétrica e superficial do corpo-deprova. O propósito de um material isolante é impedir o fluxo de corrente quando uma tensão constante é aplicada. Em outras palavras, a resistência de isolação sempre deve tender ao infinito. Entretanto, praticamente todos os materiais isolantes usados em engenharia permitem a passagem de alguma corrente, chamada corrente de fuga (TAREEV, $1965)$. 